\title{
No. 4, Vol. 7, 2016
}

Editor-in-chief: Peter G. Fedor-Freybergh, Michael Olah Including: Social Work, Humanitary Health Intervention, Nursing, Missionary Work

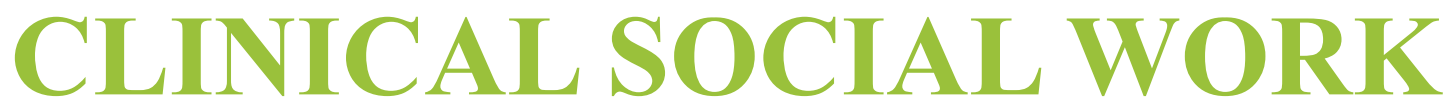
AND HEALTH INTERVENTION

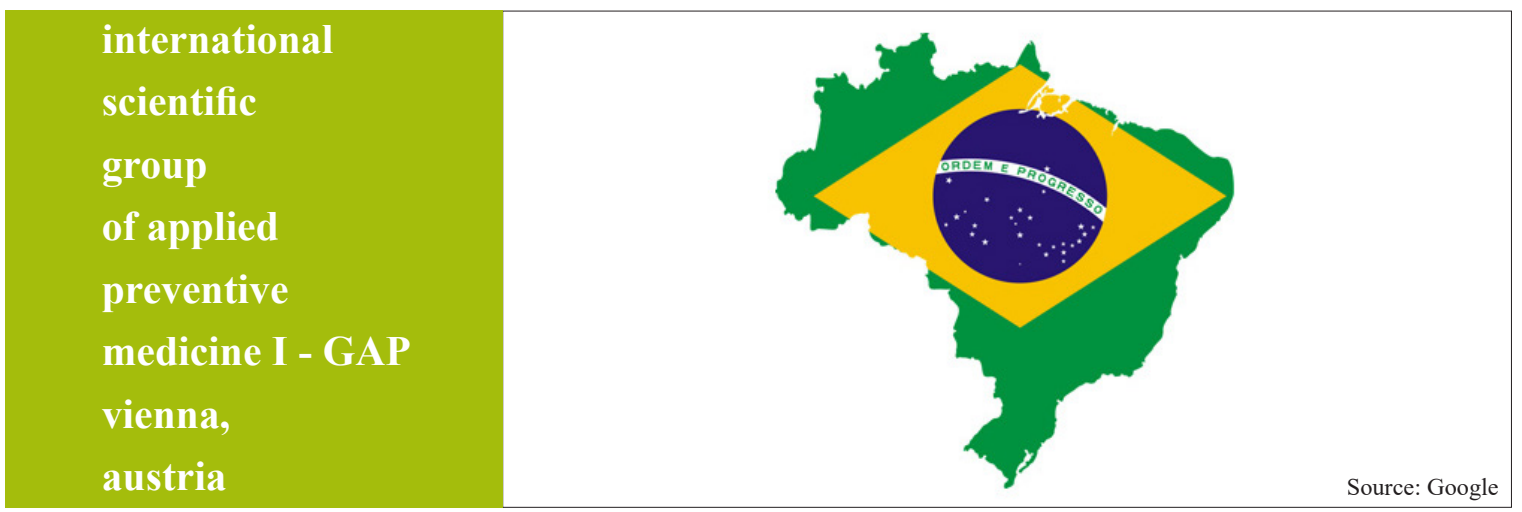

Issue: Public Health Care and Aid in Poverty in Brazil

Original Articles

$\checkmark$ UNIVERSITY-BASED PARTNERSHIPS: DESIGNING SHORT TERM STUDY ABROAD OPPORTUNITIES FOR GRADUATE STUDENTS

$\checkmark$ DROUGHT IN BRAZIL: A HIDDEN PUBLIC HEALTH DISASTER $\checkmark$ PREVENT DEPRESSION: IMPROVING ACCESS TO BRAZIL'S MENTAL HEALTH SERVICES $\checkmark$ AN ASSESSMENT OF EQUITY IN THE BRAZILIAN HEALTHCARE SYSTEM: REDISTRIBUTION OF HEALTHCARE PROFESSIONALS TO ADDRESS INEQUITIES IN REMOTE AND RURAL HEALTHCARE

$\checkmark$ HIV PREVENTION IN BRAZIL

$\checkmark$ DOES BRAZIL'S DECENTRALIZED SYSTEM IMPROVE PRIMARY CARE WITH THE FAMILY HEALTH PROGRAM?

$\checkmark$ LOW COST APPROACHES TO IMPROVE QUALITY OF LIFE \& ACCESS TO HEALTHCARE IN BRAZILIAN FAVELAS

$\checkmark$ CERVICAL CANCER SCREENING: AWARENESS AND KNOWLEDGE IN BRAZIL

$\checkmark$ PREVALENT NON-COMMUNICABLE DISEASES ACROSS BRAZIL: RISK FACTORS, PREVENTION, AND FUTURE GOALS EDUCATION: A NORTH AND SOUTH AMERICAN MODEL 


\section{Editors}

\section{Editor-in-Chief:}

Prof. Peter G. Fedor-Freybergh, MD, D.Phil, PhD, DSc, Dr.h.c. mult. (Vienna)

editor@nel.edu

Prof. Dr. Michael Olah, Ph.D. (Prague) selfmirror@protonmail.com

\section{Deputy Chief Editors:}

Prof. Dr. Dr. med. Clauss Muss, PhD. (I-GAP Vienna) office@i-gap.org

\section{Editorial board and reviewers:}

Doc. Dr. Andrea Shahum, MD (University of North

Carolina at Chapel Hill School of Medicine, USA)

Andrea.Shahum@unchealth.unc.edu

Prof. Dr. Vlastimil Kozoň, PhD. (Allgemeines

Krankenhaus - Medizinischer Universitätscampus,

Vienna)

vlastimil.kozon@univie.ac.at

Prof. Daniel J. West, Jr. Ph.D, FACHE

(University of Scranton, Department of Health

Administration and Human Resources, USA)

daniel.westascranton.edu

Dr. Steve Szydlowski, MBA, MHA, DHA

(University of Scranton school of education, USA) steven.szydlowski@scranton.edu

Prof. zw. dr hab. Pawel S. Czarnecki, Ph.D.

(Rector of the Warsaw Management University, PL) pawelaczarnecki.co

Dr. Michael Costello, MA, MBA, J.D.

(University of scranton school of education, USA)

michael.costello@scranton.edu

Doc. Dr. Gabriela Lezcano, Ph.D.

(University of California, San Francisco, USA)

gabikak@gmail.com

Prof. Dr. Roberto Cauda, Ph.D.

(Institute of Infectious Diseases, Catholic University of the Sacred Heart, Rome, IT)

rcauda@rm.unicatt.it

\section{Contact}

International Gesellschaft

für angewandte Präventionsmedizin i-gap e.V.

(International Society of Applied

Preventive Midicine i-gap)

Währinger Str. 63

A-1090 Vienna, Austria

Tel. : + $+49-176-24215020$

Fax : $+43 / 1408313129$

Mail : office@i-gap.org

Web : www.i-gap.org
Dr. Daria Kimuli, Ph.D.

(Catholic university of Eastern Africa, Nairobi, Kenya)

pechacova.daria@gmail.com

Dr. Monica Wictor Namulanda Wanjala, Ph.D.

(Catholic university of Eastern Africa, Nairobi, Kenya)

Non-public

Dr. Vitalis Okoth, Ph.D.

(Catholic university of Eastern Africa, Nairobi, Kenya)

Non-public

Dr. Johnson Mavole, Ph.D.

(Catholic university of Eastern Africa, Nairobi, Kenya) johnsonsyamp28@gmail.com

Dr. Jirina Kafkova, Ph.D. (Nairobi, St. Bakitha Clinic, Kenya) jirinka.lala@gmail.com

Prof. Dr. Selvaraj Subramanian, Ph.D.

(president of SAAaRMM, Kuala Lumpur, Malaysia)

doc.selvaraj@gmail.com

Dr. Harald Stefan, PhD.

(Krankenanstalt Rudolfstiftung, Vienna, AT )

harald.stefan@wienkav.at

Dr. Günter Dorfmeister, PhD., MBA

(Wilhelminenspital, Vienna, AT)

guenter.dorfmeister@wienkav.at

Dr. hab. Zofia Szarota, Ph.D.

(Pedagogical University of Cracow, PL) dziekwp@up.krakow.pl

\section{Commissioning and language editor:}

Prof. Dr. John Turner (Amsterdam)

Whole-Self@quicknet.nl

\section{Proofreader:}

Dr.h.c mult. prof. MUDr. Vladimír Krcmery, DrSc. FRSP, FACP

(Tropical international team of St. Elizabeth)

tropicteamagmail.com

Editorial plan for the year 2016:

Issue 1/2016: Central European Social Work and Health Care Intervention

Issue 2/2016: Health Intervention

Issue 3/2016: Public Health Intervention for Refugees

Issue 4/2016: Public Health Care and Aid in Poverty in Brazil

Issue Guarantor:
Prof. Daniel J. West, Jr. Ph.D, FACHE
Impact factor:
1.325
Affiliated Institutions:
University of Scranton, Department of Health
Administration and Human Resources, USA
Subscription rates 2016, Vol. 7, No. 4
Hybrid Open Access Journal
Additional information on Internet:
www.clinicalsocialwork.eu

The journal works on the non-profit basis. The Original Articles are published free of charge / the scope up up to 3,500 words, over the scope should be paid 50 EUR / USD for every 500 words/. All the published Articles are charged 100 EUR / USD with standard range which cannot be exceed. 


\section{Table of Contents}

\section{Original Articles}

Daniel J. West, Jr., Bernardo Ramirez

University-Based Partnerships:

Designing Short Term Study Abroad Opportunities for Graduate Students .7

\section{Donald Davison}

Drought in Brazil: a hidden Public Health Disaster

\section{Ryan Heidt}

Prevent Depression: Improving Access to Brazil's Mental Health Services 20

Prudence M. N. Akindo

An Assessment of Equity in the Brazilian Healthcare System:

Redistribution of Healthcare Professionals to Address Inequities in Remote and Rural Healthcare 25

\section{Kristen Bell}

HIV Prevention in Brazil

Jaclyn Hanley

Does Brazil's Decentralized System Improve Primary Care with the Family Health Program?.

Lindsey Jeanniton

Low Cost Approaches to Improve Quality of Life \& Access to Healthcare in Brazilian Favelas .46

Lydia Isabel Napa

Cervical Cancer Screening: Awareness and Knowledge in Brazil ...

Sarah A. Borgia

Prevalent Non-communicable Diseases Across Brazil: Risk Factors, Prevention, and Future Goals 62

Steven J. Szydlowski

Strategic Global Partnership to Cultivate Health Management Education:

A North and South American Model 67 



\section{Editorial}

$\mathrm{T}$ his special issue of the journal addresses specific areas of healthcare development and service delivery in Brazil. All of the articles recognize that Brazil, no different than other countries in South America and Europe, is struggling with rising healthcare costs, concerns about quality of care, access to care and the need to increased patient safety and leadership in the healthcare sector. Brazil's healthcare system consists of political, economic, and institutional health policies designed to create conditions that ensure equality of care and equal access to care. Brazil has formulated very specific health policies and plans to improve population health. The National Health Plan is a tool which has been used to develop guidelines and goals to guarantee the principle of unification and of social participation.

Better public health and prevention policies, as well as more effective designs in healthcare delivery, can impact health in Brazil. The Federal Constitution in Brazil declares health “... as a fundamental human right and that the state must provide necessary conditions that are essential to maintaining this fundamental human right to health." Brazil has three levels of government including the Federation, the States and Municipalities. Each of these levels are autonomous but are interdependent in providing access to healthcare services.

Health interacts with other sectors of the economy including the environment, work, education, transportation, food service, and access to other social goods. Brazil has a model of care that looks at family health as the first level of primary care. Healthcare is organized to provide for specific needs responding to population and geography. Primary care has been more difficult to achieve in the rural areas, especially the Amazon region. There is a very strong family health strategy that has been implemented in Brazil along with other advanced levels of care. The country has a hospital network and system that is classified according to local, regional, state and national hospitals. The size of the facilities varies depending on the population and healthcare needs of a specific region.

Brazil is paying a significant price for chronic diseases and the country as a whole recognizes that there are wide gaps in the provision of healthcare services within regions of the country. The strong primary care system plays an important role in reducing health inequalities, addressing the needs of aging Brazilians, and population health. Overall, it is recognized that the health sector is a key economic sector and job generator in Brazil.

Daniel J. West, Jr., Ph.D., FACHE

Professor and Chairman

Department of Health Administration \& Human Resources

University of Scranton 



\title{
Few words from the Editors-In-Chief
}

$\mathrm{T}$ his journal brings authentic experiences of our social workers, doctors and teachers working for the International Scientific Group of Applied Preventive Medicine I-GAP Vienna in Austria, where we have been preparing students for the social practise over a number of years. Our goal is to create an appropriate studying programme for social workers, a programme which would help them to fully develop their knowledge, skills and qualification. The quality level in social work studying programme is increasing along with the growing demand for social workers.

Students want to grasp both: theoretical knowledge and also the practical models used in social work. And it is our obligation to present and help students understand the theory of social work as well as showing them how to use these theoretical findings in evaluating the current social situation, setting the right goals and planning their projects.

This is a multidimensional process including integration on many levels. Students must respect client's individuality, value the social work and ethics. They must be attentive to their client's problems and do their best in applying their theoretical knowledge into practice.

It is a challenge to deliver all this to our students. That is also why we have decided to start publishing our journal. We prefer to use the term 'clinical social work' rather than social work even though the second term mentioned is more common. There is some tension in the profession of a social worker coming from the incongruity about the aim of the actual social work practice. The question is whether its mission is a global change of society or an individual change within families. What we can agree on, is that our commitment is to help people reducing and solving the problems which result from their unfortunate social conditions. We believe that it is not only our professional but also ethical responsibility to provide therapeutic help to individual and families whose lives have been marked with serious social difficulties.

Finding answers and solutions to these problems should be a part of a free and independent discussion forum within this journal. We would like to encourage you - social workers, students, teachers and all who are interested, to express your opinions and ideas by publishing in our journal. Also, there is an individual category for students' projects.

In the past few years there have been a lot of talks about the language suitable for use in the field of the social work. According to Freud, a client may be understood as a patient and a therapist is to be seen as a doctor. Terminology used to describe the relationship between the two also depends on theoretical approach. Different theories use different vocabulary as you can see also on the pages of our journal.

Specialization of clinical social work programmes provides a wide range of education. We are determined to pass our knowledge to the students and train their skills so they can one day become professionals in the field of social work. Lately, we have been witnessing some crisis in the development of theories and methods used in clinical social work. All the contributions in this journal are expressing efforts to improve the current state. This issue of CWS Journal brings articles about social work, psychology and other social sciences.

\author{
Michael Olah \\ Peter G. Fedor-Freybergh \\ Edition of the journal
}





\title{
University-Based Partnerships: Designing Short Term Study Abroad Opportunities for Graduate Students
}

\author{
D. J. West, Jr. (Daniel J. West, Jr. )1', B. Ramirez (Bernardo Ramirez )²
}

${ }^{1}$ Health Administration \& Human Resources, Original Articles $4^{\text {th }}$ Floor McGurrin Hall, Scranton, PA 18510-4699

${ }^{2}$ College of Health and Public Affairs, University of Central Florida, 12805 Pegasus Drive, Orlando, FL 32816-2200

\section{E-mail address:}

daniel.west@scranton.edu, bernardo.ramirez@ucf.edu

\section{Reprint address:}

Health Administration \&

Human Resources

$4^{\text {th }}$ Floor McGurrin Hall

Scranton, PA 18510-4699

Suource: Clinical Social Work and Health Intervention

Pages: $7-11$

Volume: 7

Cited references: 5

Issue: 4

\section{Reviewers:}

Doc. Dr. Andrea Shahum, MD

University of North Carolina at Chapel Hill School of Medicine, USA

e-mail: andrea.shahum@unchealth.unc.edu

Dr.h.c. PhDr. PaedDr. ThLic. Gyorgy Herdics, PhD.

Vysoká škola zdravotníctva a sociálnej práce sv. Alžbety, Bratislava, SK

e-mail: georgiuspaulus@gmail.com

\section{Key words:}

Globalization, Partnerships, Design phases, Health management education.

\section{Publisher:}

International Society of Applied Preventive Medicine i-gap

CSWHI 2016; 7(4): 7 - 11; DOI 10.22359/cswhi_7_4_01 @ 2016 Clinical Social Work and Health Intervention

\section{Abstract:}

University-based partnership provides an excellent foundation upon which to build graduate study abroad opportunities. A closed examination of specific phases in the study abroad model are discussed. 
Assessment and evaluation of outcomes provides data to modify the design for continued success in different countries. Study abroad opportunities can be built into graduate level courses to strength global healthcare management education.

\section{Introduction}

Designing and building a University-based partnership model that allows for short term study abroad learning experiences requires a functional framework. Brazil is a country in South America that lends itself to short term study abroad (Vettori 2015). It is a country with unique health reforms for post graduate students to examine including the design of healthcare systems, institutions and organizations, as well as special services designed to meet specific needs of the population (Gragnolati, Lindelow \& Couttolenc 2013). Like most countries in the world, Brazil spends the majority of its healthcare budget on hospital care. Recent gross domestic product indicators show that healthcare spending is approximately 9\% of the GDP (OECD, 2014). Brazil's health system is a mix of public and private funding streams and the government is the source for approximately $45 \%$ of spending. In today's global society, it is critical that post graduate students are exposed to international learning opportunities in areas of the world where healthcare systems are more developed and functional, as well as systems that are not well developed. This paper describes how to design study abroad experiences; structure various phases; and suggests teaching methods that enhance student learning outcomes (SLO).

The papers included in this special issue of the Journal of Clinical Social Work reflect research that was conducted by graduate students in preparation for a study abroad opportunity to Brazil in January 2016. The graduate level course used for study abroad is HAD 517 - Global Health Management (3 credits). This course is specifically designed and used to increase knowledge about the goals of globalization; global health; and examine progress that has been made in improving global health over the last 50 years. The course utilizes the definition established by the World Health Organization that "... health is a state of complete physical, mental and social well-being and not merely the absence of disease or infirmity" (WHO, 1946).

Students are exposed to determinants of health; measurement of health status; the importance of culture to health; the global burden of disease; risk factors for different health conditions; epidemiologic and demographic transitions; and the overall organization and design of health services and systems in various countries. Use of the millennium development goals (MDGs), as formulated in 2000 at the United Nations Millennium Summit, provides for targeted activities that are important for understanding global health issues (United Nations, 2016).

Preparation for study abroad also entails developing an understanding and appreciation for health, education, poverty and the economy. Cross cutting cultural themes involve ethical and human rights, and appropriate use of research methods. Each student is required to select a very specific area for focused research in preparation for the study abroad opportunity. This requires a more comprehensive understanding of the health systems services, culture and environment of health in a specific region or country. The course further examines women's health; children's health; adolescent's health, communicable diseases; non-communicable diseases; and ways of working together to improve global health. 


\section{Designed Phases of Study}

The course on Global Health Management has a well-designed and articulated educational process that is composed of 3 distinct phases. The model design includes the pre-phase, which is approximately 2 to 3 months, involving academic preparation and research prior to actually traveling to another country. The study abroad phase, which is composed of 10 to 14 days, involves the actual visit to the country and participation in cultural activities, educational site visits and presentation of lectures at a University and healthcare institutions. The post study phase, which is approximately 1 to 2 months, is completed after the study abroad visit to another country. Each of these phases has specific educational activities and outcomes that develops graduate level skills, competencies and knowledge.

\section{General Considerations}

Short term study abroad is very different from more extended periods of academic study in another healthcare system and country. Certain universities utilize a semester study abroad opportunity (15 weeks) and other University based partnerships utilize a more extended period of time engaging in the provision of the healthcare and interventions usually as part of a larger project. Short term study abroad reduces the amount of time in another culture. Consequently, significant preparation is required in advance of the actual study abroad opportunity to prepare the student and structure learning opportunities. The University of Scranton in the Department of Health Administration \& Human Resources, Graduate MHA Program, has developed a specialization in Global Health Management and utilizes elective courses for purposes of study abroad in different regions of the world. These courses have specific learning objectives that are outcome based and focus on developing a specific applied body of knowledge. The course is competency-based with a results orientation. The study abroad opportunity occurs during semester breaks or at the end of an academic semester so as to not interfere with other regular academic courses. An essential ingredient of the success of these study abroad courses is the careful selection and nurturing of international peer University partners and their collaborating healthcare organizations that play a pivotal role in the design and implementation of this learning experience.

It is important to note that the study abroad elective courses and teaching requires rigor and relevancy. Normally 8 to 10 students, who are in post graduate training, travel with 2 to 3 faculty members. The ratio of students to faculty is intentionally designed to be small so that there is a high degree of faculty-student interaction, teaching opportunities during the course, reflection and exposure to culture.

\section{Organization and Structure}

\section{The Pre-Phase}

In this phase of study, faculty are meeting with the students in the classroom and attempting to build a foundational knowledge base and group cohesiveness. Readings and texts are assigned and discussed in class. Lectures are conducted. Each student is required to develop a professional topic related to their area of interest and to engage in self-directed research in order to fully develop the topic for presentation to professional audiences. Each student is also required to prepare, in advance of the study abroad, a PowerPoint presentation that is clear and concise. These presentations are designed for a 15 minute presentation to be given to professional audiences at universities and while visiting healthcare institutions. 
It is during this pre-phase that attention is also devoted to travel preparation. Faculty members provide briefings on the countries that will be visited during study abroad, videos are presented from prior travel abroad experiences' and issues related to Visas and Passports are covered as well as insurance coverage, security, legal disclaimers and culture specific behaviors and norms. Students are required to make several presentations to the faculty and fellow students in advance of the study abroad. This provides an opportunity for refinement of the actual research presentation so that it is appropriately developed and referenced in the PowerPoint presentation.

\section{The Study Abroad Phase}

The study abroad phase involves traveling to the designated country and spending time on the ground in applied settings. During this phase students are required to keep a daily journal to document specific activities, thoughts, impressions and reflections. Members of the student delegation have an opportunity to take photographs that will be used to prepare a PowerPoint presentation upon return to the University. During the actual study abroad, students make presentations of their research to academics at universities and to healthcare providers in the community. Some of this research is also augmented with lectures from the host country. Professors at local universities in the host country are utilized to provide additional in-depth knowledge about healthcare services and systems. Site visits are conducted to healthcare facilities, interactions occur with professionals in the healthcare facility, and at the end of each day students are asked to reflect on the educational opportunities. It is important to note that during the study abroad phase reflection is an important teaching tool that requires faculty involvement. Time is spent with the students helping them to appropriately digest and reflect on what they have seen, examine how they feel about what has been seen, and discuss what the implications are in terms of their own healthcare professional careers and future development.

\section{The Post Phase}

The post phase can last 1 to 2 months upon returning to the University. It is during this phase that students finalize their manuscript for presentation to the faculty as a course assignment for grading. It is also during this phase that students consider presenting their professional paper at a national or international conference or to further develop their research as a manuscript for publication in an appropriate journal. Students are assigned to 3 member teams to present their study abroad experience to first year MHA graduate students entering the MHA program. They are also asked to make presentations to undergraduate students in a cultural diversity class. Finally, each student is required to undergo an oral examination at which time all of the research, reflection papers, journal entries, assignments and readings for the course are examined.

\section{Assessment and Evaluation}

Study abroad opportunities need to be carefully designed and implemented. They also need to be evaluated. This requires the use of assessment and evaluation processes whereby student skills, knowledge and competencies are evaluated, as well as looking at the overall course experience in Global Health Management. Students are asked to assess the course and instructors in addition to assessing their own skills, competencies, knowledge and abilities. During this assessment and evaluation phase the research topic selection is evaluated, PowerPoint presentations reviewed, debriefing sessions assessed as well as grading the actual presentations that are made internationally and 
domestically. Students find that the oral examination, which usually lasts 45 to 60 minutes, is an appropriate assessment process of the Global Health Management course learning experience.

\section{Conclusion}

A well rounded Jesuit education requires that students be provided with opportunities for learning about the larger community (the world) in which they live. Students need to understand the global aspects of healthcare and that there are no country borders when it comes to health. The internationalization of health requires that students develop specific knowledge, skills, and competencies that enable them to understand and appreciate complex healthcare systems. Students are also exposed to learning opportunities in healthcare systems that are in low- and middle-income countries. They need to understand poverty and complex social problems. Furthermore, students need to be exposed to models and frameworks that enable them to appreciate the constraints that are placed on healthcare systems, and have an appreciation for how access, cost and quality is organized and addressed in another country or region of the world. The Global Health Management course (study abroad) provides an opportunity for post graduate training programs to address global health issues; to provide students with an understanding of government systems and private payer systems; social health insurance; communicable and non-communicable diseases. Finally, Global Health Management enables students to study governance, leadership and management structures in different countries that are used to improve and strengthen health systems.

\section{References}

1. Gragnolati, M., Lindelow, M., Couttolenc, B. (2013) Twenty Years of Health System Reform.

2. in Brazil: An Assessment of the Sistema Unico de Saude. The World Bank. Retrieved from: http://www-wds.worldbank. org/external/default/WDSContentServer/ WDSP/IB/2013/06/21/000442464_201306 21122542/Rendered/PDF/786820PUB0EP I10Box0377351B00PUBLIC0.pdf

3. OECD (2014) Briefing note Brazil. Retrieved from: http://www.oecd.org/els/health -systems/Briefing-Note-BRAZIL-2014.pdf

4. Vettori, E. (2015) 2015 Health care outlook: Brazil. Deloitte. Retrieved from: http://www 2.deloitte.com/content/dam/Deloitte/global/ Documents/Life-Sciences-Health-Care/gxlshc-2015-health-care-outlook-brazil.pdf

5. United Nations (2016) Millennium Development Goals and Beyond 2015. Retrieved from: http:/www.un.org/millenniumgoals/

6. WHO (1946) Preamble to the Constitution of the World Health Organization as adopted by the International Health Conference, New York, 19-22 June, 1946. Retrieved from: http://www.who.int/about/definition/ en/print.html 


\section{Drought in Brazil: a hidden Public Health Disaster}

\section{Davison (Donald Davison)}

Health Administration \& Human Resources,

$4^{\text {th }}$ Floor McGurrin Hall, Scranton, PA 18510-4699

\section{E-mail address:}

donald.davison@scranton.edu

\section{Reprint address:}

Health Administration \&

Human Resources

$4^{\text {th }}$ Floor McGurrin Hall

Scranton, PA 18510-4699

Suource: Clinical Social Work and Health Intervention

Volume: 7

Issue: 4

Pages: $12-19$

Cited references: 13

\section{Reviewers:}

Doc. Dr. Gabriela Lezcano, Ph.D.

University of California, San Francisco, USA

e-mail: gabikak@gmail.com

doc. PhDr. Jiří Tůma, PhD.

VŠTVS Palestra v Praze, CZ

e-mail: jirkatuma@centrum.cz

\section{Key words:}

Climate change, Healthcare, Brazil, Population.

\section{Publisher:}

International Society of Applied Preventive Medicine i-gap

CSWHI 2016; 7(4): 12 - 19; DOI 10.22359/cswhi_7_4_02 @ 2016 Clinical Social Work and Health Intervention

\section{Abstract:}

Climate change has increased the likelihood of extreme weather events; drought being one of them. Between 1990 and 2014, drought accounted for only $8.7 \%$ of the reported natural disasters in Brazil (Basic 2015). However, $58.4 \%$ of economic issues related to natural disasters were drought related (Basic 2015). For the healthcare community of Brazil, economic crunches tighten government spending. The impact of droughts is difficult to document due to no assigned start and finish, 
with the effects accumulating slowly over time. Although great progress has been made to reduce social and economic vulnerability, Brazil must look at reviewing current programs, particularly in public health, and begin planning of new intervention with local communities. This paper aims to discuss the droughts impact on Brazil's population and to provide a planning baseline for healthcare professionals and government officials to alleviate the impact of drought for a population already living within a vulnerable environment.

\section{Drought Overview}

Brazil has been called the "Saudi Arabia of water," having an abundance of the resource that other emerging national economies (BRICS) have issues with. With just 5.7\% of the world's landmass, $20 \%$ of the world's freshwater flows through the Amazon basin within Brazil. However, as rainfall dwindles, populations and usage increase, and infrastructure breaks down, a more frightening situation is unfolding: the taps are running dry. Recently, 2012-2015, drought has reached the most populated city in the Americas and the surrounding state of São Paulo (Figure 1). The drought afflicting this area for three years has become the worst since the 1920s.
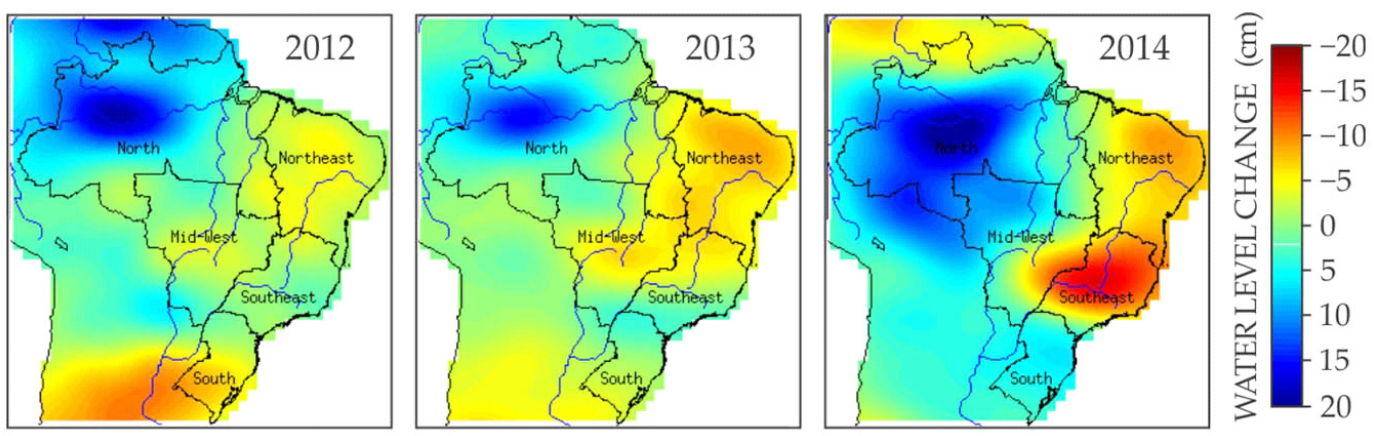

Figure 1 South American Water Levels from NASA's Gravity Recovery and Climate Experiment Spacecraft (Day, 2015)

Aside from São Paulo, a large portion of Northeast Brazil falls within the semi-arid zone. This region has a significant susceptibility to extreme drought events, particularly due to the low amount of annual rainfall and a concentration of the rainfall that it does receive over a few months per year.

\section{Causes}

The precise time of a drought's onset or end are not easily defined. Unlike sudden/ rapid emergencies such as earthquakes, tsunami's or floods, droughts are slow/insidious emergencies that appear without showing visible impacts in the short term. As a climatological event, impacts of drought depend greatly on human activities, and can be exasperated by social vulnerability. Drought is a natural disaster that generates many second and third order effects. Health implications can be numerous and far reaching. 
in $\mathrm{CO}_{2}$ within the atmosphere can lead to warmer conditions which subsequently lead to more evaporation and precipitation overall, individual regions will vary with some becoming wetter and others dryer. Known as evapotranspiration, the trees in Amazon rainforest not only remove $\mathrm{CO}_{2}$ from the atmosphere but also release vast amount of water vapor, creating so called flying rivers that subsequently fall as rain. These flying rivers create a low-pressure system that sucks in air surrounding it eventually and continually pumping moisture inland from the ocean. Deforestation degrades the low pressure systems, essentially turning off the pump. Thus, large-scale deforest-ation is believed to be a major contributor to the most recent drought in South-eastern Brazil. The impact of the atmospheric block within the Amazon rainforest and the impact it's made on precipitation in Brazil is depicted in Figure 2 below.

\section{Infrastructure}

For every ten liters treated by the Basic Sanitation Company of São Paulo State in 2012, three are not consumed or used on a regular basis (Leita 2014). These losses occur because of leaks in the distribution; illegal connections; theft; lack of measurement. In comparison, the best systems in the world such as Japan and Germany lose around $8 \%$. São Paulo is not the only city/ state experiencing water loss issues. The average Brazilian cities lost $36.9 \%$ of treated water between the treatment plant and consumer faucets in 2012 (Leita 2014).

\section{Human Activities}

The average Brazilian citizen uses 187 liters per day (DATA, 2014), way above the World Health Organization's guideline of 100. This high usage coupled with population

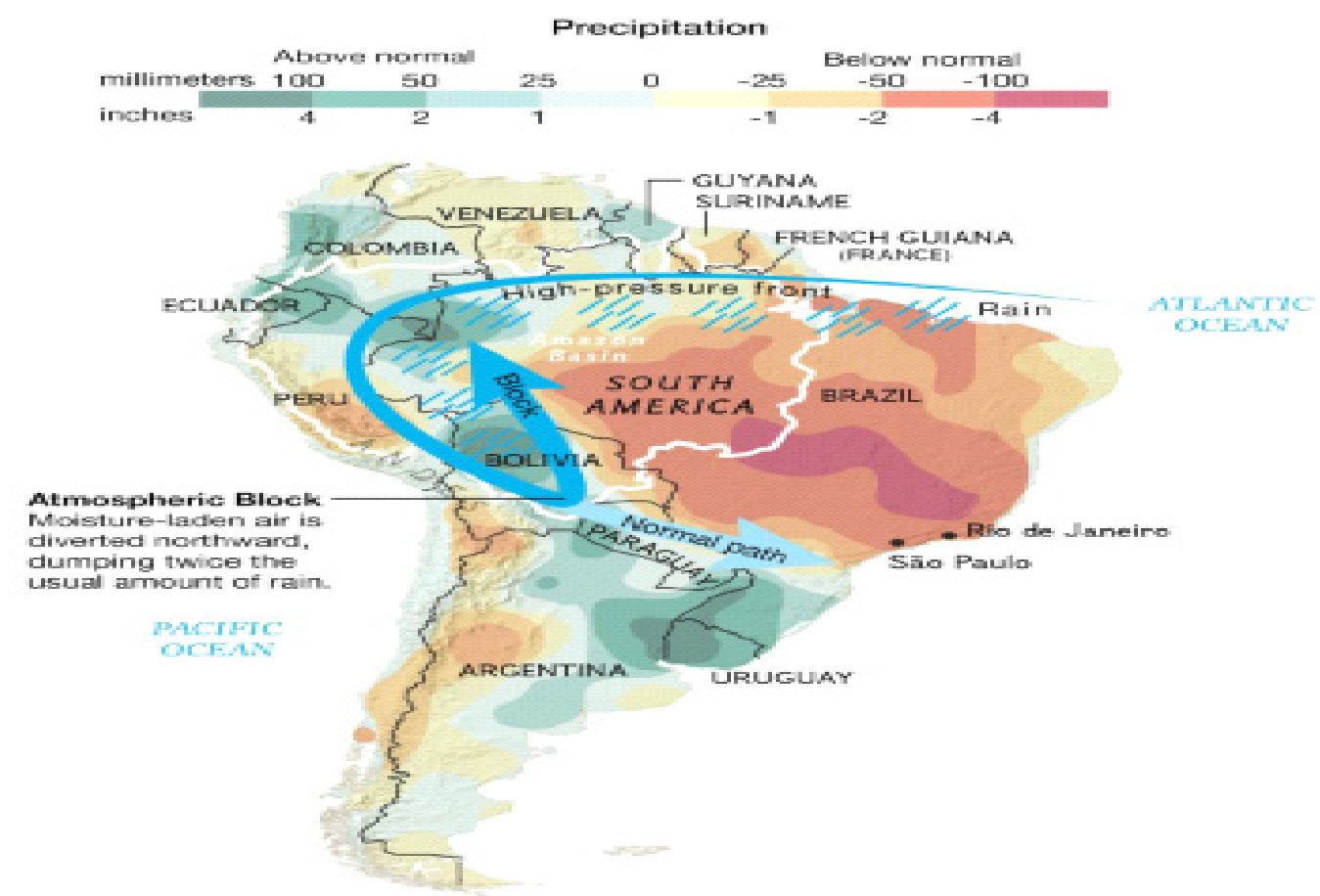

Figure 2 Altered Rain Patterns in South America Linked to Deforestation (Foster, 2015) 
growth has put the outdated reservoirs supplying the populated cities at very high water stress levels.

To add to the infrastructure woes, the water systems that supply a majority of São Paulo and other major urban areas were constructed between 1960 and 1980. From Figure 3 and Figure 4 below, the population growth in Brazil and urban areas has increased at an astounding rate from the time of construction.

\section{Population Growth:}

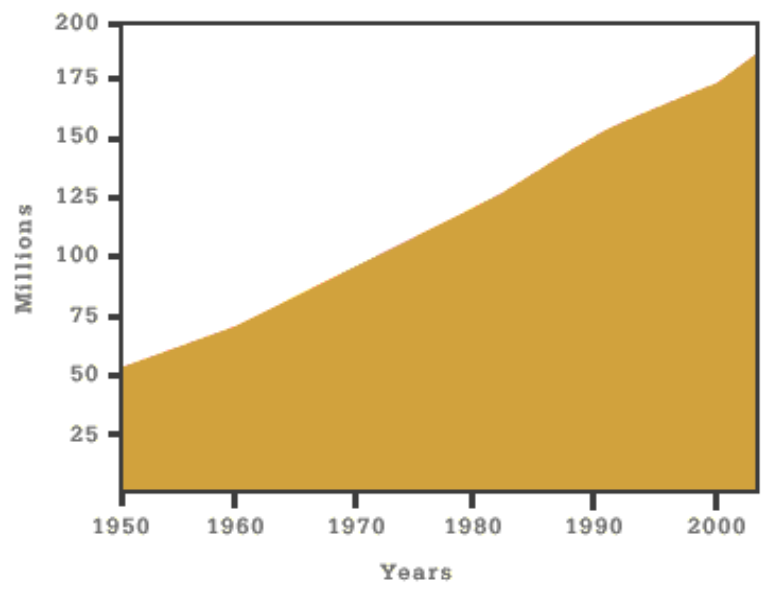

Figure 3 Population Growth in Brazil (Brito, 2006)

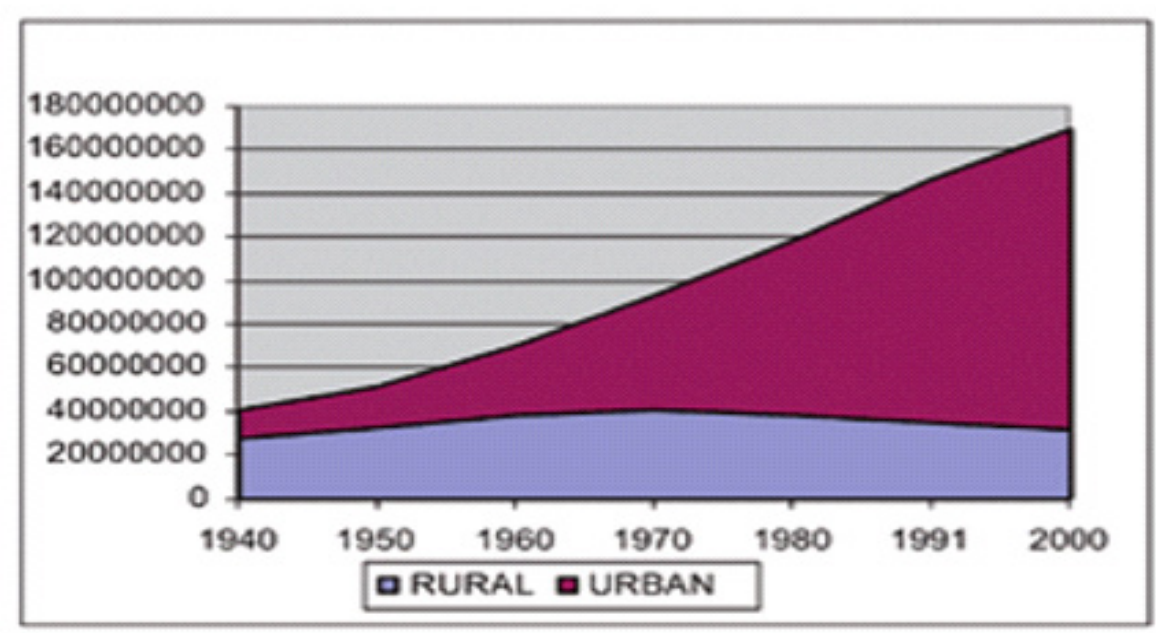

Figure 4 Population Growth in Rural \& Urban Brazil (Brito, 2006) 


\section{Health Risks}

The health risks associated with the most recent drought to plague Southeastern Brazil have yet to be determined. However, studies from droughts all over the world and Northeastern Brazil have created a baseline for what public health issues to expect. Drought can have impacts on known health risks such as inadequate or unsafe water for consumption and sanitation; increased population displacement; disruption of local health services (Sena 2014). Inadequate or unsafe water can lead to acute gastrointestinal issues; water-borne and food-borne diseases; reduced crop yields; death of livestock; infectious and parasitic diseases; skin infections. Local healthcare services can be greatly impacted as the loss of power, loss of medicines and personnel, and infection control becomes issues. Brazil and poorer regions of cities in particular could be prone to water outages and electricity loss as $75 \%$ of the electric power supply comes from hydroelec-tricity (EIA 2014).

Drought also asserts itself in acute and chronic health effects including malnutrition; vector-borne diseases; communicable diseases; respiratory conditions; psycho-social stress; mental health disorders (Sena 2014). Vector-borne diseases such as Dengue, Chikungunya, and the Zika Virus are spread via mosquitoes. It may seem that mosquito populations and viruses spread by them would dwindle as water becomes scarcer. However, the opposite is occurring in low income and rural areas within Brazil. In the poorer areas of Recife, Brazil, the lack of running water means residents have to store their own, creating potential mosquito breeding grounds. This is a common practice across many low income areas in Brazil.

One virus in particular, Zika, has received much attention in the Americas. Recently, in Brazil, local health authorities have observed an increase in Zika virus infections in the general public as well as an increase in babies born with microcephaly in northeast Brazil. Agencies investigating the Zika outbreaks are finding an increasing body of evidence about the link between Zika virus and Microcephaly. However, more investigation is needed before we understand the relationship between microcephaly in babies and the Zika virus. As recently as January 15, 2016, the United States Center for Disease Control and Prevention has issues a travel alert and out of abundance of caution, advised pregnant women to consider postponing travel to areas where Zika virus transmission is ongoing (CDC 2016).

\section{Government Intervention \& Plans Going Forward}

The 2015 United Nations Climate Change Conference held in Paris, France, from 30 November to 12 December 2015 provided a forum for world leaders to develop an agreement on the reduction of climate change. In preparation for the conference, Brazil submitted a six page plan that would contribute towards achieving the objective in reducing climate change impacts across the globe. Brazil highlighted its plan in mitigation; adaptation undertakings; implementation; and further clarified how its contribution will be implemented and upheld.

Brazil's contribution to tackle global climate change is to reduce greenhouse gas emissions by $37 \%$ below 2005 levels by 2025. Subsequent indicative contributions include reducing greenhouse gas emissions by $43 \%$ below 2005 levels by 2030 . Additionally, Brazil seeks to enhance its national capacity in water security and conservation and sustainable use of biodiversity. Furthermore, the plan enforces the implementation of the Forest Code at all levels of government. Thus, enforcing the protection and 
restoration of 12 million hectares of forests by 2030 (Federative, 2015).

\section{Impact on Healthcare Community}

The healthcare community must learn from any emergency or disaster, adopting plans to mitigate the impact for the next event. Disaster plans related to drought should aim to alleviate social vulnerability by seeking to build climate resilience, reduce economic and social losses, and alleviate poverty in drought-affected regions. A comprehensive approach that includes prevention and mitigation, preparedness, response, and recovery requires an active partnership between all relevant agencies and authorities. coordinating with key partners and stakeholders in drought efforts. Identifying atrisk populations for different drought-related implications will be vital in providing the proper care at the right place and time. Strategies and recommendations for mitigation and response to drought should be communicated to the target audience (UNISDR, 2009).

Disaster preparedness is a continual process that requires plans to be dynamic in order to learn from past events and to be effective. Training needs to be done regularly and the plan should be reviewed and amended in light of each occurrence. Drought may not

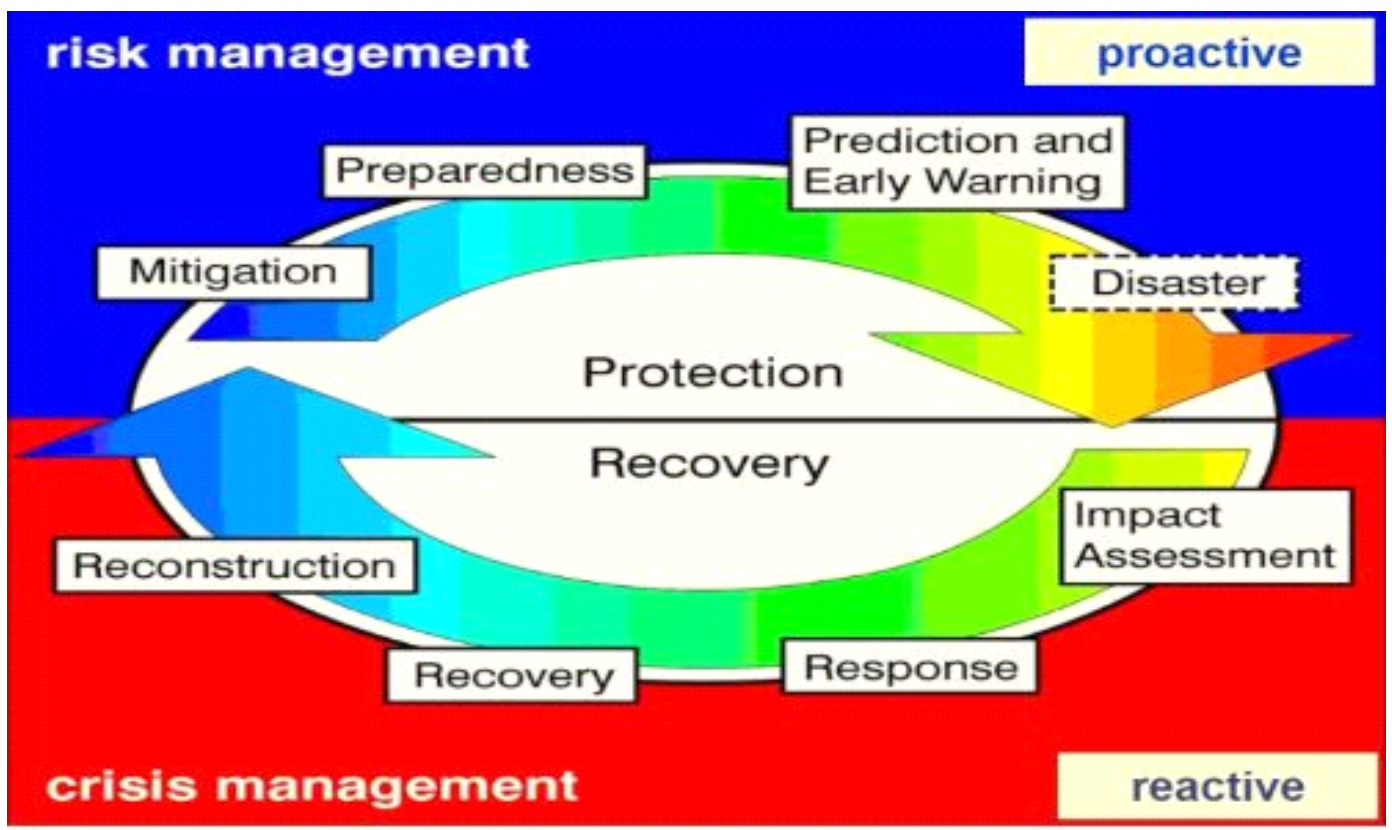

Figure 5 The cycle of disaster management (Pischke, 2014)

Disaster mitigation in the healthcare community includes: conducting an internal capacity assessment; participating in a jurisdiction-wide hazard and vulnerability assessment; conducting a public health vulnerability assessment; identifying and require a quick response like acute emergencies. However, the power issues, worker health, public health, and diseases should be documented in the event an area becomes drought stricken in the near future. 
The onset of Zika and the potential association with increased microcephaly cases has also reignited Brazil's abortion debate. Brazil's abortion laws make the procedure illegal under most circumstances. The only deviation from the abortion law is when a fetus is developing with anencephaly, a rare condition in which the baby is missing parts of its brain and skull or if a woman is raped. Decisions to legalize abortion due to microcephaly are complicated because doctors can only detect the deformities around the end of the second trimester and often the doctors cannot say what the effects will be if a baby is born with the issue.

The sudden uptick in microcephaly cases has reinvigorated a cadre of powerful women's rights activists in the country of Brazil. Wealthy Brazilian women pregnant with babies suffering from severe microcephaly or fetal malformations have options to terminate their pregnancies. These options include working with a private clinic to perform a safe abortion or hiring an attorney to make their case to a local legal tribunal. Poorer Brazilian women do not have this luxury and are afforded fewer options. Low income women seek illegal, dangerous abortions that can cause serious injuries or death.

\section{Conclusion}

Brazil is comprised of four major different areas, all in contrast of each other. Two of these regions, the Northeast and South experience droughts. In the Northeast, drought is a constant threat and the water supply struggles to sustain the population of 40 million people living in oppressive poor conditions. In the South, where the industrial and financial centers are located, excessive consumption and pollution has decreased the available water supply to the populations. These regions of Brazil present important challenges in the healthcare community. Collaboration between climate services and health services are important to strengthen risk management actions.

Even though drought is different from other natural disasters, it does not mean planning and actions should occur to help protect a community from the effects. Public health agencies across Brazil should be prepared to address public health impacts of drought within their communities at all times. Many aspects of drought have been well researched in the developed world, although there is still much to be learned about its public health implications. Epidemiologic and other studies must be conducted to provide stakeholders with drought-related data pertaining to short and long-term impacts of drought on health and the direct and indirect health effects that water shortages have on different population segments.

\section{References}

1. Basic Country Statistics and Indicators Brazil. PreventionWeb. 2015. Web. 9 Feb. 2016. <http://www.preventionweb.net/countries/bra/data/ $>$.

2. Brito, Fausto The Displacement of the Brazilian Population to the Metropolitan Areas. 24 May 2006. Web. 9 Feb. 2016. $<$ http://www.scielo.br/pdf/ea/v20n57/ en_a17v2057.pdf $>$.

3. CDC Issues Interim Travel Guidance Related to Zika virus. (2016, January 17). Retrieved January 19, 2016, from http://www. cdc.gov/media/releases/2016/s0315-zika-virus-travel.html

4. DATA 360: Average Water Use Per Person Per Day. (2014, May 28). Retrieved February 7, 2016, from http://www.data360.org/ dsg.aspx?Data_Set_Group_Id=757

5. Day, C. (2015, December 03). Weighing Brazil's Drought From Space. Retrieved January 11, 2016, from http://scitation.aip. org/content/aip/magazine/physicstoday/ news/10.1063/PT.5.7224 
6. EIA (2014, June 17) Hydropower Supplies More Than Three-Quarters of Brazil's Electric Power. Retrieved February 7, 2016, from http://www.eia.gov/todayinenergy/detail.cfm?id=16731

7. Federative Republic of Brazil Intended $\mathrm{Na}$ tionally Determined Contribution Towards Achieving the Objective of the United $\mathrm{Na}$ tions Framework Convention on Climate Change. (2015).

8. Foster, B. (2015, February 27) Quirky Winds Fuel Brazil's Devastating Drought, Amazon's Flooding. Retrieved January 10, 2016, from http://news.nationalgeographic. com/news/2015/02/150226-drought-floodssouth-america-brazil-bolivia-flying-riversenvironment/

9. Janatová, M., Tichá, M., Gerlichová, M., Řeháková, T., Švestková, O., 2015: Terapie poruch rovnováhy u pacientky po cévní mozkové př́hodě s využitím vizuální zpětné vazby In: Rehabilitácia ISSN 0375-0922, Vol. 52, 2015, No 3, p. 140-148

10. Leita, I. (2014, August 27) Sabesp perde $36 \%$ da água e trata $52 \%$ do esgoto em SP, diz instituto. Retrieved February 7,
2016, from http://g1.globo.com/sao-paulo/ noticia/2014/08/sabesp-perde-36-da-aguae-trata-52-do-lesgoto-em-sp-diz-instituto. html (translated using Google Translate)

11. NASA Global Climate Change. (2016, January 26). Retrieved February 7, 2016, from http://climate.nasa.gov/causes/

12. Pischke, Frederik (2016, 9 Feb.) Facing Droughts - The Integrated Drought Management Programme (IDMP). AID \& INTERNATIONAL DEVELOPMENT FORUM. 09 Apr. 2014. Web...<http://www.aidforum.org/ food-security/facing-droughts-the-integrated-drought-management-programme-id$\mathrm{mp}>$.

13. Sena, A., \& Barcellos, C. (2014) Managing the Health Impacts of Drought in Brazil International Journal of Environmental Research and Public Health, 11.

14. UNISDR (2009, October 14). Disaster Risk Management and Planning for Hospitals and Healthcare Facilities. Retrieved February 7, 2016, from http://www.preventionweb.net/files/11214_FreeStateProvincedisasterriskmanage.pdf 


\title{
Prevent Depression: Improving Access to Brazil's Mental Health Services
}

\author{
R. Heidt (Ryan Heidt)
}

Health Administration \& Human Resources,

$4^{\text {th }}$ Floor McGurrin Hall, Scranton, PA 18510-4699

\section{E-mail address:}

ryan.heidt@scranton.edu

\section{Reprint address:}

Health Administration \&

Human Resources

$4^{\text {th }}$ Floor McGurrin Hall

Scranton, PA 18510-4699

Suource: Clinical Social Work and Health Intervention

Volume: 7

Issue: 4

Pages: $20-24$

Cited references: 14

\section{Reviewers:}

Prof. Dr. Roberto Cauda, Ph.D.

Institute of Infectious Diseases, Catholic University of the Sacred Heart, Rome, IT

e-mail: roberto.cauda@unicatt.it

Robert J. Spinelli, MBA, MPH, DBA

Undergraduate Health Administration Program Director

e-mail: robert.spinelli@scranton.edu

\section{Key words:}

Depression, Mental health, Psychosocial Community Centers, Burden of disease.

\section{Publisher:}

International Society of Applied Preventive Medicine i-gap

CSWHI 2016; 7(4): 20 - 24; DOI 10.22359/cswhi_7_4_03 @ 2016 Clinical Social Work and Health Intervention

\section{Abstract:}

Brazil consistently ranks as one of the most violent and socially inequitable countries across the globe. Both violence and social inequality are associated with depression, resulting in Brazil having a high prevalence of the disease compared to other countries. Depression leaves a large burden on the residents of Brazil in terms of disability-adjusted life years (DALYs), resulting in higher utilization of healthcare services, more hospitalizations, and lost productivity. Brazil is 
deinstitutionalizing mental health care by utilizing Psychosocial Community Centers (CAPS) to provide mental healthcare to the population. However, there are a lack of centers in lower socioeconomic areas consequently creating a discrepancy in coverage and access to mental healthcare. Other Latin American countries such as Chile and Panama have taken steps to improve access to mental health via integrating primary care and mental healthcare. Brazil can utilize similar ideas, along with better education of primary care staff to improve access to mental healthcare.

\section{Introduction}

When people are free of depression and other psychological issues, they become happier, healthier, and more productive. Today, depression is becoming more of a concern in healthcare. Depression is the $4^{\text {th }}$ leading cause of disability worldwide affecting 350 million people. The World Health Organization suggests that depression will become the $2^{\text {nd }}$ leading cause of disability by 2020 (Kessler \& Bromet 2014). The effect this has on affected individuals includes limited activity and well-being, compromised physical health, functional impairment, and other comorbidities.

\section{Prevalence}

The World Health Organization conducted a study on 12-month prevalence rates of 19 countries across the globe. The sample included in the study was comprised of both developing and developed countries. Of the 19 countries examined, Brazil had the highest 12-month prevalence rate of depression (10.4\%) compared to the average 5.4\% (Kessler et al 2010). It is estimated that Brazilians have a $17 \%$ lifetime prevalence rate of major depressive disorder, with $66 \%$ of the cases occurring in females (Sila et al 2014). This high prevalence is exacerbated by a lack of diagnosis and treatment. It is estimated that only $15.3 \%$ of individuals affected with major depressive disorder are diagnosed and treated for their illness (Fujii et al 2012). This under-diagnosis is largely due to unequal access to care and undertrained primary care staff in mental health screening and detection.

\section{Risk Factors}

The high prevalence rate of depression in Brazil is largely due to the high rate of urbanization. Brazil's urban population is $85 \%$, which is in the top $20 \%$ of all countries worldwide (The World Bank (2016). There needs to be an increase in facilities and infrastructure to accommodate the increase in population in cities. However, this usually does not happen in parallel with the rate of urbanization, resulting in poverty, decreased social support, and an increase in violence, which are all risk factors for depression (Srivastava 2009). Therefore, this high percentage of urban population leads to more individuals at-risk for depression.

\section{Burdens}

Depression puts a significant burden on the residents of Brazil. Burdens due to depression are measured via disability-adjusted life years (DALYs). DALYs are the years of life lost due to premature mortality plus years lost due to disability for people living with a health condition or its consequences (The World Health Organization 2016). DALYs are associated with a decrease in economic production, decrease of quality of life, and an increase in healthcare costs. Mental health disorders account for $21.5 \%$ of all of DALYs in Brazil. Depression is the number one factor for DALYs in women and number seven in men. Depression puts a burden on affected individuals through co-morbidities. Individuals with depression are significantly more likely to have anxiety disorders, drug use disorders, nicotine dependence, sleep problems, among 
many more (Fujii et al 2012). Additionally, individuals with depression are significantly more likely to visit the emergency room and have hospitalizations for any medical condition. It is estimated that in $2011,10.7 \%$ of all the sickness benefits claims in Brazil were due to mental health issues with depression being the main cause (Barbosa-Branco et al 2012).

\section{Healthcare in Brazil}

Healthcare in Brazil is provided through the Family Health Strategy (FHS) and Psychosocial Community Centers (CAPS). The Family Health Strategy is comprised of interdisciplinary teams that consist of physicians, nurses, nurse assistants, and four to six community health agents. These teams provide primary care to specific geographic locations. Because these teams are interdisciplinary, it provides an opportunity to integrate mental health professionals onto these teams; however, these teams still largely focus on primary care. (Macinko \& Harris 2015). Psychosocial Community Centers are teams that provide continuous treatment for individuals with severe and persistent mental disorders. These centers provide clinical care and psychosocial rehabilitation in an outpatient setting, while providing partial hospitalization for more severe cases (WHO-AIMS Report on Mental Health System in Brazil 2007). Some of these centers are open 24 hours a day providing access to diverse care, home visits, and allow access to psychiatric medication. There are approximately 1,500 CAPS centers across Brazil, with most of the centers being located in the south and southeast regions of Brazil (Mateus 2008). This skewed placement of centers results in unequal access to mental healthcare. Unfortunately, the traditional evaluation of CAPS coverage in Brazil is based on the number of centers in the geographic location divided by the population of that area. Therefore, with the 1,500 centers and approximate 200 million population, it is estimated that CAPS cover $63 \%$ of Brazil. However, this ratio does not account for geographic location of centers, ultimately miscalculating the actual coverage of CAPS. For example, the State of Rio Grande do Sul ranks $3^{\text {rd }}$ in CAPS coverage based on this calculation. When examined further, it was estimated that only $51 \%$ of Rio Grande do Sul's population had adequate coverage to mental health and " $43.5 \%$ of the state's inhabitants live in municipalities in which coverage rates are $30 \%$ below expected levels" (Lejderman 2010). The estimate of CAPS coverage is misleading. Many areas that are lower in socioeconomic levels have less access to mental healthcare. The quality of mental health in these regions ultimately depends on the degree of communication and integration between the Family Health Strategy teams and Psychosocial Community Center teams. The cities of Sobral and Petropolis utilize good integration models, in which the Family Health Strategy teams take all non-emergency cases first. The CAPS teams visit the Family Health Strategy teams once a month to act as a source of support. This allows for increased communication and teamwork between the teams, resulting in more appropriate referrals to the CAPS. These cities saw a reduction in hospitalizations by $45 \%$ due to an increased degree of communication between primary care and mental health (The World Health Organization). The ultimate goal of CAPS is to de-institutionalize mental health, therefore decreasing the number of psychiatric inpatient beds. One initiative that aids in decreasing the number of inpatient psychiatric beds is the Return Home Program. This program helps to "reintegrate" individuals back into society and increase social inclusion of individuals with "long histories of hospitalization" (WHO-AIMS Report on Mental Health System in Brazil 2007). This program rewards individuals when they leave the psychiatric hospital by giving them financial incentives that are equivalent to 
$\$ 140$ US dollars. There are approximately 3,000 individuals currently benefiting from the Return Home Program.

\section{Latin America's Mental Health Policy}

When compared to the rest of Latin America, Brazil is on the forefront of de-institutionalizing mental health. There are two other countries in particular that are also succeeding with their initiatives to de-institutionalize mental health: Chile and Panama. Brazil, Chile, and Panama have been able to reduce the average number of psychiatric beds per 100,000 from 24 beds to 9 beds over the last decade in their respective countries. To put that in perspective, the rest of Latin America's average number of psychiatric beds have only decreased from 20 beds to 15 beds over the last decade (Minoletti et al 2012). Chile and Panama have had success of decreasing the number of inpatient psychiatric beds by focusing integrating primary care and mental health. Chile utilizes community mental health centers, similar to that of Brazil, which allows for decentralization and improved local resource allocation. Additionally, Chile implemented the National Depression Detection and Treatment Program, which train primary care physicians on mental health screening and detection techniques. The number of patients in this program has increased by $600 \%$ since 2001 (Minoletti et al 2012). Similarly, Panama trains all nurses and non-physicians in early detection of mental health and provides formal mental health screening training for staff.

\section{Improvements to Brazil's Mental Health Policy}

The World Health Organization has three suggestions in regards to mental health policy: de-institutionalize mental health; integrate mental health into primary care; develop community mental health services (WHOAIMS Report on Mental Health System in Brazil 2007).

Although Brazil is on the forefront of de-institutionalizing mental health and utilizing community mental health services compared to the rest of Latin America, there are many areas of improvement to increase access to these essential services. In particular, the main issue is integrating mental health intro primary care. A big concern is that the Psychosocial Community Centers are primarily located around higher socioeconomic regions. This leaves a discrepancy in mental health care for less wealthy individuals. One solution to mitigate this consequence is to create a model of integration for the primary care teams and mental health teams. Similar to models utilized in Sobral and Petropolis, when these teams work closely together there are improvements in quality of care and more appropriate referrals to the mental health teams. Brazil should also implement a formal training program to train primary care staff on early detection and screening for mental healthcare. This training will allow primary care staff to diagnosis and treat less severe cases, leaving the more severe cases for the Psychosocial Community Centers (Gonçalves et al 2011). Chile and Panama, both of which utilize formalized training in mental health for their primary care staff, have seen improvements in quality of care; an increase in the number of patients being treated for mental health; a decrease in the number of psychiatric inpatient beds. Lastly, it is important that Brazil implement a national database that can better track CAPS coverage and performance evaluations. This national database would help identity further areas for improvement in care while more accurately portraying the current status of mental healthcare throughout Brazil. By utilizing these suggested solutions, access to mental healthcare could improve throughout Brazil. 


\section{Conclusion}

Ultimately, the cost of lost productivity due to depression exceeds the cost of direct treatment. Improving access to mental health services will allow individuals to become healthier, happier, and more productive. The current budget for mental health care is $2.38 \%$ of the health budget (Mental Health Atlas 2011). The World Health Organization suggests that this should increase to $5 \%$ in order to match the size of the burden that depression has in Brazil (WHO-AIMS Report on Mental Health System in Brazil 2007).

\section{References}

1. Barbosa-Branco, A., Bültmann U., Steenstra, I. (2012). Sickness benefits claims due to mental disorders in Brazil: associations in a population-based study. Cadernos de Saúde Pública, 28 (10), 1854-1866.

2. Fujii, R., Goren, A., Annunziata, K. et al (2012). Prevalence, awareness, treatment, and burden of major depressive disorder: estimates from the National Health and Wellness Survey in Brazil. Value in Health Regional Issues, 1, 235-243.

3. Gonçalves, R., Vieira, F., Delgado, P. (2011). Mental health policy in Brazil: federal expenditure evolution between 2001 and 2009. Revistade Saúde Pública, 46 (1), 1-7.

4. Kessler, R., Bromet, E. (2014). The epidemiology of depression across cultures. Annual Review of Public Health, 34, 119-138.

5. Kessler, R., Birnbaum. H., Shahly, V. et al (2010). Age differences in the prevalence and comorbidity of DSM-IV major depressive episodes: Results from the WHO World Mental Health Initiative, Depress Anxiety, 27 (4), 251-364.

6. Lejdman, F. (2010). The fallacy of adequate coverage offered by Psychosocial Care Centers in the state of Rio Grande Do Sul: a comment. Revista de Psiquatria do Rio Grande do Sul, 32 (1), 1-2.

7. Macinko. J., Harris, M. (2015). Brazil's Family Health Strategy-Delivering community-based primary care in a Universal Health System. The New England Journal of Medicine, 372 (73), 2177-2181.

8. Mateus, M. et al (2008). The mental health systems in Brazil: Policies and future challenges. Interntational Journal of Mental Health Systems, 2, 12.

9. Minoletti, A., Galea, S., Susser, E. (2012). Community mental health services in Latin America for people with severe mental disorders. Public Health Reviews. 34.

10. Srivastava, K. (2009). Urbanization and mental health. Industrial Psychiatric Journal, 18 (2), 75-76. The World Bank (2016). Retrieved from http://data.worldbank.org/indicator/SP.URB.TOTL.IN.ZS

11. The World Health Organization (2016). Health statistics and information systems. Retrieved from http://www.who.int/healthinfo/global_burden_disease/metrics_daly/en/

12. Vetkasov, A., Hošková, B., Sobotková, I. 2015: Spolehlivost měření pohybu dolních

13. žeber a brániční mobility radiografickou metodou u osob po poranění míchy. In: Rehabilitácia ISSN 0375-0922, Vol. 52, 2015, No 4, p. 228-235.

14. World Health Organization (2007). WHOAims report on mental health in Brazil. Retrieved from http://www.who.int/mental health/evidence/who_aims_report_brazil.pdf

15. The World Health Organization (n.d.) Integrated primary care for mental health in the City of Sobral. Retrieved from http://www. who.int/mental_health/policy/services/Brazil.pdf World Health Organization (2011). Mental Health Atlas 2011. Retrieved from http://www.who.int/mental_health/evidencel atlas/profiles/bra_mh_profile.pdf? $u=1$ 


\title{
An Assessment of Equity in the Brazilian Healthcare System: Redistribution of Healthcare Professionals to Address Inequities in Remote and Rural Healthcare
}

\author{
P. M. N. Akindo (Prudence M. N. Akindo)
}

Health Administration \& Human Resources,

McGurrin Hall, Scranton, PA 18510-4699

\section{E-mail address:}

akindoterence@yahoo.com

\section{Reprint address:}

Health Administration \&

Human Resources

$4^{\text {th }}$ Floor McGurrin Hall

Scranton, PA 18510-4699

Suource: Clinical Social Work and Health Intervention

Pages: $25-32$

Volume: 7

Issue: 4

\section{Reviewers:}

Dr. Johnson Nzau Mavole, Ph.D.

Catholic university of Eastern Africa, Nairobi, Kenya

e-mail: jmavole@cuea.edu

prof. MUDr. Anton Gúth, CSc.

Univerzitná nemocnica Bratislava

e-mail: anton.guth@kr.unb.sk

\section{Key words:}

Brazil's healthcare system, Healtcare professionals, Urban areas, Lucrative icentives.

\section{Publisher:}

International Society of Applied Preventive Medicine i-gap

CSWHI 2016; 7(4): 25 - 32; DOI 10.22359/cswhi_7_4_04 @ 2016 Clinical Social Work and Health Intervention

\section{Abstract:}

This document provides an in-depth assessment of Brazil's healthcare system with specific emphasis on the characteristics that shape the distribution of providers across the country. The drastic differences in the ratio of providers between the public and private sectors, alongside an even bigger distinction between available providers in rural and urban areas 
presents a hindrance to Brazil's premise of equal access to care for all. This document also presents three proven solutions that can successfully redistribute healthcare professionals (physicians in particular), in favor of Brazils remote vulnerable communities and rural regions. These proven recommendations include (1) the use of telehealth; (2) Lucrative incentives; (3) Creating and strengthening public and private partnerships.

\section{Introduction}

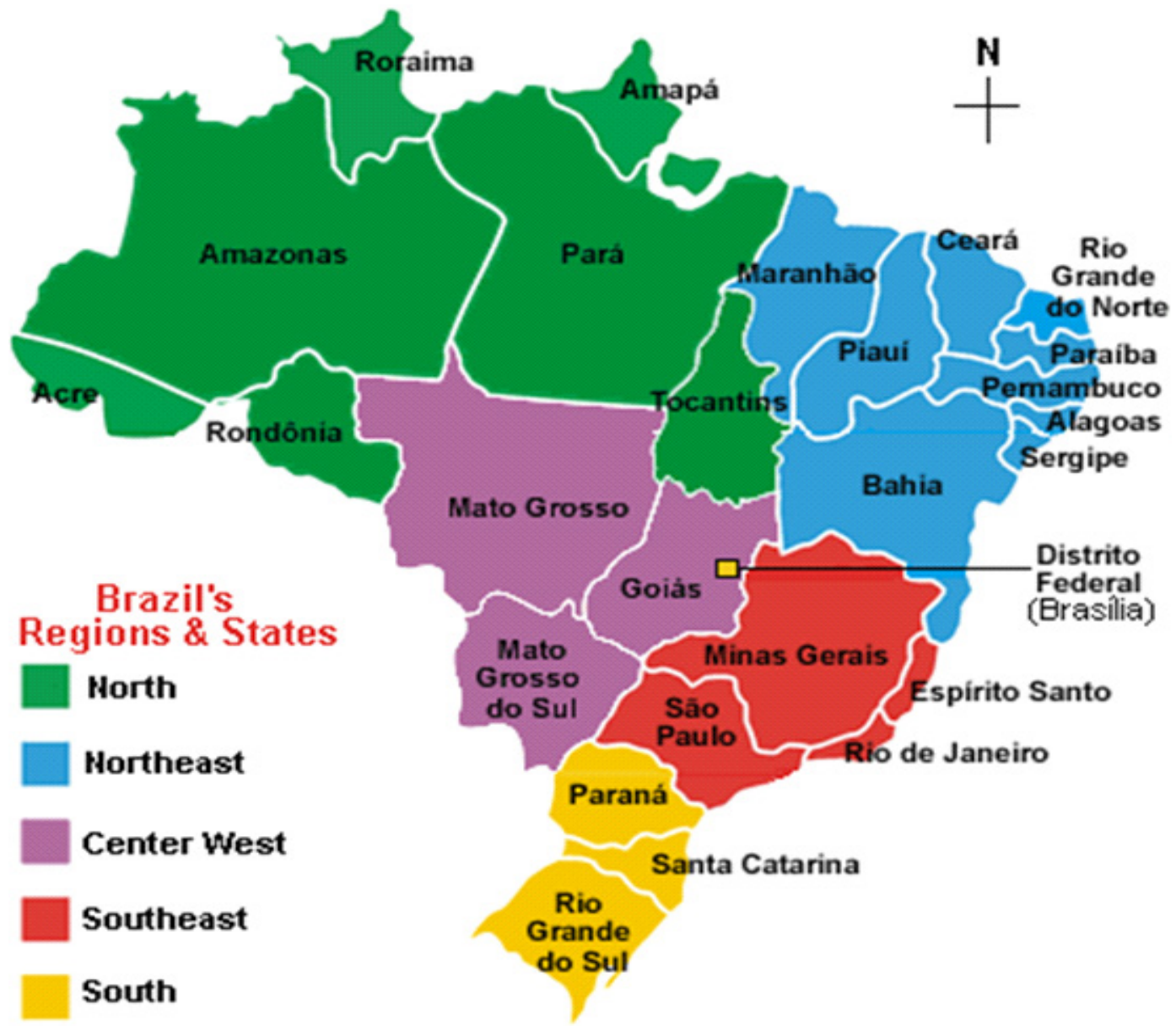

Figure 1 Geographic Regions of Brazil

Since the institution of Sistema Único de Saúde (SUS), Brazil's Universal Healthcare System, access to healthcare in Brazil has increased with utilization increases noticeable in all 26 states and demographics. Instituted under the belief that healthcare is a right and it is the duty of the government to provide it, SUS made Brazil one of the largest public healthcare providers in the world.
However, increases in healthcare utilization has consistently not been matched by sufficient healthcare spending. Between 2011 and 2015, Brazil spent 9.7 percent of it's gross domestic product (GDP) on healthcare. With a 2015 physician density "averaging 1.95 physicians per 1.000 habitants", "far below neighboring Argentina (3.2) and Uruguay (3.7)," the impact of physician shortages on 
overall quality of care cannot go unnoticed. Therefore, an increase in healthcare expenditure will help Brazil improve its allocation of federal, state and municipal resources to favor the poorest regions and segments of its population: shifting from just a focus on equal access to healthcare for all towards high quality healthcare for all.

\section{Public vs. Private Provider Distributions}

Brazil's national health system is characterized by a public and private sector. The public sector which is funded by the federal, state and municipal governments through taxes and social contributions, accounts for about 75 percent of the Brazilian population; mostly the lower-income and poor. Care in the public sector is provided free at point of delivery by public or contracted private providers. The public sector makes up about 32 percent of all Brazil hospitals and about 44 percent of all Brazilian physicians. It is evident that the provider ratio is not sufficient to handle the patient population in the public sector which is often characterized by overcrowding, long patient wait times, access difficulty etc. More so, " 46 percent of Brazil's health spending was funded by public sources in 2012, compared to an average of 72 percent in OECD countries." Therefore, inadequate governmental spending in the public sector is also a major contributor to the poor quality of care commonly associated with it.

Brazil's poor public health system is "boosting the use of private healthcare and employer-subsidized private health insurance" among 25 percent of the Brazilian population who can afford it. Responsible for about 52 percent of total healthcare spending in 2013, the private sector is the main source of health funding in Brazil's national health system. This sector makes up about 65 percent of all Brazils hospitals and about 56 percent of the physician population. With healthcare professionals choosing to work for the private system over the public due to the favorable working conditions associated with it, the significant disparities that exist between the public and private health sectors of Brazil are not surprising.

\section{Urban vs. Rural Provider Distributions}

As with most other countries in the world, the shortage of physicians in rural areas is one of the contributing factors to poor health outcomes associated with remote regions. In spite of SUS, and its push for equal access to healthcare for all Brazilians, "people living in remote and vulnerable communities still face poor access to operative health services." In 2014, 14.6 percent of the Brazilian population was considered to be living in rural areas. The north, northeast and center west regions are areas experiencing the greatest shortage of physicians. For example, in 2014, the State of Maranhão in the northeast, had 0.58 physicians per 1,000 inhabitants while the richer Rio de Janeiro had 3.44. (Figure 1. shows the geographic breakdown of Brazil by regions).

Numerous initiatives, including the recent Primary Care Professional Appreciation Program (Programa de Valorização dos Profissionais da Atenção Básica-PROVAB), have been implemented in efforts to attract health professionals to remote areas. However, these programs have not been as successful given that physician professional participation has remained below local or regional needs. In 2013, the "Mais Médicos" Program was introduced in Brazil "as part of a series of measures to fight inequalities in access to operative primary care." The Program was structured on three levels of action: the "Projeto Mais Médicos para o Brasil" (More Physicians for Brazil Project or PMMB; an emergency physician provision program for vulnerable areas. As shown in Figure 1., the success of PMMB was reliant on the successful recruitment of foreign physicians from the 49 participating countries, primarily Cuba (11,429 physicians); crediting PMMB to be 
the most effective in recruiting and placing the magnitude of physicians demanded for the remote communities. These foreign doctors "sign a three year contract", promising to dedicate their "activities to basic family medicine" in the city or town designated by the ministry "in exchange for a 10,000 BRL $(\$ 5,000)$ monthly payment." that the core of Brazil's physician shortage problem actually lies in how physicians are distributed throughout the country.

\section{Recommendations}

Rather than continue with foreign recruiting, which although effective, is only a shortterm strategy which results in high turnover;

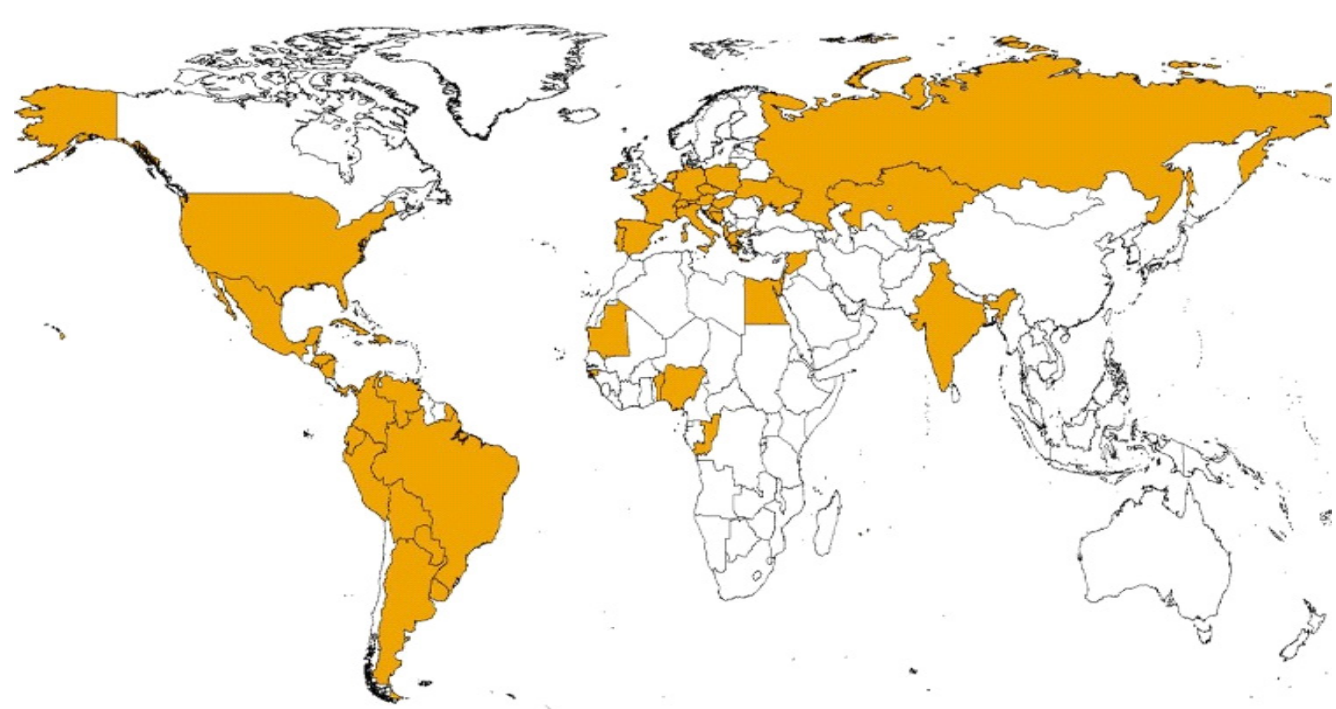

Figure 2 Countries of origin (professional practice) of the participating physicians of the Mais Médicos Para o Brasil Program.

The recruitment of foreign physicians was met with lots of opposition from most Brazilian doctors who claim "the main cause for inadequate physician coverage" is the country's "inadequate medical infrastructure." In addition, the fact that these foreign doctors are only allowed to sign three-year contracts, questions the sustainability of the PMMB program. What happens after the three years is up and the doctor decides to return back to his/her home country; does the system start all over again with recruiting and placing a new foreign physician, or does that area return to its physician-shortage condition? The problem therefore lies beyond the numbers. The federal government and medical groups must recognize sustainable strategies must be implemented in efforts to address long-term, the physician shortage problem in Brazil. Investments in telehealth, public-private partnerships, and incentives, will result in the distribution of physicians in remote vulnerable areas; reducing the existing health inequities and enhancing the quality of health in these areas.

\section{Telehealth}

"Health professionals in remote areas tend to be young and inexperienced and are often isolated and in need of further training." "The use of telehealth to provide care, impart education or conduct research," has the potential to reduce existing healthcare inequities prevalent in rural areas. By serving 
as a platform for effective "communication between primary care practitioners and specialists in reference centers," telehealth facilitates access to diagnostic tests thus enhancing healthcare quality in underserved communities. The results of pilot studies conducted on the use of telehealth in vulnerable communities of Brazil have been successful in addressing the needs of healthcare professionals in those regions. However, these studies have not been replicated or enforced as the standard of care in most of Brazil's remote vulnerable regions.

In 2005, the government of Minas Gerais State funded the establishment of The Telehealth Network, connecting the teaching hospitals of five public Universities with Municipal Health Departments. electrocardiographs, digital cameras (e.g. for photographing skin lesions), webcams and low-band-width internet." The "primary care professionals used the networks website to address questions to University staff in areas such as Medicine, Nursing, Dentistry, Physiotherapy, Nutrition, Pharmacy, Psychology and Audiology; allowing them to perform their clinical activities with the support of a network of Specialists on duty in the Universities." Monitoring for quality, and user satisfaction, in addition to using economic indicators such as implementation cost per site, unitary activity per site and patient referral cost to perform cost-effectiveness analyses; the results of the project proved effective, technically and financially feasible, and physician satisfaction in remote locations increased markedly.

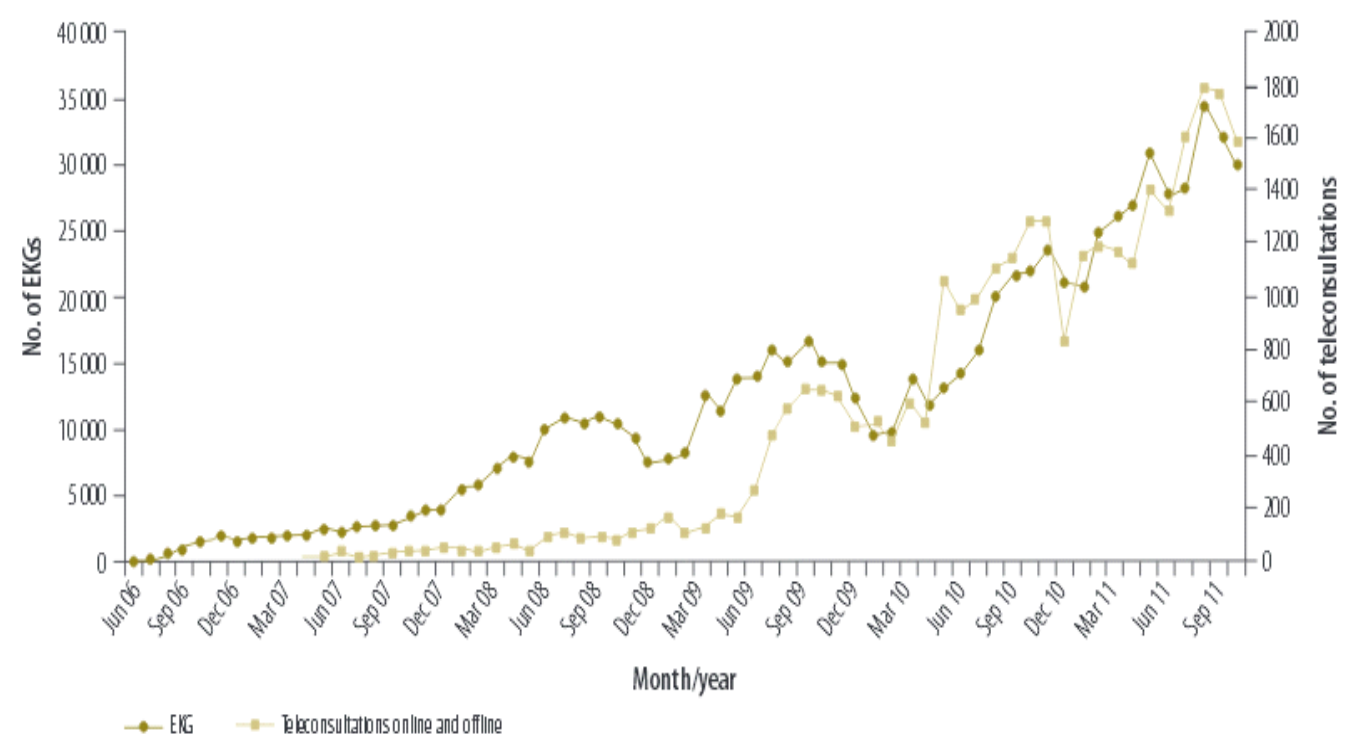

Figure 3 Electrocardiograms (EKGs) and teleconsultations conducted through the Telehealth Network of Minas Gerais, Brazil, June 2006-October 2011

In 2007, the Telehealth Network began providing teleconsultations with a focus on tele-cardiology (Minas Telecardio Project). The "network relied on low-cost technical equipment easily accessible to poor villages such as computers, printers, digital
Another pilot project, Connected Healthy Children (CHC)-Brazil, was performed in February 2014 by Cisco in partnership with the state of Sergipe Brazil. This project also resulted in significant improvements to healthcare access as well as the quality of care received 
by patients. Sergipe is located in the northeast region of Brazil, an area prone to the shortage of Medical Specialists. Limited access to collaboration technologies in Sergipe (and other rural states) is also another challenge; leaving clinicians in these rural regions "virtually unable to connect with medical peers who have the specialized expertise they need." The CHC pilot program was first launched "in collaboration with the Federal University of Sergipe" in the Sergipe municipalities of Tobais Barreto and Lagarto. The goals of the program were to; improve clinician-to-patient care; facilitate clinician-to-clinician collaboration; enhance continuing medical education; extend healthcare information and telehealth communications to the community at large. Figure 4 and 5 below show the steps taken to ensure that consultations and collaboration goals were accomplished.

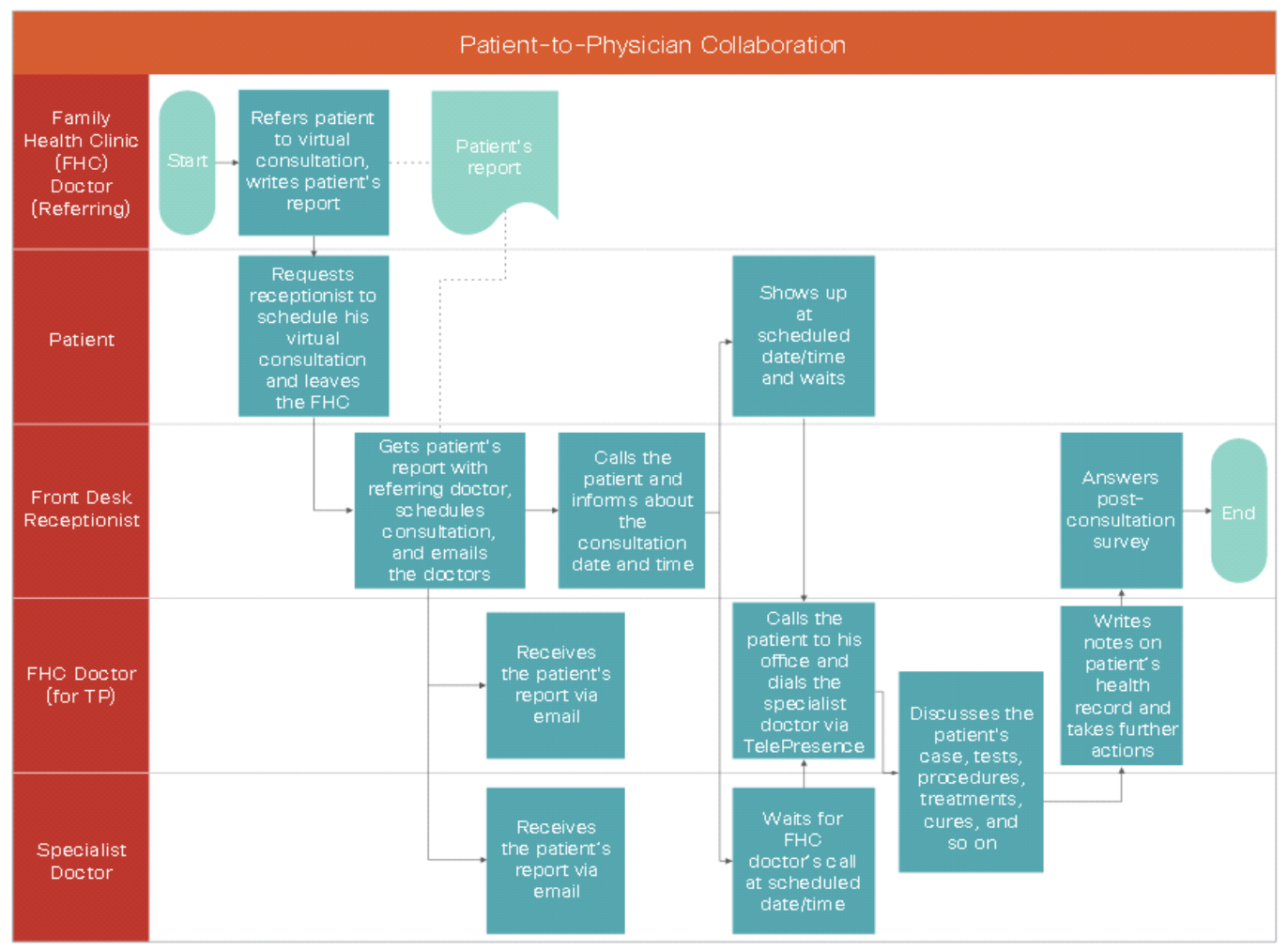

Figure 4 Steps in a Typical Consultation

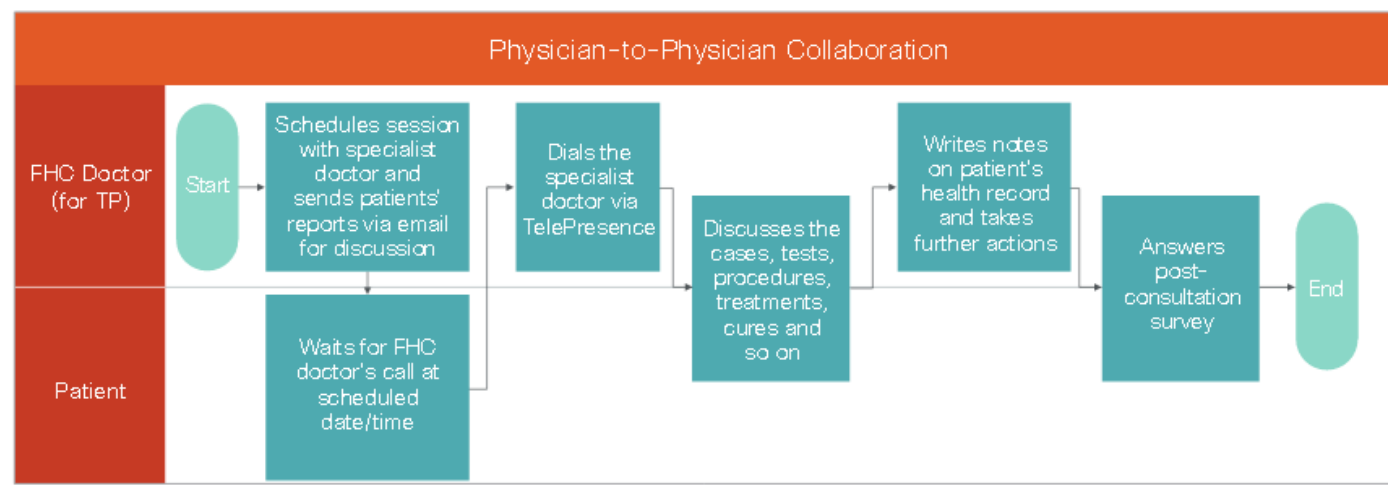

Figure 5 Physician-to-Physician Collaboration 
"Telemedicine benefits the University in the areas of research and information gathering. But its role in the community is direct and important. It can serve a large number of children and other people where face toface visits aren't possible" says Professor Angelo Antoniolli, Dean at the Federal University of Sergipe. 40 patients were able to benefit from telehealth consultations in the initial pilot of $\mathrm{CHC}$. This number included the case of... "a two-year-old boy from rural Tobias Barreto who showed symptoms of urticarial (hives), an allergic reaction that can have many causes. The boy needed to see a Specialist to confirm the diagnosis and receive a treatment plan. Instead of making a two-hour, 80 -mile $(130 \mathrm{~km})$ trip to Aracaju for an office visit, the patient's family walked with him to a local family health clinic. There, using high-definition videoconferencing, a Pediatric Allergy Specialist from UFS's Teaching Hospital conducted a real-time consultation. The doctor never had to leave the hospital, and the family avoided a stressful journey-saving travel time, travel costs, and missed work."

The effectiveness of telehealth in addressing inequities in the rural regions is evident in the number of respondents who support it $(93 \%)$. The telehealth pilot programs developed to support healthcare professionals in Minas Gerais and Sergipe, Brazil, have produced good results overall at relatively little cost. These programs are proving to be sustainable long-term strategies, helping to bridge access to care gaps between urban and rural regions in Brazil. Government investment and enforcing of telehealth as the standard of care across Brazil will promote needed replication of such models in all rural regions helping the government fulfill it's constitutional premise of equal access to high-quality care for all.

\section{Incentives}

In Brazil, "most medical students and doctors tend to come from wealthier areas which is usually where they stay." Poor urban and rural areas are usually not attractive to this elite group of professionals. Barriers hindering physician desire to practice in rural areas include but are not limited to the fact that these physicians fear professional isolation-having no one to consult on a difficult case. Therefore, to better manage the distribution of the healthcare workforce the government must provide lucrative incentives that attract physicians to rural vulnerable areas. Educational, technological and financial resources should be leveraged on by the federal government to get physicians to move shop.

Given that majority of Brazilian physicians come from wealthy communities which is where they choose to practice, providing educational incentives such as scholarships, grants, and tuition reimbursements to rural students who choose to study medicine, or to students who chose to practice in rural regions, is influential in attracting the workforce demanded in these vulnerable regions. It must also be noted that as more students from rural areas attain physician status, the probability of them returning to practice close to family is much higher than that of students from wealthy urban areas. China and Thailand (countries experiencing similar healthcare workforce distribution problems as those in Brazil) have had success in this strategy through the recruitment of rural students for free education in medical schools in exchange for hometown placement. Thailand has also instituted a mandatory requirement for clinical rotations for medical students in rural areas during medical studies; all possible strategies Brazil can emulate to attract and retain physicians in rural areas. 
Governmental investments in telehealth programs that foster collaboration between Clinicians in remote and urban areas will challenge the fear of professional isolation typically associated with rural areas. Knowing that they can virtually connect with medical peers who have the specialized expertise they need access to, serves as an incentive for more physicians to move. Of course, lucrative salaries and benefits also have the potential of incentivizing physicians to move and practice in rural areas. As stated by Francisco Eduardo de Campos (Executive Secretary of UNASUS), one of the barriers to attracting health professionals for work in rural areas is few job opportunities for their spouses. Often times, such a move leaves the physician as the sole provider for his/her household. Therefore, offering lucrative salaries/benefits for such remote locations eliminates this barrier and increases the likelihood for physicians to move and stay.

\section{Public and Private Partnerships}

Public-private partnerships (PPP) in Brazil are essential to the quality of care. Such partnerships allow for the expansion of care, improvement of facilities and increases in service efficiency. Opened in 2010, Hospital do Subúrbio, located in the underserved area of Salvador, Bahia in the northeast region, was the first PPP in Brazil. This facility was built by the public sector, but equipped, operated and managed by the private sector. "The objectives of the government of Bahia for this PPP were to ensure that all its population had access to high quality emergency health services while also establishing a new benchmark within the public health system that could be replicated throughout the country." Because payments to the private partner were linked to key performance indicators based on qualitative and quantitative targets, this PPP "created incentives for high levels of performance." Also, mitigating government risk was done through the establishment of a payment mechanism which resulted in "increasing interest by the private sector and the possibility of obtaining financing for the project." The success of the Hospital do Subúrbio's PPP has resulted in six other Brazilian states currently developing PPPs. An even more successful trend will be to see more states, especially those in rural areas replicate such PPPs so as to fulfill the premise of universal access to high quality healthcare.

\section{Conclusion}

To successfully move in the direction mandated by SUS, Brazil must redistribute its workforce to support its most vulnerable populations. Lack of skilled healthcare professionals in rural regions is a primary contributing factor to the negative health outcomes that characterize the overall health status of the country. By investing in the use of telehealth; provision of lucrative incentives; encouraging partnerships between public and private sectors; all proven strategies that have positively impacted the quality of care in certain rural regions, Brazil stands a better chance of successfully bridging that gap between access and high quality care. 


\section{HIV Prevention in Brazil}

\section{K. Bell (Kristen Bell)}

University of Scranton of Panuska College of Professional Studies,

Original Articles

Office of Undergraduate Admissions, 800 Linden Street, Scranton, PA 18510-4699

\section{E-mail address:}

kristen.bell@scranton.edu

\section{Reprint address:}

University of Scranton of Panuska College of Professional Studies

Office of Undergraduate Admissions

800 Linden Street

Scranton, PA 18510-4699

Suource: Clinical Social Work and Health Intervention

Volume: 7

Issue: 4

Pages: $33-40$

Cited references: 8

\section{Reviewers:}

Dr. Michael Costello, MA, MBA, J.D.

University of scranton school of education, USA

e-mail: michael.costello@scranton.edu

Dr.S.R. Boselin Prabhu, DUC., B.E., M.E., Ph.D

V.S.B College of Engineering-Technical Campus, Coimbatore, India

e-mail: eben4uever@gmail.com

\section{Key words:}

HIV, Prevention, Brazil, Antiretroviral treatment.

\section{Publisher:}

International Society of Applied Preventive Medicine i-gap

CSWHI 2016; 7(4): 33 - 40; DOI 10.22359/cswhi_7_4_05 @ 2016 Clinical Social Work and Health Intervention

\section{Abstract:}

HIV is a significant health concern worldwide, and combating this disease is an important millennium development goal formulated at the United Nations Millennium Summit in 2000. A target was set to halt HIV/AIDS by 2015 and reverse its spread (Skolnik 2016). Brazil sets a high standard of protocol for the prevention and treatment of HIV and AIDS, not only in Latin America, but on a global level. The prevalence of HIV in Brazil, Latin America, and worldwide are examined, along with HIV prevention and treatment strategies in Brazil. Studies that have been 
conducted in other Latin American countries are reviewed that imply the critical role education and community organizations have in combating the disease which focus on key populations and high-risk groups. The impact of the prevention and treatment strategies in Brazil demonstrate the strong political and ethical commitment Brazil has towards the health of their population.is very rare, CRP response in a patient was significant.

\section{Introduction}

Human Immunodeficiency Virus (HIV) continues to be a growing pandemic concern. HIV is spread through certain body fluids that attack the body's immune system, specifically the CD4 or T cells. The human body cannot rid itself of HIV. Once HIV is acquired, it is present for life. HIV destroys many $\mathrm{T}$ cells over time, which hinders the body from fighting off various diseases and infections. HIV can lead to Acquired Immunodeficiency Syndrome (AIDS) if left untreated. Antiretroviral treatment has been available since the mid-1990s, and it is known to reduce the spread of infection and decrease the risk of the acquirement of AIDS. No cure exists for $\mathrm{HIV}$, so it is critical for individuals at risk or living with HIV to seek education and treatment (CDC 2015).

\section{Prevalence of HIV}

There are an estimated 35 million people worldwide that have been infected with HIV in 2013, and 1.5 million have suffered AIDS-related deaths (Skolnik 2016). There have been 2.1 million people newly affected with HIV in 2013. Of the 35 million people infected with HIV, 55\% are females (Skolnik 2016).

The region with the highest prevalence rate of HIV/AIDS in adults 15-49 years of age is sub-Saharan Africa at $4.7 \%$, followed by Eastern Europe and Central Asia at $0.7 \%$. Brazil and the United States of America have comparable rates of HIV/AIDS, around $0.6 \%$ (Skolnik 2016).

In Latin America, 1.6 million people were living with HIV in 2013, with a prevalence rate of $0.4 \%$. There were 94,000 new infections, 47,000 AIDS-related deaths, and $44 \%$ of adults were on antiretroviral treatment (AVERT 2015).

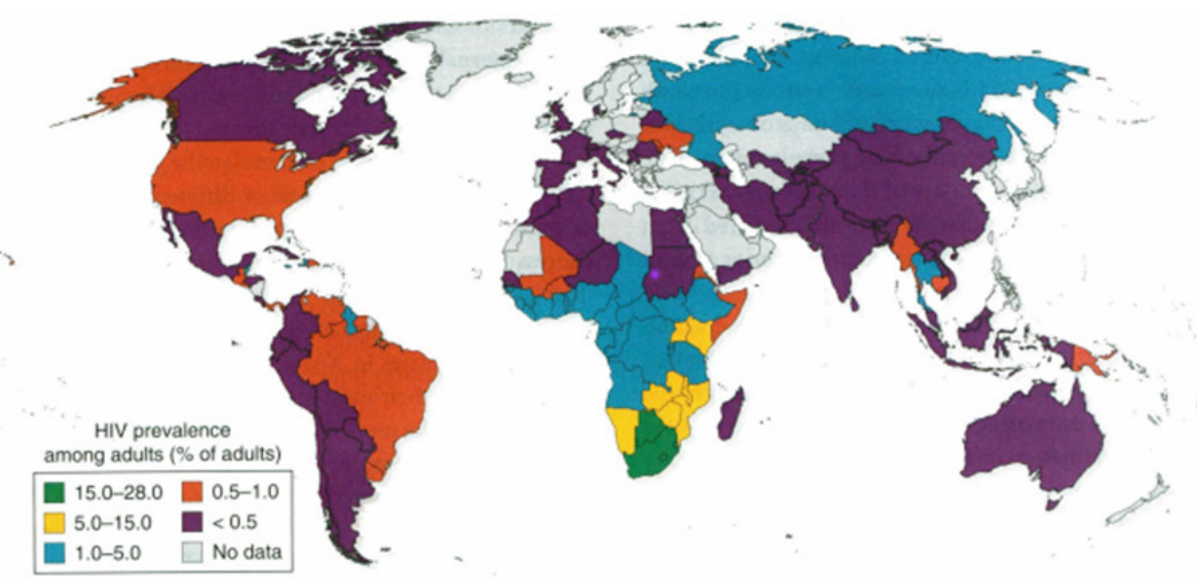

Figure 1 HIV prevalence by country. Reprinted from Global Health $1013^{\text {rd }}$ Ed. (p 327), by R.L. Skolnik 2016, Burlington, MA: Jones and Bartlett Learning. Copyright 2016 by Jones \& Bartlett Learning, LLC, an Ascend Learning Company. 
Brazil represents the largest number of people living with HIV in Latin America at $47.3 \%$. In 2013, there were 730,000 people living with HIV (a prevalence rate of $0.6 \%$ ). In 2013, there have been 44,000 new HIV infections, 16,000 AIDS-related deaths, and $41 \%$ of adults receiving antiretroviral treatment (AVERT 2015). Brazil has seen an average of new infections of HIV on an average of 37,000 between the years 2002 and 2012. There has also been a rise of new infections from 2005 and 2013 by 11\% (AVERT 2015).

\section{High Risk Activities and Key Affected Populations}

HIV can be spread through unprotected sex, mother-to-child transmission during birth or breastfeeding, blood, including by transfusion and needle sharing, and/or transplantation of infected tissue or organs (Skolnik 2016). Uncircumcised males bare a higher risk of acquiring HIV, and females are at a greater biological and social risk than males of being infected with HIV (Skolnik 2016). Male-to-female sexual transmission of HIV is greater than female-to-male transmission (Skolnik 2016). The Progress Report of the Brazilian Response to HIV/AIDS (20102011) examined the high-risk groups of HIV based on studies conducted in 10 Brazilian municipalities between 2008 and 2009 (Manaus, Recife, Salvador, Belo Horizonte, Rio de Janeiro, Santos, Curitiba, Itajaí, Campo Grande and Brasília) (Brazilian Ministry of Health 2012). The estimated prevalence rates of HIV were $10.5 \%$ among men who have sex with men, 5.1\% among sex workers, and 5.9\% among injecting drug users (Brazilian Ministry of Health 2012). It is important to note that sex work is legal in Brazil, which puts these individuals, especially females, at a greater risk of acquiring HIV.

\section{Goals of Brazilian Government}

The government of Brazil has made a significant contribution to the UNAIDS Global AIDS Response Report 2015 which provides progress and challenges of the response to HIV developed by the Department of STI, AIDS and Viral Hepatitis in 2014 (UNAIDS 2015). The government of Brazil and other countries of the Latin American region have set $90 / 90 / 90$ targets to be achieved by the year 2020. These targets are defined as $90 \%$ of people living with HIV/AIDS knowing their HIV status; 90\% of people living with HIV/AIDS receiving antiretroviral treatment; $90 \%$ of people receiving antiretroviral treatment virally suppressed by the year 2020 (UNAIDS 2015). The targets were defined in May 2014 during the first Latin American and Caribbean Forum on the HIV Care Continuum held in Mexico City. The ways in which these goals will be achieved are by increasing access to prevention, diagnosis, and treatment; combating the stigma and discrimination of an HIV diagnosis; promoting the human rights of people living with HIV.

\section{Hiv Continuum of Care in Brazil}

The Global AIDS Response Progress Reporting (GARPR) provides baseline statistics of the HIV Continuum of Care in Brazil adapted from the Ministry of Health/ Surveillance Secretariat/

Department of STI, AIDS, and Viral Hepatitis in 2013. As mentioned previously, there were 730,000 people living with HIV and AIDS in Brazil in 2013. Of those $730,000,80 \%(589,000)$ knew their diagnosis. Approximately two thirds of the $80 \%$ $(537,000)$ had been linked to health services, and $61 \%(448,000)$ were retained in care. Of the $48 \%(355,000)$ receiving antiretroviral treatment, $82.5 \%(293,000)$ of those receiving antiretroviral treatment had an undetectable virus load (UNAIDS, 2015). 


\section{HIV Prevention Strategies in Brazil}

In 2013, the Department of STI, AIDS, and Viral Hepatitis, in partnership with the Ministry of Health and civil society organizations in Brazil, launched "Viva Melhor Sabendo" or "Live Better Knowing" as a strategy for rapid HIV testing with oral fluid among the key populations. The name of the project refers to the benefits of knowing an HIV diagnosis. Testing occurs in the communities of Brazil that have participating organizations. In the first stage of the project, 36 cities in all five regions of Brazil were involved. "Viva Melhor Sabendo" uses a peer sharing strategy which is defined as the "sharing of knowledge between equals or between people or groups having the same profile and sharing the same experiences thus facilitating the exchange of knowledge and practices" (UNAIDS 2015). This strategy enables key populations to be reached in key locations outside of healthcare facilities and the spread of information of HIV to peers of similar backgrounds. At the end of 2014, "Viva Melhor Sabendo" was carried out in partnership with 48 non-governmental organizations (NGOs) from four key populations connected to HIV: gay men, transgenders, sex workers, and people who use drugs (UNAIDS 2015). Tests performed by this project are displayed in Table 1. Of the number of people tested between March 2014 and January 2015, $43 \%$ were never tested before the project, and $29 \%$ of the positive cases were never tested before the project (UNAIDS 2015).

The prevention of HIV from mother to child transmission is attempted by the provision of routine recommendations that HIV positive mothers do not breastfeed; rapid HIV testing in maternity units; routine recommendations that all pregnant women should be tested (AVERT 2015). Over the last 10 years, the detection rates of HIV among pregnant women have increased significantly: in 2004 the rate was 2.0 cases per 1,000 live births, which increased to 2.5 cases in 2013. The AIDS detection in newborns has significantly decreased since 2004 by $35.7 \%$ (UNAIDS 2015).

Table 1 Tests by "Viva Melhor Sabendo"March 2014- Jan 2015

\begin{tabular}{|lrcc|}
\hline Key Populations & $\begin{array}{c}\text { \# of People } \\
\text { Tested }\end{array}$ & $\begin{array}{c}\text { \# of Positive } \\
\text { Cases }\end{array}$ & $\begin{array}{c}\text { \% of Positive } \\
\text { Cases }\end{array}$ \\
\hline Transvestites & 626 & 80 & $12.8 \%$ \\
Transsexuals & 435 & 29 & $6.6 \%$ \\
Male sex workers & 504 & 21 & $4.1 \%$ \\
Female sex workers & 3,418 & 40 & $1.2 \%$ \\
People who use drugs & 2,697 & 47 & $1.7 \%$ \\
Gay men \& other & 3,011 & 142 & $4.7 \%$ \\
MSM & & & \\
Other populations & 5,142 & 52 & $1.0 \%$ \\
Total & 15,833 & 411 & $2.6 \%$ \\
\hline
\end{tabular}

Table 1 Tests performed by "Viva Melhor Sabendo" March 2014 - January 2015. Adapted from "The Brazilian Response to HIV and AIDS." (2015) Global AIDS Response Progress Reporting Narrative Report, UNAIDS. Brasilia, DF. 
The government of Brazil has guaranteed universal and free of charge access to antiretroviral treatment for people living with HIV and AIDS since 1996. In 2002, there were 300,000 people worldwide receiving HIV treatment, and half of those people were receiving treatment in Brazil (WHO 2013). This suggests the impact of the strong political commitment Brazil has towards fighting HIV and the mobilization of substantial resources throughout Brazil. By 2011, 80\% of people living with HIV and AIDS were receiving antiretroviral treatment, and the mortality rates of AIDS-related deaths significantly decreased (WHO 2013). Mortality rates of AIDS-related deaths compared to non-AIDS-related and unknown deaths are shown in Figure 2. positive adults begin treatment regardless of their CD4 cell count, or before their immune system has yet been compromised. "Option B+" was implemented in 2012, which allows pregnant women to begin treatment regardless of their CD4 cell count. "Test and Treat" was implemented in 2013, which expanded this philosophy to all HIV positive adults. Brazil was the third country in the world to adopt the "Test and Treat" program in its nation recommendations (UNAIDS 2015). These programs are used as forms of prevention of the spread of the disease.

In 2014, 75,000 new people living with HIV and AIDS were receiving treatment, which was a $31 \%$ increase since 2013 . Based on the clinical data, $36 \%$ of Brazilians receiv-

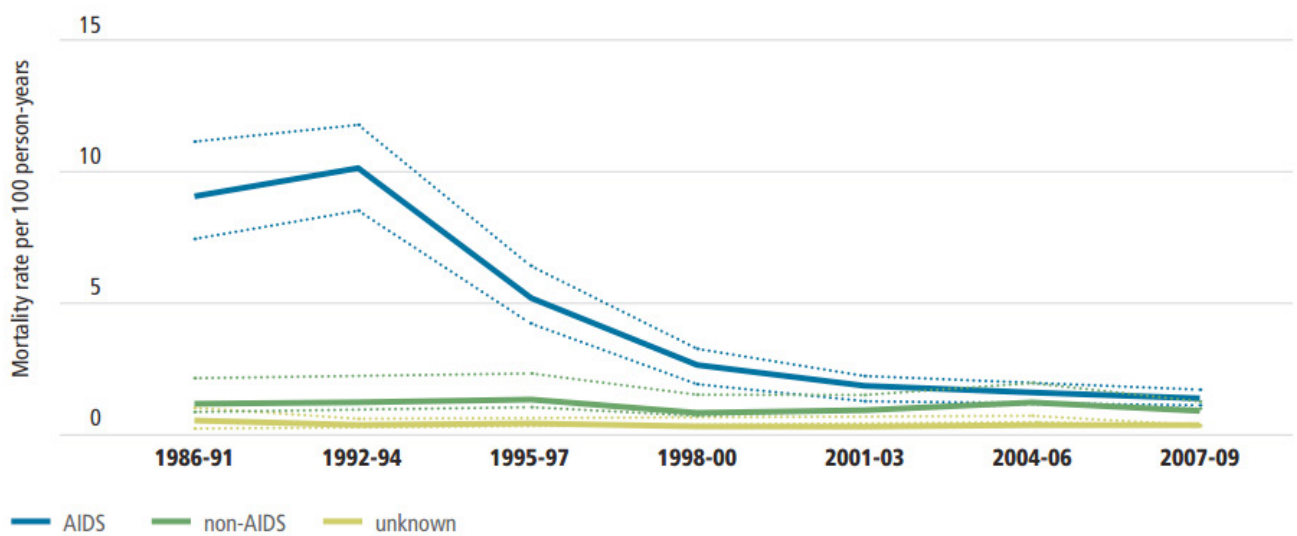

Figure 2 Mortality Rates in Brazil for AIDS-related, non-AIDS-related, and unknown causes of death, 1986-2009. Reprinted from Global Update on HIV Treatment 2013: Results, Impact and Opportunities (p. 44) 2013 World Health Organization.

In Brazil, the mortality rates from AIDS-related causes have declined dramatically, from 9.2 deaths per 100 person-years in 1986-1991 to 1.4 deaths per 100 person - years in 2007-2009. The rates of non-AIDS-related deaths and unknown causes of death have remained relatively stable over time (WHO 2013).

There are treatment programs in Brazil that have been implemented to allow HIV ing treatment in 2014 had CD4 cell counts above 500 cells $/ \mathrm{mm}^{3}$. This data suggests the prevention strategy is effective (UNAIDS 2015). Overall, there is a tendency of towards a decrease in the population of people living with HIV and AIDS seeking health services with late HIV infection (CD4 counts below 200 cells $/ \mathrm{mm}^{3}$ ), decreasing from $31 \%$ in 2009 to $26 \%$ in 2014 (UNAIDS 2015). 


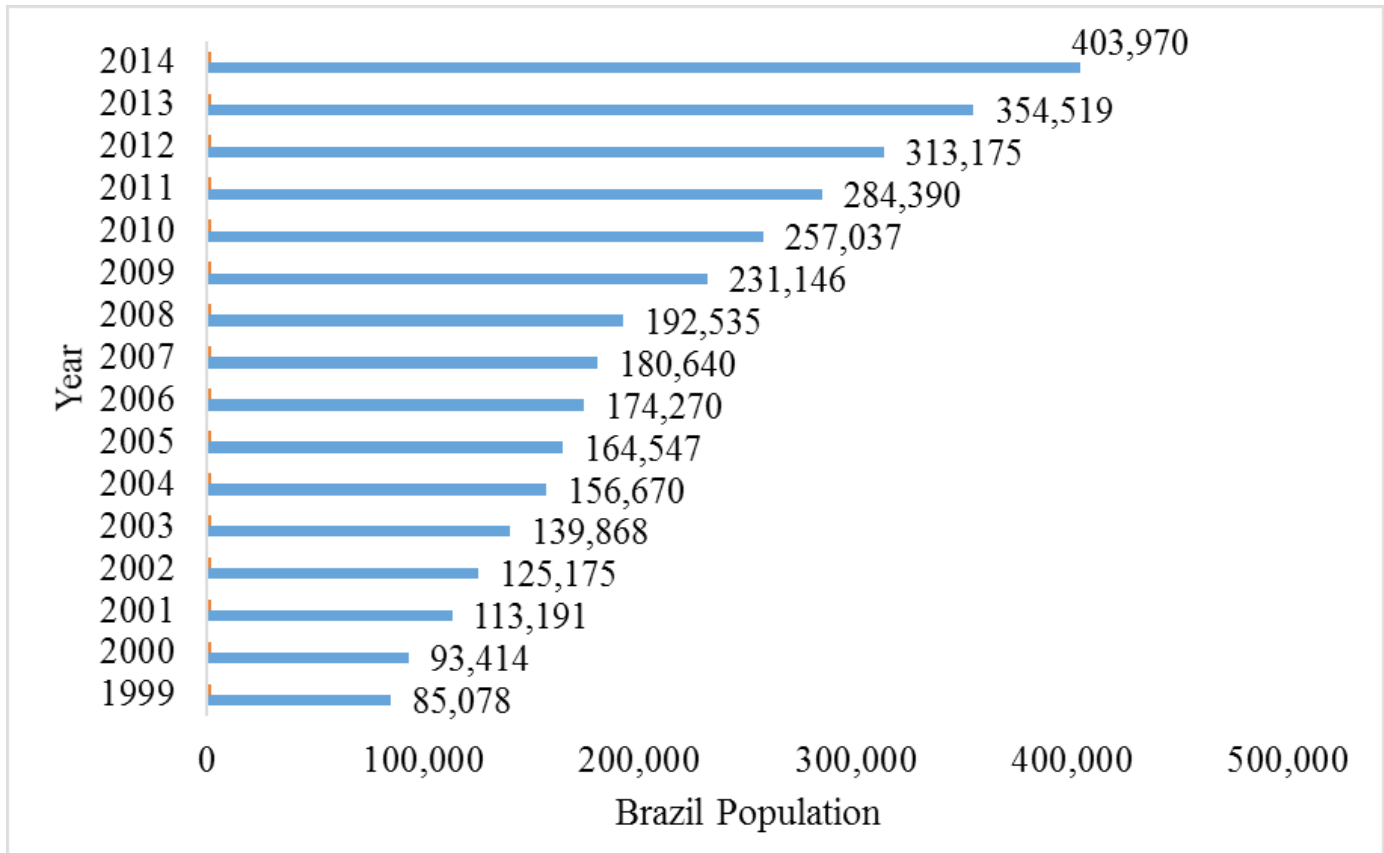

Figure 3 Evolution of ART. Reprinted from The Brazilian Response to HIV and AIDS (p. 50) in Global AIDS Response Progress Reporting, 2015, Brasilia: UNAIDS.

\section{Hiv Prevention Studies in Other Latin American Countries}

HIV testing and counseling to low income and key populations is vital to reduce the spread and increase the education of HIV. Community leaders play a critical role in education, which is evident from an HIV testing and counseling study conducted in Colombia by the Corporación de Lucha Contra el Sida (CLS) published in AIDS Research and Treatment (2014). This study noted that a mere $20 \%$ of individuals in Colombia are tested for HIV (Galindo-Quintero et al 2014). CLS implemented a multidisciplinary, provider-initiated, population-based HIV testing and counseling strategy called BAFI. CLS used two different approaches: the 1st Group was led by healthcare providers (BAFI-1); the 2nd was led by CLS and community leaders (BAFI-2). Both groups provided consented HIV screening testing; a demographic questionnaire; self-reported HIV knowledge and behavior questionnaires; pre \& posttest counselling; confirmatory HIV tests; clinical follow-up; access to comprehensive care; antiretroviral treatment (Galindo-Quintero et al 2014). The results for this study for BAFI-1 and BAFI-2 are respectively: HIV positive-confirmed prevalence $=0.29 \% \& 3.86 \%$; return rate for confirmatory results $=62.5 \% \&$ $93.7 \%$; return rate for comprehensive care $=83.3 \% \& 92.8 \%$, and ART initiation rate $=20 \% \& 76.9 \%$ (Jaime Galindo-Quintero et al 2014). BAFI-2 was significantly more effective on each indicator used in the approaches. This study implies that community-based approaches to high-risk groups are optimal, and it supports the community-based education strategy used in Brazil, "Viva Melhor Sabendo."

The impact of a professionally-facilitated peer group was examined in a study conducted in Chile, known as "Mano a Mano: Mujer" published in Health Care Women 
International (2012). The intervention and control groups consisted of low-income Latino women between 20 and 40 years of age. The peer group consisted of trained female health educators that provided the intervention group with six sessions, two hours each, of education on various HIV topics. directed to the key populations at risk, as well as treatment programs that are shown to be effective. As mentioned previously, the goal established by the Brazilian government is to reach $90 / 90 / 90$ targets by 2020. Based on the baseline statistics of the HIV continuum of care in Brazil, it is possible to achieve these targets. Brazil has set an

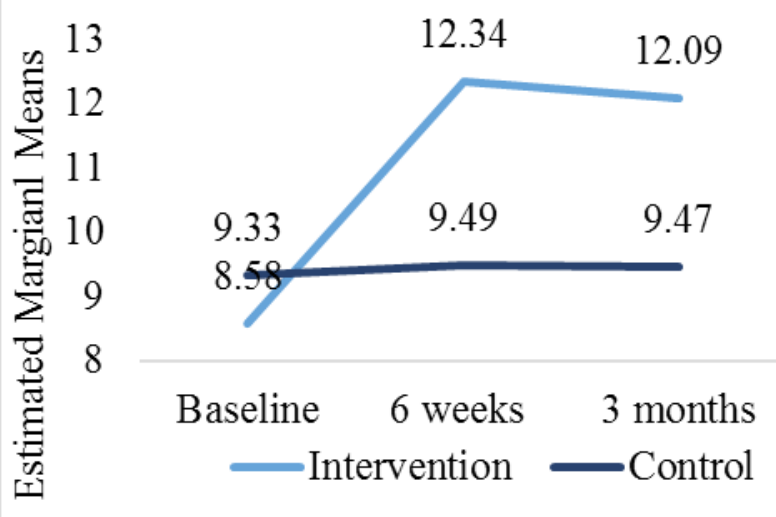

Figure 4 HIV risk knowledge at baseline, six weeks, and three months of follow up. Reprinted from "Mano a Mano Mujer: An Effective HIV Prevention for Chilean Women," by Cianelli, R. et al 2012, Health Care Women International, 33(4). 2012 by PubMed Central.

The results displayed in Figure 4 show the intervention group had significantly higher rates of HIV-related knowledge, more positive attitudes towards people living with HIV, greater self-efficacy, more communication with their partners of safe sex, and decreased depression symptoms. This study implies that working with low-income women is a key element for HIV prevention in Chile and Latin America, and should be addressed broadly at a community level.

\section{Conclusion}

HIV is a growing pandemic issue, especially in Africa, Eastern Europe, and Asia. Although Brazil has the highest prevalence rate of $\mathrm{HIV}$ in Latin America, there are strong educational programs implemented example for HIV prevention and treatment for many countries around the world. The studies conducted in Colombia and Chile support the critical roles of the community leaders and organizations for involvement in education and intervention of low-income and key populations at risk, which have been ongoing and supported by the government in Brazil.

\section{References}

1. "About HIV/AIDS." (2015) Centers for Disease Control and Prevention. http:// www.cdc.gov/hiv/basics/whatishiv.html

2. Cianelli, R. et al (2012) Mano a Mano Mujer: An Effective HIV Prevention for Chilean Women. Health Care Women International 33(4): 321-341. Retrieved from 
http://www.ncbi.nlm.nih.gov/pmc/articles/ PMC3348920/

3. Galindo-Quintero, J et al (2014) HIV Testing and Counselling in Colombia: Local Experience on Two Different Recruitment Strategies to Better Reach Low Socioeconomic Status Communities. AIDS Research and Treatment 2014. Retrieved from http:// dx.doi.org/10.1155/2014/803685

4. Čeledová, L., Čevela, R., Vaňásková , E., Bienertová, J., Pražmová, V. 2015: Dopady sociální reformy na posuzování stupně závislosti pro účely pŕispěvku na péči a význam ergodiagnostiky při sociální rehabilitaci jeho pŕ́jemců . In: Rehabilitácia ISSN 0375-0922, Vol. 52, 2015, No 1, p. 38-48

5. Global Update on HIV Treatment 2013: Results, Impact, and Opportunities (2013). World Health Organization. Retrieved from http://www.unaids.org/sites/default/files/ media_asset/20130630_treatment_report_ en_0.pdf
6. HIV and AIDS in Brazil (2015) Averting HIV and AIDS. Retrieved from http://www. avert.org/professionals/hiv-around-world/ latin-america/brazil

7. Progress Report on the Brazilian Response to HIV/AIDS (2010-2011) (2012). Brazilian Ministry of Health, Health Surveillance Secretariat, Department of STD, AIDS, and Viral Hepatitis. Retrieved from http://www. unaids.org/sites/default/files/en/dataanalysis/knowyourresponse/countryprogressreports/2012countries/UNGASS_2012_ingles_rev_08jun.pdf

8. Skolnik, R (2016). Global Health $1013^{\text {rd }}$ ed. Burlington, MA: Jones \& Bartlett Learning.

9. The Brazilian Response to HIV and AIDS. (2015). Global AIDS Response Progress Reporting (GARPR). Retrieved from http:// www.unaids.org/sites/default/files/country/ documents/BRA_narrative_report_2015. pdf 


\title{
Does Brazil's Decentralized System Improve Primary Care with the Family Health Program?
}

\author{
J. Hanley (Jaclyn Hanley)
}

College of Health and Public Affairs, University of Central Florida,

12805 Pegasus Drive, Orlando, FL 32816-2200

\section{E-mail address:}

jaclyn.hanley@scranton.edu

\section{Reprint address:}

College of Health and Public Affairs

University of Central Florida

12805 Pegasus Drive,

Orlando, FL 32816-2200

Suource: Clinical Social Work and Health Intervention

Volume: 7

Issue: 4

Pages: $41-45$

Cited references: 0

\section{Reviewers:}

Dr. hab. Zofia Szarota, Ph.D.

Pedagogical University of Cracow, PL

e-mail: dziekwp@up.krakow.pl

Dr. Urbanus Mwinzi Ndolo, PhD

Catholic University of Eastern Africa

e-mail: umndolo@gmail.com

\section{Key words:}

Health sector, Unified Health System, Family Health Program.

\section{Publisher:}

International Society of Applied Preventive Medicine i-gap

CSWHI 2016; 7(4): 41 - 45; DOI 10.22359/cswhi_7_4_06 @ 2016 Clinical Social Work and Health Intervention

\section{Abstract:}

The health sector in Brazil has undergone important changes, particularly with the development of the Sistema Unico de Saúde or Unified Health System (SUS). Decentralization is an important principle of SUS and advances have been made in transferring responsibilities and resources to the local government units, known as municipios. The decentralized SUS system has fostered progress in several aspects and areas of healthcare system, especially with the implementation of the 
Family Health Program (PSF). With the implementation and growth of the decentralized program, The Family Health Program (PSF) has resulted in substantial benefits to the healthcare system, but research shows it does not necessarily improve the primary care services delivered in Brazil.

\section{Introduction}

Brazil is the largest country in South America; it covers 8.5 million square kilometers which is nearly half of the South American continent. In 2010, Brazil had an estimated population of $190,732,694$ with most of the population living in urban areas. Brazil is the world's fifth most populous country and functions as a federal republic with 26 states, a federal district and 5,563 municipalities. Brazil was once a colony of Portugal from the year 1500 onward and gained political independence in 1822 and became a republic in 1889. Brazil has undergone major political, economic, demographic and social changes in the past 40 years which shaped the healthcare system in the country.

Federative Republic of Brazil has made major changes to its healthcare system with the development of the Sistema Único de Saúde or Unified Health System (SUS). From 1964 to 1985 Brazil was ruled by military dictatorship. The health system during this time period of military rule was riddled with inequality in accessing healthcare services. The wealthy had much better healthcare than the poor; the unemployed had very limited access to care. A civil-society movement to restore democracy began in the 1970 s, which lead to the development of a major health reform movement. An economic recession in the early 1980s brought with it the downfall of the military dictatorship and a transition to democracy. After the downfall of the military dictatorship, the Sistema Único de Saúde was put into place when the 1988 Constitution was signed; recognizing health as a citizen's right and a duty of the state.

\section{Background on Brazil's Healthcare System}

The Sistema Único de Saúde was created to provide universal healthcare access to all of the citizens of the country of Brazil. The SUS aims to provide comprehensive, universal preventive; curative care through decentralized management and provision of health services; promote; community participation at all administrative levels. The Sistema Unico de Saúde is composed of three parts: (1) services funded and provided by SUS itself; (2) private healthcare services, made up of for-profit and not-for-profit organizations and providers, from which the SUS and the private insurance system contract services; (3) a private insurance system, the Supplementary Health System which includes over 1,500 private insurers, and which supports the purchase of services by the insured from either SUS providers or private providers.

One of the primary purposes of the Sistema Único de Saúde was to decentralize health policy down to the state and municipality level where they are responsible for managing and providing primary care services. According to Merriam-Webster Dictionary, decentralization has two meanings which include the dispersion or distribution of functions and powers; secondly, the delegation of power from a central authority to regional and local authorities. The Brazilian health system's challenges include reforming its financial structure to ensure universality, equity, and long term sustainability; renegotiating public and private roles; reshaping the model of care to cater to Brazil's rapid demographic and epidemiological changes; lack of human resources, 
especially doctors; assuring quality of care and the safety of patients. Brazil also has to overcome a political challenge of strengthened political support so that financing can be restructured and the roles of both the public and private sector can be redefined.

In 1996, Brazil implemented a decentralized primary care program called The Family Health Program (known as PSF). The Family Health Program is designed to provide accessible, comprehensive care for the whole person at the community level. PSF provides and coordinates care and health promotion in clinics, patients' homes and in the community. A Family Health Program team is made up of a Doctor, Nurse, Nurse Assistant and four to six community health workers/agents. Each team is assigned to a geographic area defined by 600-1,000 families. In 2008, Oral Health Workers became part of the Family Health Program teams.

\section{Outcomes}

The Family Health Program (PSF) grew rapidly since its implementation which means coverage from the program has also grown rapidly. The PSF is the world's largest community-based primary care program. In 1999, the Family Health Program had 4,114 teams to provide care. In 2010, Brazil had about 33,000 Family Health Program teams. About $70 \%$ of Brazil's population is covered by the Family Health Program (PSF). Despite the fact that the Family Health Program has grown rapidly since its implementation, it needs to expand coverage to all of Brazil's population to better improve primary care in the country.

With the implementation and expansion of the Family Health Program, there has been an increased access to health services in Brazil. Family Health Program participants are generally more likely to have a usual source of care because of more professional healthcare teams at the community level. In 1998, 54.6\% of Brazilians had seen a doctor at least once in the past year; this percentage increased to $62.8 \%$ in 2003 and increased again to $67.8 \%$ in 2008 . Between 1998 and 2008, the number of Brazilians who had access to yearly dental care also expanded from $33 \%$ to $40 \%$. The Family Health Program gives access to primary care services to a significant portion of Brazil's population but access to these teams calls for improvement.

With the implementation of the Family Health Program (PSF), there was been significant reductions in Infant Mortality Rates and Post-neonatal Infant Mortality Rates. Infant Mortality Rate is defined as the number of deaths under one year of age per 1,000 live births among the population occurring in a specified geographical area during the same given year of the given geographical area. From 1996 to 2004, the infant mortality rate decreased from 24.1 to 16.1 per 1000 live births. Post-neonatal Mortality Rates defined the number of babies who die between 29 and 365 days of life per 1,000 live births. Between 1998 and 2006, Post-neonatal morality fell to nearly half of its initial value due to the expansion of the Family Health Program; due to the increased number of ambulatory care facilities per capita; improvements in clean water supply; and lower illiteracy rates. Post-neonatal morality rate per 1,000 live births went from 14.24 in 1998 to 6.92 in 2006.

Other outcomes from Sistema Único de Saúde and the Family Health Program include the under-5 mortality rate, decreasing from 55 per 1,000 live births in 1990 to 19 per 1,000 live births in 2010. The average life expectancy has increased from 67 in 1990 to 73 in 2010; maternal mortality has decreased from 120 per 100,000 live births in 1990 to 56 per 100,000 in 2010. 


\section{Does Brazil's Decentralized System Improve Primary Care?}

Brazil's decentralized system doesn't necessarily improve primary care in the country because it was never associated with worst performance. With the expansion of the Family Health Program, substantial health benefits have resulted in a somewhat better delivery of healthcare. Going forward, Brazil has to address the overwhelming need to improve healthcare in the country, and to identify problems in access to and quality of care. Brazil also has to address issues and problems to further improve primary care in the country. It has to address issues/problems such as reforming its financial structure to ensure universality, equity, and long term sustainability; renegotiating public and private roles; reshaping the model of care to cater to Brazil's rapid demographic and epidemiological changes; with lack of human resources, especially Doctors, to assure the quality of care and the safety of patients. Also, since the Family Health Program (PSF) covers about 70 percent of the population in Brazil, the program needs to expand to reach 100 percent of the population especially in rural areas which need primary care services. These actions have the potential not only to improve the health system's efficiency but also to improve the quality of people's lives.

\section{Comparison of Healthcare in India \& Finland}

India: Healthcare is one of India's largest services sectors. Under the Constitution in India, health is a state subject; each state has its own healthcare delivery system in which both public and private operate. The challenges its healthcare system faces include the need to reduce mortality rates; improve physical infrastructure; the necessity to provide health insurance, ensure the availability of trained medical personnel; etc. There has been a rise in both communicable and non-communicable diseases. In 1982, the National Health Policy started. Within the campaign, a three-tier system of self-governance was established and comprised 900 villages (panchayats). During the NH Policy, primary health care centers and their referring sub-centers were brought under the jurisdiction of villages in order to engage more closely with the community to identify and implement effective changes to respond to local health need. The National Rural Health Mission (NRHM), launched in 2005 , is the first health program to improve the health system and the health status of the people. One of the areas NRHM sought to increase was decentralization and to achieve district management of health program.

India has varying levels of success with having a decentralized system. Kerala, India, has been an outlier with better health outcomes in a number of areas compared to most states in India. The following are some examples of the outcomes: lower infant mortality rate of 12 per 1,000 live births in Kerala vs. 40 per 1,000 live births in India; lower maternal mortality ratio of 66 per 100,000 live births in Kerala vs. 178 per 100,000 live births in India. These outcomes can be attributed to factors such as strong emphasis from the state government on public health and primary healthcare; health infrastructure; decentralized governance; financial planning; girls' education; community participation; willingness to improve systems in response to identified gaps.

Finland: In Finland, the organization of healthcare services have been considered a public responsibility; municipalities being responsible for providing basic medical services. During the 1980s and 1990s, state regulation gradually decreased. After 1993, changes in legislation, planning and financial incentives were introduced which 
increased decentralization in the system. Legislation eventually brought three major changes: redesign of the state subsidy system; relaxation of the rules on service provision; decentralization of detailed planning. There are some structures in the Finnish healthcare system which are perceived as problematic: the level of decentralization; poor steering capacity in the system; relatively weak position of primary care; a lack of cooperation between primary and secondary care; dual financing. Finland's decentralized system does not work in its favor to the following reasons: municipalities appeared to be too small to provide sustainable quality services for local needs and achieve advantages of economies of scale which means efficiency is decreasing; inequality in access and utilization of services increased between municipalities and is related to decentralization of healthcare to small units; planning and development capacity and knowledge are scarce in local municipalities, especially regarding secondary levels of care; municipalities' power position over hospitals is low, leading to transfer of human and economic resources from primary health services to specialized healthcare and from rural areas to urban regions.

\section{Conclusion}

Brazil has undergone major political, economic, demographic and social changes in the past 40 years which have shaped the healthcare system in the country. The healthcare in Brazil has undergone important changes, particularly with the development of the Sistema Único de Saúde (Unified Health System (SUS)) in 1988. Decentralization is an important principle of SUS and advances have been made in transferring responsibilities and resources to the municipios or at the community level in Brazil. With the implementation and growth of the decentralized primary care program, The Family Health Program (PSF) has resulted in substantial benefits, but doesn't necessarily improve the primary care in Brazil. Brazil has to address its major issues and problems to further improve primary care. 


\section{Low Cost Approaches to Improve Quality of Life \& Access to Healthcare in Brazilian Favelas}

\section{Jeanniton (Lindsey Jeanniton)}

Health Administration \& Human Resources,

\section{Original Articles}

$4^{\text {th }}$ Floor McGurrin Hall, Scranton, PA 18510-4699

\section{E-mail address:}

ljeanniton4@gmail.com

\section{Reprint address:}

Health Administration \&

Human Resources

$4^{\text {th }}$ Floor McGurrin Hall

Scranton, PA 18510-4699

Suource: Clinical Social Work and Health Intervention

Volume: 7

Issue: 4

Pages: $46-54$

\section{Reviewers:}

Dr. Jirina Kafkova, Ph.D.

Nairobi, St. Bakitha Clinic, Kenya

e-mail: jirinka.lala@gmail.com

Dr. Alexander Wolf

Association of palliative and hospice care, Kiev, Ukraine

e-mail: doroha@inbox.ru

\section{Key words:}

Extreme poverty, Brazil, Healthcare, Education, Malnutrition.

\section{Publisher:}

International Society of Applied Preventive Medicine i-gap

CSWHI 2016; 7(4): 46 - 54; 10.22359/cswhi_7_4_07 @ 2016 Clinical Social Work and Health Intervention

\section{Abstract:}

Throughout Brazil, there is a wide gap between the rich and the poor in respect to their resources. There are about 12 million people in Brazil who live in extreme poverty within shantytowns, known as favelas. ${ }^{17}$ These people lack basic public services, such as education, space, and most importantly healthcare. These people lack basic public services such as education, space, and most importantly healthcare. As a result, 
there are high incidences of malnutrition, diarrhea, skin diseases, and many other diseases. ${ }^{15}$ In addition, living in such conditions can negatively impact one's health. Six factors that can greatly improve and maintain healthy living in the favelas: cleanliness; nutrition; doctor visits; herbal remedies (tomar cha); sympathetic magic; spirituality. In order to better the quality and access of healthcare for the people living in the favelas, it is necessary to use low cost strategies. Using other countries' strategies and implementations can help Brazil improve healthcare in the favelas.

\section{Introduction}

The extreme differences in socioeconomic status among people in Brazil contribute to the health conditions. ${ }^{14}$ Poor living conditions in Brazilian favelas, also known as shantytowns or slums, present a major challenge; increases in health problems, diseases, and mortalities. For example, the crowded housing increases the spread of tropical diseases; a major problem Brazil must address. To improve healthcare in the favelas, it is important for healthcare managers and leaders to look at the costs, quality and access. There have been many models and programs used in other countries with similar conditions like the favelas to improve healthcare. Three low cost strategies proposed to improve both the quality and access are 1) Information and Communications Technology, 2) Transportation Program, 3) Target Program that Benefits the Poor.

\section{Problems and Challenges}

Favelas are units of irregular self-constructed housing that are occupied illegally. These housing units are usually located on the hillsides; some overlook urban cities and rich areas of Brazil. ${ }^{5}$ Poor living conditions are the root of many problems Brazilians living in the favelas face. Some of these conditions include the crowding of buildings; unsanitary conditions; poor nutrition; pollution. As shown in Figure 1, health and education are the two topics which matter the most to people in Brazil. ${ }^{3}$ However, as illustrated below the favelas suffer in regards to health, quality of education, and safety. Specifically in Rio de Janeiro, residents living in the favelas live about 13 years less than people born in the wealthy areas. Child mortality rates are also five times higher. ${ }^{8}$

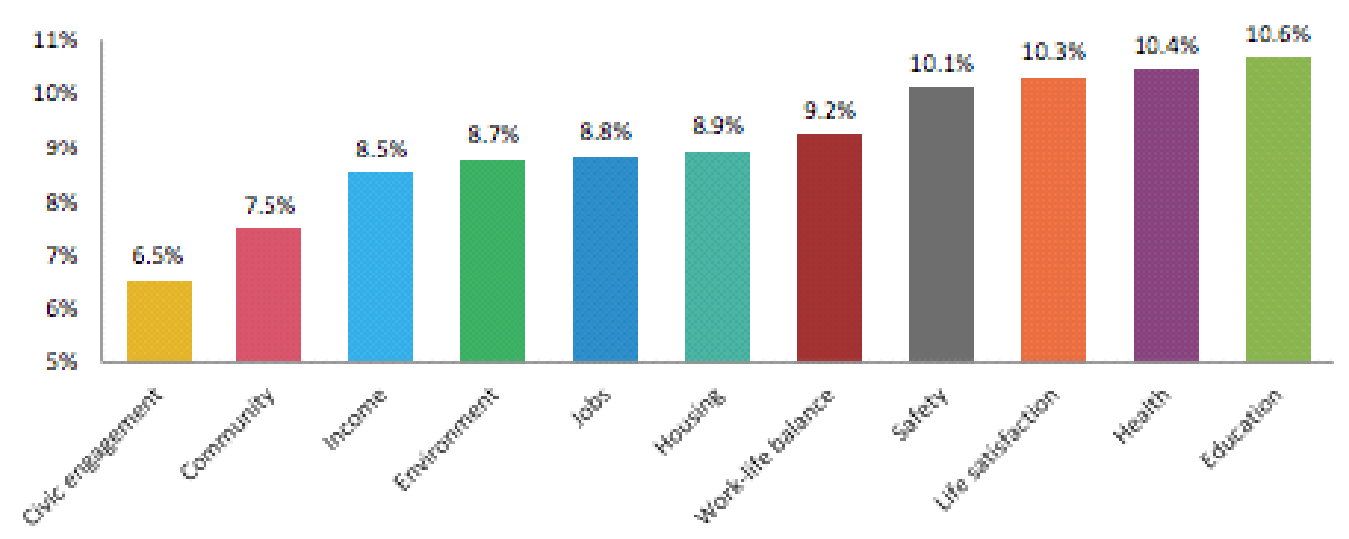

Figure 1 Topics that Matter the Most to People in Brazil. ${ }^{13}$ 
One of the barriers people living in the favelas face is the lack of education. Brazil recognizes the importance of education, and provides free public education at all levels. However, due to the socioeconomic gap present in Brazil, there is a major academic difference among the schools. Due to the lack of resources and adequate amenities, the children in less affluent areas are unable to receive a proper education and suffer for this later in life. In addition, there are children who are unable to attend school because they are malnourished. Other families need their children to start working in order to contribute to the household income. There are many laborers as young as 10 years old who decide to forego a public education to earn money to help their family. ${ }^{4}$

Due to the overcrowding of buildings and narrow roads, most of the favelas lack effective sewage systems and have limited access to portable water and waste management systems. ${ }^{12}$ Most diseases such as Cholera, Malaria, and Dengue Fever are all linked to deficient waste and water systems. Poor sewage diseases, major health problems, and mortality rates.

\section{Neglected Tropical Diseases}

People living in favelas face an increasing number of cases of, and deaths by, Neglected Tropical Diseases (NTD). It is crucial that Brazil address these diseases by educating the people, and implementing low cost strategies to fix healthcare in these areas. According to the World Health Organization, several of the world's major NTDs occur in Brazil. However, most of these NTDs are found in the favelas because of the overcrowded housing, inadequate supply of water, and poor sewage system and waste management. Table 1 illustrates the types of NTDs, along with the number of reported cases and number of deaths from 1998 through 2007. ${ }^{9}$ Malaria and Dengue Fever show a high number of reported cases, and Tuberculosis is the cause of a large number of deaths. Although this is data from 2007, the number of reported cases of and deaths from NTDs has increased and the new Zika virus is a major health concern in Brazil. ${ }^{9}$

\begin{tabular}{|c|c|c|c|}
\hline Nezlected Tropical Diseases & Toeal number of reported cases & Number of deaths & Case fanality rate \\
\hline Visceral Leishmanizsis & 33,787 & 1,598 & $4.73 \%$ \\
\hline Tegumentary Leixhmaniasis (a) & 268.866 & $616 * * *$ & 0225 \\
\hline Malaria & $4,791,853$ & 960 & $002 \%$ \\
\hline Dengue fever & $3,317,662$ & 463 & 00138 \\
\hline Tubercukasis & 631.887 & 22,937 & $3.3 \%$ \\
\hline Chagas' Disease* & 444 & 14 & $3 \%$ \\
\hline Schislosamiasis & $1,031,838$ & 4,539 & $0.43 \%$ \\
\hline Leprosy $* *(\mathrm{a})$ & 405.860 & 11,794 & $29 \%$ \\
\hline
\end{tabular}

Source: Health Serveillance Service of the Ministry of Health of Brazil and DNTASUS. Death by (a) were not considered bexic cause of dead. * Data available cely for Acute Chagas' Disease from 2005 through $2008 ; \cdots$ Data available from 2004 to 2006 . $\cdots$ Dats available from 2001 to 2007.

Table 1 Estimated Number of Neglected Tropical Diseases in Brazil (from 1998 through 2007) ${ }^{9}$

systems and waste management systems result in increases of mosquitos. ${ }^{12}$ Infestations of mosquitos carry viruses which are then transmitted to a large number of people living in these favelas. Poor living conditions in the favelas of Brazil are linked to the rise in cases and transmission of neglected tropical
Parasitic, bacterial, fungal, ectoparasitic, or viral agents can cause these NTDs. The majority of these NTDs are transmitted by mosquitos, which is a big problem in the favelas. The favelas create a perfect environment for disease causing mosquitos to breed. ${ }^{15}$ The WHO has separated these 
NTDs into 3categories based on emergence, control, and drug availability. Table 2 divides the NTDs into the three categories. ${ }^{9}$ Understanding how NTDs are separated into 3 categories is important. In order for Brazil to prevent and lower the cases of NTDs, implementation of low cost strategies to help improve the quality of life and access to healthcare must move forward. Following models from countries with similar conditions and diseases as Brazil is a step in the right direction to fix this problem. Although most of these NTDs are transmitted in poor living conditions in the favelas, Figure 2 shows the distribution of the NTDs throughout Brazil. similar conditions to the Brazilian favelas have implemented models focusing on low cost and improvement of healthcare. In healthcare, cost, access, and quality are all connected. Even though many of the health problems come from poor living conditions, and most of the living conditions cannot be fixed, there are ways of improving healthcare. Implementing programs and using models from other countries with similar conditions can help improve the healthcare in the favelas. It is proposed that three low cost strategies can promote better quality of life and access to care in Brazilian favelas. 3 low cost strategies are:

\begin{tabular}{lll}
\hline $\begin{array}{l}\text { Category } 1 . \\
\begin{array}{l}\text { Emerging and } \\
\text { uncontrolled disease }\end{array}\end{array}$ & $\begin{array}{l}\text { Category 2. } \\
\text { Control strategy available } \\
\text { Disease burden persists }\end{array}$ & $\begin{array}{l}\text { Category 3. } \\
\text { Control strategy effective } \\
\text { Disease burden falling } \\
\text { Elimination planned }\end{array}$ \\
\hline Leishmaniasis & Malaria & Chagas' Discase \\
African Trypanosomiasis & Schistosomiasis & Leprosy \\
Dengue fever & Tuberculosis & Lymphatic filariasis \\
& & Onchocerciasis \\
\hline
\end{tabular}

Table 2 WHO categorization of NTDs based on emergence, control and drug availability ${ }^{9}$

\section{Low Cost Strategies}

In order to fix a problem, it must first be identified by analyzing all the contributing factors. Many poor environments with

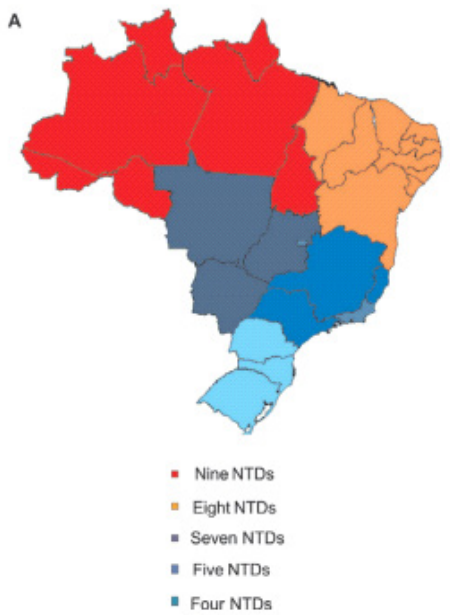

- Information and Communications Technology

- Transportation Program

- Target Program that Benefits the Poor

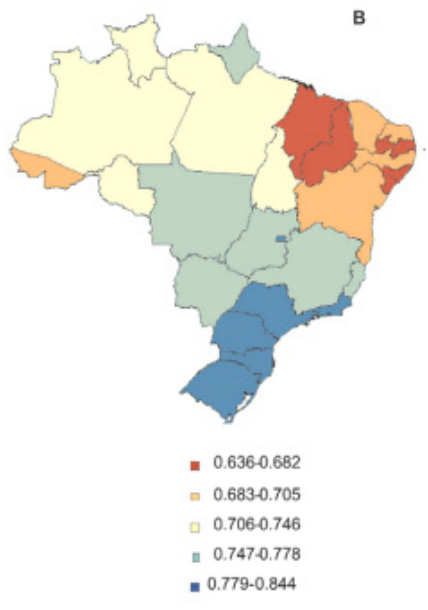

Figure 2 (A) Distribution of the main Neglected Tropical Diseases in Brazil from the Health Surveillance Service (Ministry of Health) ${ }^{9}$ 


\section{Information and Communications Technology}

Technology can have a tremendously positive effect on healthcare. Implementers are searching for innovative approaches to eliminate geographic and financial barriers to health. Several countries are using a variety of information and communications technology tools to help improve quality and access of healthcare with low cost. There are many purposes of technology-enabled programs, some of which are illustrated in Figure 3, and each program serves a certain purpose in the use of technology. ${ }^{11}$
Implementing technology-enabled programs in Brazil is a low cost strategy that will be useful in the favelas. Technology-enabled programs overcome distances between physicians and patients by replacing a traditional office with telemedicine. By facilitating greater communication with patients, technology-enabled programs provide health workers or programs, and patients with general health education outside of regular office locations and hours. Technology-enabled programs may additionally improve diagnosis and treatment, which will allow health workers to improve clinical performance during training or in the field, and will allow health workers to make better decisions and diagnosis. ${ }^{11}$

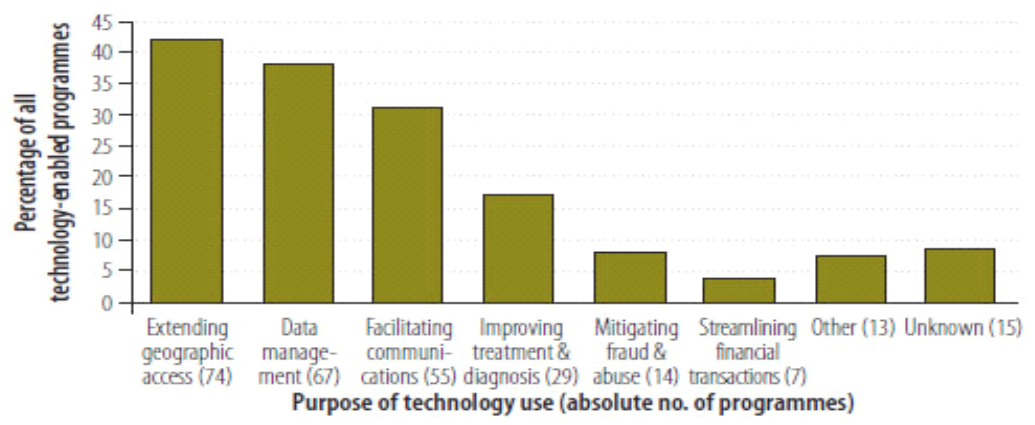

Note: Individual programmes can fall under multiple purposes; as such, percentages do not sum to 100 . Source: Center for Health Market Innovations.

Figure 3 Technology-Enabled Programs, by Purpose of Use of Technology"
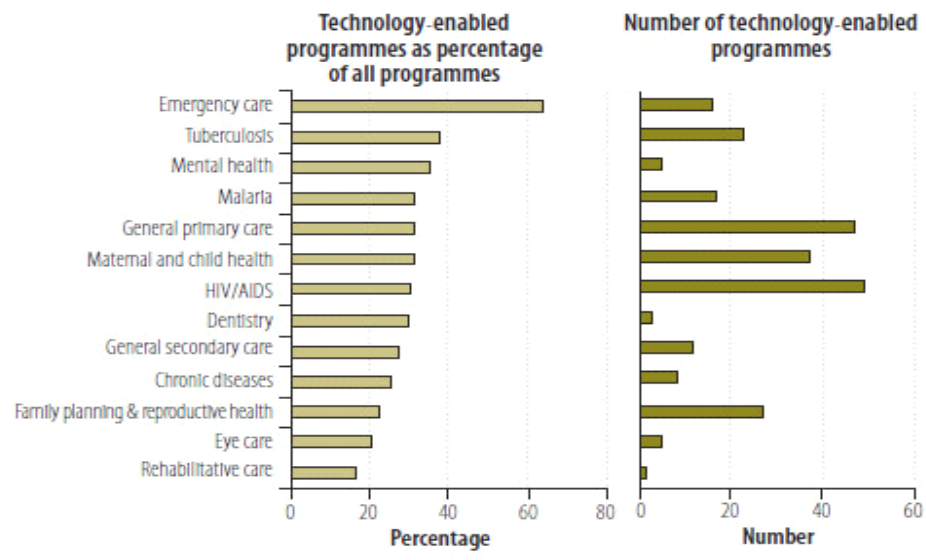

Source: Center for Health Market Innovations.

AIDS, acquired immunodeficiency syndrome; HIV, human immunodeficiency virus.

Figure 4 Technology-Enabled Programs, by Health Focus ${ }^{11}$ 
As stated previously, some of Brazil's NTDs that are increasing in cases and number of deaths are malaria and tuberculosis. HIV/AIDS is also a problem in Brazil, especially in the favelas. In 2013, there have been about 730,000 people living with HIV and 16,000 AIDS-related deaths. ${ }^{17}$ Figure 4 illustrates the number of technology enabled programs used to improve certain diseases and types of care. Implementing these programs will help improve the problems and health issues that occur in the favelas. That being said, many devices can be used to move the programs forward in the right direction. Table 3 illustrates how many devices such as phones and computers are used for technology-enabled programs. A large part of the population in the favelas uses mobile technology and computers. ${ }^{11}$
Phones serve many purposes besides communication. In fact, the Brazilian Government has invested heavily in mobile telephone networks and in broadband. In the favelas, "LAN houses" allow many people to access the internet and have become quite popular. UN Women, UNICEF and UN-Habitat launched an online website and smartphone app in 2013 to provide support services for women and girls and to report any violence, especially in the favelas. ${ }^{18}$ If Brazil took this initiative to improve safety, then implementing technology-enabled programs specifically for phones will improve the quality and access of healthcare at a low cost. A simple messaging system and data system that can be reviewed by Doctors could improve the healthcare in the favelas. Table 4 discusses the outcomes of mobile devices used in countries. The results provide Brazil with valuable data, and support the integration of mobile devices into everyday healthcare.

\begin{tabular}{lcc}
\hline Device & \multicolumn{2}{c}{ Programmes } \\
\cline { 2 - 3 } & No. & \% a \\
\hline Phone & 125 & 71 \\
Computer & 68 & 39 \\
Camera [video/photo] & 13 & 7 \\
PDAs/tablets & 11 & 6 \\
GPS & 9 & 5 \\
Remote diagnostic tool & 8 & 5 \\
Smartcard & 6 & 3 \\
Unique identification & 5 & 3 \\
Radio & 5 & 3 \\
Other & 14 & 8 \\
\hline
\end{tabular}

GPS, global positioning system; PDA, personal digital assistant.

a Represents the percentage among all technology-enabled programmes.

Source: Center for Health Market Innovations.

Table 3 Technology-Enabled Programs, by Type of Device ${ }^{11}$ 


\begin{tabular}{|c|c|c|}
\hline Country & $\begin{array}{c}\text { Indication / } \\
\text { Disease }\end{array}$ & Results \\
\hline United States & HIV & $\begin{array}{l}\text { "...high satisfaction with the messaging } \\
\text { system ... it helped with medication } \\
\text { adherence." } \\
\text { Participants reported missing one or } \\
\text { more doses on } 36 \% \text { of } 743 \text { queries. }\end{array}$ \\
\hline Tenerife & Diabetes & $\begin{array}{l}\text { Patients used system every } 2.0 \text { days } \\
\text { and doctors reviewed data every } 4.0 \\
\text { days Seventy five percent expressed a } \\
\text { preference for sending their data via } \\
\text { the mobile phone SMS }\end{array}$ \\
\hline South Africa & Tuberculosis & Adherence not measured \\
\hline South Africa & HIV & $\begin{array}{l}\text { Data published at the Civil } \\
\text { Engineering Department of The } \\
\text { University of Cape Town. }\end{array}$ \\
\hline
\end{tabular}

Table 4 Outcomes of Mobile ${ }^{6}$

\section{Transportation Program}

Transportation is a critical area in healthcare access, serving as a link between home and health facilities. ${ }^{1}$ Not many hospitals are located in the favelas, and transportation can be costly for many people in Brazil, especially the people living in favelas. Also, favelas are filled with narrow roads where travelling can be difficult. A perfect example of a transportation program that Brazil can implement is Riders for Health, an organization used by many countries in Africa. This organization makes sure that healthcare is more widely available for people. "Their mission is to make the 'last mile' is the most important mile in healthcare delivery: creating, showing and sharing the solutions for achieving truly equitable healthcare." ${ }^{14}$ Similar to Brazil's health issues such as malaria, tuberculosis, HIV/AIDS, Riders for Health serves a great purpose to prevent, educate, and treat people with these diseases in Africa. By managing motorcycles, ambulances, and other four-wheel vehicles, health workers are able to follow up with patients, conduct health education meetings, and create a link with primary health centers to improve patient samples, supplies and medicines. ${ }^{14}$ Riders for Health is a program Brazil can implement or use as a model to develop a transportation program reaching out to the people in the favelas.

\section{Target Program that Benefits the Poor}

To improve both quality and access to healthcare, specifically for poor and developing areas, a low cost strategy that targets vulnerable populations would be most effective. An example that Brazil can perhaps follow is Mexico's implementation of PROGRESSA. Mexico used this program as a strategy to decrease poverty while improving health and education.

PROGRESSA's role was "to lay the groundwork for a healthy, well-educated population who could successfully contribute to Mexico's economic development and break the intergenerational cycle of poverty." 
This program offered cash transfers to the poor in exchange for sending their children to school and regular attendance at health clinics and sessions that focuses on nutritional education. This program proved to be extremely successful and had positive outcomes in Mexico. ${ }^{10}$ For example, children involved with PROGRESSA had a 12 percent lower incidence of illness, households were consuming higher-quality foods, and there were an increased number of prenatal visits. ${ }^{10}$ Implementing a similar program like PROGRESSA that benefits and targets the poor in Brazil will certainly improve the quality of life of the people living in the favelas at a very low cost.

\section{Conclusion}

There are many ways to improve the health conditions in a certain area. Healthcare Managers and Professionals must identify the problems, and take the necessary actions and steps to solve them. Brazil's social gap between the rich and the poor will not change overnight. The problems and challenges of Brazilian favelas such as poor living conditions and Neglected Tropical Diseases increase the rate of disease transmission and the number of deaths among that population. By implementing low cost strategies it is possible to alleviate identified problems and therefore improve access to healthcare and people's quality of life. The three low cost strategies discussed, 1) Information and Communication Technology, 2) Transportation Program, and 3) Target Program that Benefits the Poor are just some approaches that are used by countries with living conditions and health problems similar to Brazil's favelas.

\section{References}

1. Atuoye, K.N., Dixon, J., Rishworth, A., Galaa, S.Z., Boamah, S. A., Luginaah, I. (2015). Can she make it? Transportation barriers to accessing maternal and child healthcare services in rural Ghana. BMC Health Services Research BMC Health Serv Res, 15(1). doi:10.1186/s12913-015-1005-y

2. BMC Health Services Research (Can she make it? Transportation barriers to accessing maternal and child healthcare services in rural Ghana) http://bmchealthservres. biomedcentral.com/articles/10.1186/ s12913-015-1005-y

3. Brazil (2015, October). Retrieved February 16, 2016, from http://www.oecdbetterlifeindex.org/countries/brazil/

4. Brazil (n.d.). Retrieved February 16, 2016 http://www.brazil.org.za/social-issues.html.

5. Global Footprints (n.d.) Favelas in Brazil. Retrieved from http://www.globalfootprints. org/issues/local/homeless/favelas.htm

6. Globalization and Health (2006). Retrieved January 6, 2016, fromhttp:/globalizationandhealth.biomedcentral.com/articles/ 10.1186/1744-8603-2-9

7. Unger, A., Riley, L. (2007). Slum Health: From Understanding to Action Plos Med PLoS Medicine. In Rio de Janeiro's favelas (2013, June 6) a new online tool tackles violence against women and girls. Retrieved February 16, 2016, from http:/www.unwomen.org/en/news/stories/2013/6/rio-dejaneiro-apps-to-end-violence-in-favelas

8. IRIN, UN-HABITAT (September, 2007). Rio: fighting for the favelas. Tomorrow's Crises Today: The humanitarian impact of urbanization. Retrieved from http://www. irinnews.org/pdf/in-depth/tomorrowscrisestoday-chapter6.pdf

9. Kawková, S., Bužgová, R. 2015: Aktivizace seniorů s demencí v pobytovém zařízení sociálních služeb a její vliv na kvalitu života. In: Rehabilitácia ISSN 0375-0922, Vol. 52, 2015, No 4, p. 249-256

10. Lindoso, J., Lindoso, A. (2009). Neglected tropical diseases in Brazil Revista Do Instituto De Medicina Tropical De São Paulo Rev. Inst. Med. Trop. S. Paulo, 247-253. 
11. Leigh Gantner (2007). Case Study \#5-1, "PROGRESA: An Integrated Approach to Poverty Alleviation in Mexico”. In: Per Pinstrup-Andersen and Fuzhi Cheng (editors), Food Policy for Developing Countries: Case Studies. 11pp.URL: http://cip.cornell. edu/dns.gfs/1200428168

12. Lewis, T., Synowiec, C., Lagomarsino, G., Schweitzer, J. (2012). E-health in low-and middle-income countries: Findings from the Center for Health Market Innovations. Bulletin of the World Health Organization Bull World Health Org, 332-340.

13. Logan, A. (2015). Fixing Favelas: Urban Housing Problems in Brazil. Retrieved February 16, 2016, from http://borgenproject. org/fixing-favelas-urban-housing-problems-brazil/
14. Welcome to Riders (n.d.). Retrieved January 6, 2016, from http://www.riders.org/ about-us.

15. Szwarcwald, C.L. (2000). Health conditions and residential concentration of poverty: A Study in Rio de Janeiro, Brazil. Journal of Epidemiology \& Community Health, 54(7), $530-536<$ jech $>$.

16. The Favelas of Brazil (n.d.). Retrieved February 16, 2016, from http://www.csus.edu/ writingcenter/corream/essay.html

17. UN Joint Program on HIV/AIDS (UNAIDS) The Gap Report 2014, available at: http://www.refworld.org/docid/53f1e1604. html [accessed 16 February 2016]

18. United, Favelas Would form Brazil's 5th Largest State (2013, February 23). Retrieved from http://www.rioonwatch.org/?p=6913 


\section{Cervical Cancer Screening: Awareness and Knowledge in Brazil}

\section{I. Napa (Lydia Isabel Napa)}

Health Administration \& Human Resources,

\section{Original Articles} $4^{\text {th }}$ Floor McGurrin Hall, Scranton, PA $18510-4699$

\section{E-mail address:}

lydiaisabel.napa@scranton.edu

\section{Reprint address:}

Health Administration \&

Human Resources

$4^{\text {th }}$ Floor McGurrin Hall

Scranton, PA 18510-4699

Suource: Clinical Social Work and Health Intervention

Volume: 7

Issue: 4

Pages: $55-61$

Cited references: 17

\section{Reviewers:}

Dr. Michael Costello, MA, MBA, J.D.

University of scranton school of education, USA

e-mail: michael.costello@scranton.edu

Dr. Michał Szyszka

Janusz Korczak Pedagogical University in Warsaw, PL

e-mail: szyszkathome@gmail.com

\section{Key words:}

Cervical cancer, Cervix, Cancer screening, Cytology, Brazil, Global, Prevention, Precancerous cells, Latin America, Initiatives, Health services.

\section{Publisher:}

International Society of Applied Preventive Medicine i-gap

CSWHI 2016; 7(4): 55 - 61; 10.22359/cswhi_7_4_08 @ 2016 Clinical Social Work and Health Intervention

\section{Abstract:}

Cervical cancer is one of the deadliest forms of cancer killing an estimated 260,000 women worldwide. Most deaths are in developing countries, where screening and treatment for precancerous lesions are unavailable or women have limited access to healthcare. This holds true for Brazil, as cervical cancer is the second leading cancer amongst Brazilian women killing an estimated of 8,400 women annually. Yet cervical cancer is 
one of the easiest preventable cancers by routine human papillomavirus (HPV) and cytological tests. These have been proven to significantly decrease cervical cancer deaths and rising incidence rates. The state of Brazil has aimed to increase knowledge and awareness of cervical cancer screening and prevention through initiatives throughout the country. Other Latin American countries have implemented initiatives that found success in increasing awareness of cervical cancer screening in low resource settings. However, there are still challenges and barriers that women face in cervical cancer screening such as social economic factors. Nevertheless, the future of cervical cancer prevention is promising by increasing the availability of cytological tests, promoting screening efforts, and using evidence-based recommendations.

\section{Introduction}

Cervical cancer is a type of cancer that starts at the cells lining the cervix at the lower part of the uterus, which connects to the vagina (Mayo Clinic 2015). These cells do not become cancerous instantaneously, but gradually develop into pre-cancerous cells in an area called the transformation zone. Some women with pre-cancerous cells in the cervix will develop into cancer, while many women's pre-cancerous cells will go away on its own without any form treatment (American Cancer Society, 2015).

The World Health Organization (WHO) estimated that over 520,000 women are diagnosed with cervical cancer annually and over 260,000 deaths are due to this disease (Bruni, Barrionuevo-Rosas, Albero et al 2015) (Figure 1). Cervical cancer ranks as the $4^{\text {th }}$ cause of female cancer in the world and the $2^{\text {nd }}$ most common cause of cancer in women ages 15 to 44 years old (Bruni, Barrionuevo-Rosas, Albero et al 2015). Many deaths are from developing countries, where detection and treatment for pre-cancerous lesions and cells

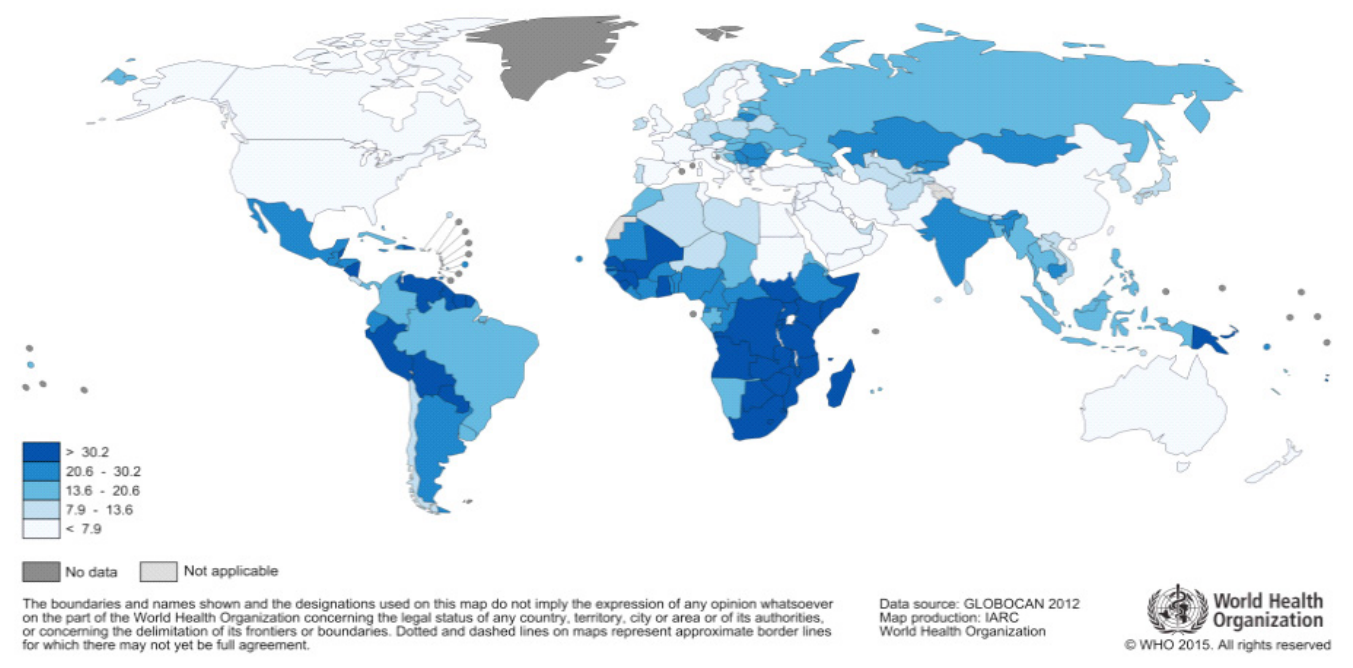

Figure 1 Source: Estimated Cervical Cancer Incidence Worldwide in 2012. Reprinted from Cervical Cancer Estimated Incidence, Mortality, and Prevalence Worldwide in 2012 by Globocan (2012) and the World Health Organization (WHO 2015) Retrieved from http://libguides. gwumc.edu/c.php?g=27779\&p=170358 
are unavailable or women have limited access to healthcare services. By 2030, the Pan American Health Organization (PAHO) estimates a $45 \%$ increase of mortality rates in countries such as Latin America and the Caribbean due to the inequitable health service distribution (PAHO 2014). This hold true for Brazil, as cervical cancer is the $2^{\text {nd }}$ cause of cancer amongst Brazilian women, where there is an estimated annual incidence rate of 18,503 and 8,414 deaths due to cervical cancer. In comparison, Latin American countries have an incidence rate of 45,008 and 19,374 deaths (Bruni, Barrionuevo-Rosas, Albero, \& et al., 2015).

\section{Risk Factors}

The human papillomavirus (HPV), is a sexually transmitted disease and is one of the most common risk factors that cause most cervical cancers. Since HPV is so common, a majority of sexually active men and women will be infected at some point in their lives (CDC 2014). There are over 100 strains of HPV and many do not cause any problems or show any symptoms, while some strains of HPV can cause genital or skin warts (CDC 2014). According the World Health Organization (WHO), HPV types 16 and 18 are responsible for $70 \%$ of cervical cancer cases worldwide (Bruni, Barrionuevo-Rosas, Albero et al 2015).

There are several risk factors that can increase the chances of developing cervical cancer such as smoking, human immunodeficiency virus (HIV), taking oral contraceptives for a long period of time, early sexual activity, and having multiple sex partners.

\section{Brazil Initiatives}

One of the first population-based screening programs in Brazil for cervical cancer started in 1956 at Rio de Janerio. The Social Pioneers Foundations (Fundação das Pioneiras
Sociais) was a philanthropic organization that was very active in education and health, especially in the field of chronic degenerative diseases and female cancers. In the area of female cancers, they directed two problems that were challenging Brazil for this type of cancer. The two issues were fostering engagement with lower-class women who had a difficult time in obtaining healthcare services and medical information, and increasing the quality of cytological tests (Porto \& Habib, 2014). In order to improve these problems, the organization reached out their activities to 10 Brazilian states creating specialized hospitals, a research center, and a "Health on Wheels Program," which included hospital units floating on the Amazon (Porto \& Habib, 2014). In 1968, the first official cytopathology school was created to "provide suitable training for technicians who had the strategic role of taking the first readings of test slide" (Porto \& Habib 2014). Another early initiative began in 1965 at the City of Campinas, São Paulo by the leadership of the University of Campinas in accordance with the Pan American Health Organization guidelines. The Cervical Cancer Control Program was considered Brazil's first experience with a continuous on-going action of cervical cancer screening (Porto \& Habib 2014). During the 10 years of the program, there were 19,195 cytological tests per year annually and during its $4^{\text {th }}$ year it showed a decrease in the number of detected pre-cancerous lesions (Porto \& Habib 2014). Nevertheless, another program was initiated around the same time in the Campinas region focusing on three areas: Campinas, Piracicaba, and São João. Since this program began, cervical cancer screening in the public health system ensured that diagnosis and treatment were free of charge (Zeferino, Pinotti, \& Neves et al 2006). Overtime, the number of cervical cancer screening has been increasing as shown on Table 1. In 2002, over 400,000 cervical cancer tests that were performed by the public health system laboratories. 


\begin{tabular}{|l|l|l|l|}
\hline Year & $\begin{array}{l}\text { University of Campinas } \\
\text { cytopathology laboratory } \\
\text { (Number of tests) }\end{array}$ & $\begin{array}{l}\text { Other cytopathology } \\
\text { laboratories } \\
\text { (Number of tests) }\end{array}$ & Total \\
\hline $\mathbf{1 9 9 5}$ & 139,435 & 81,175 & 220,610 \\
\hline $\mathbf{1 9 9 6}$ & 147,317 & 77,056 & 224,373 \\
\hline $\mathbf{1 9 9 7}$ & 193,249 & 66,503 & 259,752 \\
\hline $\mathbf{1 9 9 8}$ & 219,290 & 57,275 & 276,565 \\
\hline $\mathbf{1 9 9 9}$ & 221,572 & 57,613 & 279,185 \\
\hline $\mathbf{2 0 0 0}$ & 219,635 & 72,274 & 291,909 \\
\hline $\mathbf{2 0 0 1}$ & 235,212 & 150,238 & 386,450 \\
\hline $\mathbf{2 0 0 2}$ & 289,837 & 112,190 & 402,027 \\
\hline
\end{tabular}

Table 1 Source: Total number of Pap smears performed annually from 1995 to 2002 in the Campinas Region, São Paulo State, Brazil. Reprinted from "Organization of cervical cancer screening in Campinas and surrounding region, São Paulo State, Brazil" by Zeferino, Pinotti, \& Neves et al. Saúde Pública, Rio de Janeiro 22(9), 1909 - 1914. Copyright 2006.

The National Cancer Institute of Brazil (INCA) introduced a cervical cancer-screening project, Viva Mulher (Long Live Women) that assisted in controlling cervical cancer disease. It was established in 1997 at six localities: Belém (Pará), Curitiba (Paraná), Brasília (in the regions of Tabatinga, Ceilândia and Samambaia, as well as the Federal District), Recife (Pernambuco), the west zone of Rio de Janeiro City (Rio de Janeiro), and the state of Sergipe (Teixeira, 2015). The campaign's goals were to lower incidence and mortality rates by expanding access to cytological tests and to give the appropriate treatment to precursor lesions in $100 \%$ of all cases. Additionally, their target was to "collect samples for cytological examinations from $70 \%$ of women ages 35-49 years who had never taken the exam; guarantee that all exam results will be given back within one month or less; monitor all women with a positive cytology result until completion of treatment" (Teixeira 2015). The campaign consisted of two phases: the 1st in 1998, the 2nd in 2002.
The 1st phase had several successes such as performing over 3 million pap smears: $72.1 \%$ of women were in their target's population and $38.6 \%$ of women examined never had a pap smear; implementation of an electronic system for monitoring results; establishment of 244 Centers for high-frequency surgery was available; the formation of a regional tertiary healthcare network (Porto \& Habib 2014). Brazil's Ministry of Health used the opportunity to make a pledge in Beijing, where many Health Professionals and Academics warned, "about the weak efficacy of temporary actions and the need to create an ongoing, standardized program to control cervical cancer in Brazil" (Porto \& Habib 2014).

The 2nd phase began its preparation much earlier than the 1st phase. The goals of the second phase were similar to the first phase targeting the same age population who had never had a pap smear or not had one in the past three years (Porto \& Habib 2014). The goal was to test 2.5 million women by sending out materials for pap smear test. It was deemed successful as over 3.8 million 
women received a pap smear test (Porto \& Habib 2014). With a high response rate, the campaign coordinators expanded the age group from 25 to 59 years old and decided that no women would be turned away when requesting a pap smear test.

There has been no new campaign for the Viva Mulher since 2002, the program is currently focusing their priorities in supporting and improving the network of oncology care by providing technical assistance to Brazil's Health Departments and reviewing the indicators used for its initiatives (Teixeira 2015).

\section{Latin American Intitatives}

When compared to other Latin American countries, Brazil had similar initiatives to increase awareness and knowledge to women in low-resource settings. PAHO developed the Regional Strategy and Action Plan for Comprehensive Cervical Cancer Prevention and Control (PAHO 2011). A project was developed to support the implementation of this Regional and Action plan in selected countries. The goal of this project was to prevent cervical cancer in low resource settings in selected Latin American countries and the goals were as follows:

- To increase knowledge and awareness among women, their partners, and health providers about cervical cancer risk factors, prevention, and early detection.

- To strengthen the competencies of health providers and the capacity of the health system to deliver high quality cervical cancer screening, early detection and pre-cancer treatment.

- To increase the number of women screened.

- To ensure that at least $95 \%$ of women screened and detected with cervical abnormalities in the project are followed and treated appropriately.

(PAHO, 2011)
Guatemala and Honduras participated in this project and showed success in increasing awareness for cervical cancer screening. In Guatemala, it helped "expand access to cervical cancer screening and pre-cancerous treatment services and establish Cervical Cancer Early Detection Clinics in 8 high burden health areas in the country" (PAHO 2011). In addition, the country developed standardized protocols of early detection and treatment for pre-cancerous lesions that were distributed to 29 Health Care Areas in the country. Also, a "Cervical Cancer Pathology Manual" was published, which contained the framework for clinics on the detection and treatment for cervical cancer screening and precancerous lesions (PAHO 2011). Another main strategy that Guatemala used was a "Screen and Treat Approach: "This idea was that women who had precancerous lesions through visual inspection screening would receive cryotherapy treatment that same day (PAHO 2011). This strategy improved access to treatment and reduced the losses of follow up care.

In order to increase awareness and knowledge in Honduras, educational materials and over 37,500 brochures on cervical cancer prevention were distributed to women's health clinics and communities. In addition, to strengthen the competencies of healthcare providers, the Honduras National Norms and Procedures for Cervical Cancer Prevention and Control were developed (PAHO 2011). As the result of the new norm of cervical cancer, an additional 14,672 pap smears were performed in 2010 as compared to 2009 (PAHO 2011) (Figure 2). With that said, one of the most important developments that Honduras had was the implementation of the information system that allowed patient monitoring and ensured follow-up care (PAHO, 2011). 


\section{Challenges}

There are still many challenges and barriers that many women face, especially those living in low-resource settings and poverty. Additionally, personal and community barriers hinder women from receiving health care services. For example, some women fear that their husbands will reject them if they have this disease (Goodman \& Nour 2014). Another personal barrier is their religious guilt and cultural belief that women were being punished for their sexual behaviors and activities (Goodman \& Nour 2014).

In Brazil, Lorenzi et al. stated "Brazil has not implemented an organized population based cervical cancer screening program, and not even a universal system to invite all women to realize these examinations" (Loreni, Syrjänen, Longatto-Filho 2015). However, the government has a program to control how cytopathology examinations are performed so that women who are sexually active ages 25 years and older can get a pap smear test every 3 years as long as there has been two consecutive negative smears within five years (Loreni, Syrjänen, \& Longatto-Filho 2015). Yet, it is not recommend for women under the age of 25 years to get screened for cervical cancer due to the fact that many precancerous lesions clears on their own (Loreni, Syrjänen, Longatto-Filho 2015).

\section{Future of Cervical Cancer Prevention}

When looking into the future of cervical cancer in Brazil, it is important to have a strong medical infrastructure; financial stability; the community at large must promote screening efforts. Also, that primary screening with HPV testing will be expected in the future as a standard of care and Healthcare Professionals should consider educating women about HPV vaccines and new cytology tests. Furthermore, it is recommended that Healthcare Professionals use evidence- based recommendations because if these are not followed: over-treatment of lesions that may normally clear within a few months; certain treatments may increase the risk of complications in pregnancy; unnecessary psychological distress (fear of cancer, anxiety, and being stigmatized) may result (Arrossi, Silvina, Paolino et al 2010).

In 2011, Brazil's president, Dilma Rousseff, and Minister of Health, Alexandre Padilha, announced that $\$ 2.8$ billion US dollars will be invested to fight against breast and cervical cancer which would assist in strengthening the primary healthcare, increasing awareness through campaigns, and supporting an outpatient and hospital network of the Brazilian Public System (UICC 2015). With continuous strategies; new adaptations; encouragement of technical and financial support especially in quality of care; continuous monitoring and evaluation can lead to a decrease of cervical cancer incidence and mortality rates.

\section{References}

1. American Cancer Society (2015). What is cervical cancer? Retrieved October 1, 2015 from http://www.cancer.org/cancer/ cervicalcancer/detailedguide/cervical-cancer-what-is-cervical-cancer

2. Arrossi, Silvina, Paolino, Melisa, \& Sankaranarayanan, Rengaswamy (2010). Challenges faced by cervical cancer prevention programs in developing countries: a situational analysis of program organization in Argentina. Revista Panamericana de Salud Pública 28(4), 249-257.

3. Retrieved January 06, 2016, from http:// www.scielosp.org/scielo.php?script $=$ sci arttext\&pid=S1020-49892010001000003 $\& \operatorname{lng}=$ en $\&$ tlng $=$ en.

4. Bruni L, Barrionuevo-Rosas L, Albero G, Aldea M, Serrano B, Valencia S, Brotons M, 
Mena M, Cosano R, Muñoz J, Bosch FX, de Sanjosé S, Castellsagué X. ICO Information

5. Centre on HPV and Cancer (HPV Information Centre). Human Papillomavirus and Related Diseases in the World. Summary Report 2015- 12-23. [Data Accessed]

6. Centers for Disease Control and Prevention (CDC) (2014). What are the risk factors for cervical cancer? Retrieved January 3, 2016 from http://www.cdc.gov/cancer/cervical/ basic_info/risk_factors.htm

7. Goodman, A., Nour, N. (2014). Cervical Cancer Screening: The Complex Interplay of Medical Infrastructure, Society, and Culture. The Oncologist, 19(4), 315-317. http:// doi.org/10.1634/theoncologist.2014-0083

8. Lorenzi, A., Syränen, K., Longatto-Filho, A. (2015). Human papillomavirus (HPV) screening and cervical cancer burden. A Brazilian perspective. Virology Journal, (12)112, 1-6. DOI 10.1186/s12985-015-0342-0

9. Mayo Clinic Staff (2015). Cervical Cancer. Retrieved October 1, 2015 from http://www. mayoclinic.org/diseases-conditions/cervical-cancer/basics/definition/con-20030522

10. PanAmericanHealthOrganization(2014).Cervical Cancer Screening: Yesterday and Today. Retrieved January 3, 2016 from http://www. paho.org/hq/index.php?option=com_content\&view=article\&id=9995\%3A2014-cervical-cancer-screening-yesterday-and-today \& catid $=6601 \% 3 \mathrm{Akbr}-\mathrm{case}-$ studies\&Itemid $=40275 \&$ lang $=$ en

11. Pan American Health Organization (2011). Preventing Cervical Cancer in Latin America. Public Health Agency of Canada. Retrieved January 3, 2016 from http://www. paho.org/hq/index.php?option=com_docman\&task $=$ doc_view\&gid $=17399 \&$ Itemid $=$

12. Porto, M., Habib P. (2014) Viva Mulher: constructing a cervical cancer control program in Brazil. 34(1): 101-123. Scielo. Retrieved October 3, 2015 from http:// scielo.isciii.es/scielo.php?script $=$ sci_arttext\&pid $=$ S0211-95362014000100006\&1ng=es. http://dx.doi.org/10.4321/S0211-953 62014000100006

13. Teixeira, Luiz Antonio (2015). From gynaecology offices to screening campaigns: a brief history of cervical cancer prevention in Brazil. História, Ciências, Saúde-Manguinhos, 22(1), 221-239. https://dx.doi.org/ $10.1590 / \mathrm{S} 0104-59702015000100013$

14. UICC (2015). Prevention and treatment of cervical and breast cancer in Brazil. Retrieved January 16, 2016 from http://www.uicc.org/ advocacy/prevention-and-treatment-cervical-and-breast-cancer-brazil

15. World Health Organization and Globocan (2012-2015). Cervical Cancer Estimated Incidence, Mortality, and Prevalence Worldwide in 2012. Retrieved October 2, 2015 from http://globocan.iarc.fr/old/FactSheets/ cancers/cervix-new.asp

16. World Health Organization (2015). Human papillomavirus (HPV) and cervical cancer. Retrieved February 9, 2016 from http://www. who.int/mediacentre/factsheets/fs380/en/

17. Zeferino, L., Pinotti, J., Neves Jorge, J. (2006). Organization of cervical cancer screening in Campinas and surrounding region,São Paulo State, Brazil. Retrieved January 3, 2016 from http://www.scielosp.org/ $\mathrm{pdf} / \mathrm{csp} / \mathrm{v} 22 \mathrm{n} 9 / 15 . \mathrm{pdf}$ 


\title{
Prevalent Non-communicable Diseases Across Brazil: Risk Factors, Prevention, and Future Goals
}

\author{
5. A. Borgia (Sarah A. Borgia)
}

Health Administration \& Human Resources,

Original Articles

$4^{\text {th }}$ Floor McGurrin Hall, Scranton, PA 18510-4699

\section{E-mail address:}

sarah.borgia@scranton.edu

\section{Reprint address:}

Health Administration \&

Human Resources

$4^{\text {th }}$ Floor McGurrin Hall

Scranton, PA 18510-4699

Suource: Clinical Social Work and Health Intervention

Volume: 7

Issue: 4

Pages: $62-66$

Cited references: 0

\section{Reviewers:}

Prof. Dr. Roberto Cauda, Ph.D.

Institute of Infectious Diseases, Catholic University of the Sacred Heart, Rome, IT

e-mail: roberto.cauda@Unicatt.it

Dr. Zoltán Pataky

HÚG v Ženeve, CH

e-mail: zoltan.pataky@hcuge.ch

\section{Key words:}

Non-communicable diseases, Risk factors, Prevention.

\section{Publisher:}

International Society of Applied Preventive Medicine i-gap

CSWHI 2016; 7(4): 62 - 66; DOI 10.22359/cswhi_7_4_09 @ 2016 Clinical Social Work and Health Intervention

\section{Abstract:}

Over the past century, the country of Brazil has seen tremendous growth in their economy, including - increased mechanization, urbanization, and industrialization. Collectively, these changes have made a negative impact in the public health sector in Brazil because they have contributed to the increasing number of individuals who have developed a non-communicable disease. Non-communicable diseases (NCDs), also known as chronic diseases, are developed over time and are caused 
by a various number of risk factors. With these risk factors uncontrolled, the burden only continues to rise and have a profound impact on the health and quality of life for any individual living with a NCD. Additionally, those individuals living with a NCD can be heavily burdened financially, psychically, and socially. Currently, NCD's represent the largest mortality and morbidity burden in the Brazil. The increasing burden of NCD's have not only become a serious public health issue for the country of Brazil, but for many countries across the globe. An important way to reduce NCDs is to focus on lessening the risk factors associated with these diseases. Currently, Brazil has implemented and continues to develop solutions to reduce this burden but they still have a long way to go. This paper will examine the impact of NCD's on the population of Brazil including: risk factors associated with these chronic diseases; how this country' prevalence of NCD's compares to other countries across the globe; what is being done throughout Brazil to combat this growing burden.

\section{Introduction}

Having good health is something to be thankful for because it is not something that everyone possesses due to various ailments such as non-communicable diseases (NCD). Living with an NCD can cause a significant burden on not just one's health, but one's overall quality of life. There are several elements about NCDs which can provide clearer understanding of what they are.

First, NCD cannot be spread from person to person by an infectious agent, even if they might be associated with one. Second, they tend to last a long time. Third, they can be very disabling, can seriously impair the ability of people to engage in day-to-day activities, and often lead to death if they are not treated appropriately. NCDs kill 38 million people each year and almost three quarters of NCD deaths - 28 million - occur in low and middle income countries. The four main types of Non-communicable Diseases are cardiovascular diseases (like heart attacks and stroke); cancer; chronic respiratory diseases (such as chronic obstructed pulmonary disease and asthma); diabetes. In Brazil, cardiovascular diseases accounted for the highest percentage of NCDs, followed by cancer, other NCDS such as respiratory diseases, and finally diabetes, as shown in Table 1. Additionally, the main risk factors that contribute to the development of NCD's include tobacco use, physical inactivity, unhealthy diet and the harmful use of alcohol. Strategies that focus on lessening the risk factors that lead to NCDs is a vital element in the aim to reduce the large burdens they create for Brazil and so many other countries worldwide.

\section{Impact in Brazil}

Brazil, a country that is filled with beautiful beaches, mountains and home to many famous tourist attractions to which individuals travel from all over the world travel to see, faces the unwavering burden of non-communicable diseases (NCD's). There are several statistics that can provide a clearer idea of how negatively this burden impacts Brazil. For example, in $2007,72 \%$ of all deaths were attributable to NCD's. Additionally, they are the main source of disease burden in Brazil. Next, the percentage of avoidable chronic disease hospitalizations in Brazil was 20\% in 2007, for adults ages 20-79. Lastly, the economic impact of NCDs in Brazil was $\$ 72$ million in 2005. (World Bank 2005) The driving forces that have contributed to the rise in 
NCDs include greater income; more mechanization and industrialization; improved access to food; urbanization; a globalization of unhealthy eating habits.

Compared on worldwide and regional levels, the chronic disease burden in Brazil can be further examined. In 2014, the total percentage of the population who died from an NCD in Brazil was 74\%; the total percentage of the population who died from an NCD in Latin America was 36\% in 2007 and worldwide was $68 \%$ in 2012 . These statistics indicate that the prevalence in Brazil exceeds both national and worldwide per- and alcohol consumption following behind, as shown in table 2. Currently, the highest trending risk factors in Brazil related to NCDs is overweight and obesity. In 2012, around one in seven Brazilians were classed as obese. Globally, Brazil is far behind countries such as the United States and Mexico, where around a third of people are obese, but the concern is the rapid rate of weight gain. With healthier foods becoming more expensive, lower income families have to opt to choose foods that may be higher in sugar and fat because they are the cheaper option. Collectively, the high prevalence of these risk factors are the triggers that

Table 2 Risk Factor Prevalence in Brazil, Data from World Health Organization

\begin{tabular}{|l|c|c|c|}
\hline & Male & Female & Total \\
\hline Obesity (2008) & $16.0 \%$ & $21.4 \%$ & $18.8 \%$ \\
\hline Tobacco Use (2011) & $22 \%$ & $13 \%$ & $17 \%$ \\
\hline Raised Blood Pressure (2008) & $36.8 \%$ & $25.3 \%$ & $30.8 \%$ \\
\hline Total alcohol per capita consumption, in liters (2010) & 13.6 & 4.2 & 8.7 \\
\hline
\end{tabular}

centages of deaths due to non-communicable diseases. If prevention measures are not properly implemented, and management of NCDs goes uncontrolled, the direct and indirect costs of NCDs will continue to pose important fiscal and public challenges for the country of Brazil.

\section{Risk Factors}

As mentioned earlier, the main risk factors that contribute to the development of NCD's include tobacco use, physical inactivity, unhealthy diet and the harmful use of alcohol. These factors are also main contributors for obesity and raised blood pressure rates, which greatly contribute to the development in NCDs. In Brazil, raised blood pressure in adults (18 or older) contributed as risk factor the total highest percentage, followed by obesity, tobacco use,

\section{Prevention Strategies}

Because of the extreme burden NCDs place on Brazil, several prevention strategies along with health promotion initiatives have been put in place that aim to combat the risk factors that lead to NCDs. In 2006, after discussion and agreement at federal, state, and municipal levels, a broad health promotion was approved. To further support local health promotion actives, the Ministry of Health contributed a great deal of funding to expand on the interventions put in place to combat risk factors and increase promotion of health. For example, to combat the highest trending risk factor of obesity, the country has launched a nationwide program to increase physical activity and improve diet, known as the Academia's da Saude. The Ministry of Health's goal is to expand Academia's da Saude of Brazil's promotion of physical 
activity to 4,000 municipalities by 2011 . By 2010, this physical activity network already included 469 projects. This is just one indicator that the promotion of a healthier lifestyle is a priority of Brazil's health system.

In 2006, to respond to the increasing prevalence of tobacco use, Brazil ratified the WHO Framework Convention on Tobacco Control. A free national hotline, whose number is placed within the cigarette pack warning, offers guidance on smoking cessation. Additionally, several new tobacco control bills have been approved at the national, state and municipal levels. In February, 2011, to respond to the increasing prevalence of those with raised blood pressure (hypertension), Brazil's Ministry of Health initiated the Health is Priceless Program. This program offers free medication to control and reduce the burden of hypertension, diabetes and asthma. The program distributes, free of charge, 11 medicines - six for hypertension and five for diabetes to control blood pressure and diabetes. As of February, 2014, the program, active in 4,119 cities through a network of 30,136 pharmacies, has provided services to 6.6 million diabetic and 16.4 million hypertensive patients. The three initiatives discussed within this section are an example of how Brazil has been taking action to combat their highest concerning risk factors for NCDs.

\section{Strategic Action Plan}

Looking towards the future of the noncommunicable disease burden in Brazil, the Unified Health System of Brazil (SUS) and the Ministry of Health set forth an NCD Action Plan 2011-2022. This action plan included a wide array of initiatives to respond to the ongoing epidemic of NCD's throughout Brazil. One aspect of the action plan included a National Health Survey administered in 2013. This survey was distributed for the purpose of producing data on national health status: risk behaviors; health services access; financing; etc. Data collection is very beneficial in the healthcare industry because it provides a deeper insight on the issue that has to be solved therefore makes it possible to produce the most appropriate solution to that specific issue, such as NCD prevention strategies. The strategic action plan also included targets to help reach their goals of reducing mortality and risk factors from NCDs. Some of the targets include reducing NCD premature death rate ( $<70$ years) by $2 \%$ a year; increasing fruit and vegetable consumption; reducing the prevalence of harmful alcohol consumption; reducing average salt intake; increasing the prevalence of physical activity.

Because the NCD burden is not a problem unique to Brazil and affects a majority of countries around the globe, The World Health Assembly endorsed the World Health Organization (WHO) Global Action Plan for the Prevention and Control of NCDs 20132020. This plan aims to reduce the number of premature deaths from NCDs by $25 \%$ by 2025 through nine voluntary global targets. The nine targets focus in part by addressing factors such as tobacco use; harmful use of alcohol; unhealthy diet; physical inactivities that increase people's risk of developing these diseases. The plan offers a menu of "best buy" or cost-effective, high-impact interventions for meeting the nine voluntary global targets such as banning all forms of tobacco and alcohol advertising; replacing trans fats with polyunsaturated fats; promoting and protecting breast feeding; preventing cervical cancer through screening. More than 190 countries, including Brazil, agreed in 2011 to adopt all nine voluntary targets in the WHO Global Action Plan 2013-2020. The adoption of the WHO voluntary targets were incorporated into their country's action plan. These initiatives show that Brazil is taking a proactive approach to reduce the burden of NCDs. 


\section{Conclusion}

In conclusion, it is clear to see how non-communicable diseases have become a major health priority in Brazil due to the large economic and social adverse effects they have throughout the communities within the country. On an individual level, NCDs impose financial, social, and health burdens. With obesity being the highest trending risk factor for NCDs due to unhealthy eating habits and a lack of physical activity, the initiate to promote a healthier lifestyle has to start at a young age. It is also important to stress that the most important way to reduce NCDs is to focus on lessening the risk factors associated with these diseases. In the long term, it is much less expensive for government to invest in prevention measures than to provide costly medical treatments to treat NCDs. In summary, Brazil has made significant progress in their efforts to reduce NCD by creating initiatives and having programs in place that have successfully reduced various risk factors such as tobacco use and raise blood pressure. Additionally, Brazil is active in its efforts both domestically and globally to address the threat of NCDs by striving to reach critical targets set out in their strategic action plan. Although progress has been made, comparing the NCD burden in Brazil on both a national and global level indicates that they have long roads ahead of them in order to reduce the mortality and morbidity rates associated with these diseases. With the continuous population growth and industrialization trends in Brazil, the NCD challenge will remain prevalent for years to come. So it is vital for healthcare sector and government in Brazil to remain proactive in their approach to reduce the NCD burden. In conclusion, Brazil has shown a great effort in reducing the NCD burden and in time, future data will allow the world to see the progress that has been made by the various initiatives set forth. 


\section{Strategic Global Partnership to Cultivate Health Management Education: A North and South American Model}

\section{J. Szydlowski (Steven J. Szydlowski)}

Health Administration \& Human Resources,

$4^{\text {th }}$ Floor McGurrin Hall, Scranton, PA 18510-4699

\section{E-mail address:}

steven.szydlowski@scranton.edu

\section{Reprint address:}

Health Administration \&

Human Resources

$4^{\text {th }}$ Floor McGurrin Hall

Scranton, PA 18510-4699

Suource: Clinical Social Work and Health Intervention

Volume: 7

Issue: 4

Pages: $67-70$

Cited references: 8

\section{Reviewers:}

Dr. Johnson Nzau Mavole, Ph.D.

Catholic university of Eastern Africa, Nairobi, Kenya

e-mail: jmavole@cuea.edu

prof. MUDr. Juraj Benca, PhD.

Vysoká škola zdravotníctva a sociálnej práce sv. Alžbety, Bratislava

e-mail: benca@vssvalzbety.sk

\section{Key words:}

Global health, competency-based education, parternships.

\section{Publisher:}

International Society of Applied Preventive Medicine i-gap

CSWHI 2016; 7(4): 67 - 70; DOI 10.22359/cswhi_7_4_10 @ 2016 Clinical Social Work and Health Intervention

\section{Abstract:}

Developing future health care leaders continues to emphasize the need for competency based education. Given the increasing impact global health issues has on health status and population health on a country, graduate health care management program should include exposure to knowledge and skills in the curriculum. The geographic boundaries of domestic based graduate education often limit the ability for global engagement. Many student experiences diversity among the profile in 
classroom, whether on-line or residential, and some content related material on global issues. The paper reviews a strategic global partnership model used to expose students to health issues and health systems using study abroad learning. A three-year case study between partner institutions in North and South America is examined. The findings identify critical factors and best practices needed for sustaining global health partnerships.

\section{Introduction}

The movement towards Competencybased Health Management Education is well underway. Demands from stakeholders continue to push the need for capable healthcare leaders who are high performers engaging in various domains of management. Assessment and continuous development of healthcare managers is needed. Several competency models and assessment exist such as the Healthcare Leadership Alliance and American College of Health Executives 2016 Competencies Assessment tool identifying competency attainment in five domains (ACHE, 2016). The International Hospital Federation (2015) has also identified leadership competencies required for healthcare leaders to be effective in global environments. Several other models exist. A core component to competency development in both academic and clinical settings depends upon the translation of theory to practice. The additional challenge in preparing students and clinicians for global work is providing an environment and context for competency development. Truong, Paradies and Priest (2014) discuss theory to practice through specific interventions aimed at developing cultural competency in healthcare professionals to improve patient healthcare outcomes. Opportunities for students to gain exposure to context where cultural competence can be developed is particularly important when dealing with health disparities and social justice issues (Rajaram \& Bockrath, (2014).
Although workforce and classroom diversity exposes individuals to ethnic and cultural activities, it is far from a full emersion experience that often occurs in study abroad or Physicians Without Borders opportunities to develop global health competencies. This article describes how strategic global partnerships are formed to provide a platform for health management education, research, and service. Special emphasis is placed on a North American and South American partnership between academic and health institutions.

\section{Steps in Partnership Formation and Structure}

Building global partnerships is an enduring process that requires a vested interest by at least two individuals. Common values and intention to fortify a lasting relationship needs to be present. An essential first step is commitment, in most cases volunteerism, by a few individuals to establish the partnership. The perseverance to work through the technology, language, time, and other potential barriers is needed. Cultural competence, respect, and appreciation for the hard work to form a partnership is needed in the early stages. Without this commitment early partner-ship formation is virtually impossible. Once the intention is present by the vested individuals, in many cases faculty and clinicians, buy-in from senior leadership is needed. If the institutions where the vested individuals preside, proclaim as part of their mission global outreach, service, 
or collaboration, support is more easily obtained. The strategic plan can then serve as the basis for supporting the global partnership with direct and indirect backing. Direct support can be in the form of financial and human resources. Indirect support can be in the formal documentation to establish ongoing partnership activities. Evidence of ongoing faculty and clinician teaching, scholarship, and service can eventually lead to resource allocation from the institution.

A memorandum of understanding (MOU) serves as a basic document that outlines the mutually agreed upon activities of the global partnership. Initially, the MOU is intended to facilitate less formal activities such as faculty to faculty research and teaching; clinical peer to peer sharing; hosting student lectures. As the partnership grows, the MOU can be modified to include more formal initiatives such as enrolling in classes, joint degrees, and other educational endeavors to provide context for global health management competency development.

University-based partnerships often serve as the platform for global health education initiatives to flourish. Universities have historical foundation and stability to support sustainable partnerships. University-based partnerships are more stable resulting from long-standing faculty commitment to education. Additionally, many health management and allied health professions schools have existing clinical-based partners who have staff willing to support educational endeavors intended to support global health education and population health.

\section{Critical Factors in Sustaining Health Management Partnerships}

There are several factors that contribute to the success of health management partnerships. Some of these factors include:
- Institutional support

- University-based and health institutionbased partnerships

- Faculty scholarship and research

- Co-teaching between partner institutions

- Student learning

- Service-orientation

- Building on existing global partnerships

- Friendship and common ground

- Succession planning

- Early/mid-careerist commitment

Institutional support is a key element to sustainability. Senior administration needs to recognize and commit to long-term engagement. This is more likely when faculty or clinicians have established a track record of research and scholarship, teaching, and opportunities for students to participate in service learning. Service orientation, social justice, and principles of human rights can serve as the premise for ongoing collaboration.

Building upon existing partnerships provides a solid framework for sustainability. Health Management Partnerships that have realized long term accomplishments can be used to form multi-national models. Recently, partners from St. Elizabeth University, Slovakia, PUC-RIO, Brazil, and the University of Scranton, USA, conducted a global forum for health services research in January 2016. The Scranton-Slovakia Health Management Education Partnership was established in 1995 (West 1995) and the Scranton-Brazil Health Management Education partnership was established in 2013 to include University and Health Institutions.

\section{Conclusion}

Global Health Management Education Partnerships provide opportunities for students, faculty, and clinical staff to engage in 
educational activities that supports holistic personal development. Emma-Louise Aveling and Grahman Martin (2013) describe the transformative nature of international healthcare partnerships in developing countries beyond traditional market forces and nationalistic initiatives. Julio Frenk and Suerie Moon (2013) recognize the challenges for governance in global health settings. Through university-based and healthcare based initiatives, governance is more informed through individual leadership and partnership agreements at a more micro-level.

Long-term and short-term study abroad: student research; faculty teaching; exposure to social justice issues in underserved communities in both Brazil and United States can provide the contextual setting for global competencies to be developed. Acknowledging the importance of global health, nurturing healthcare leaders who understand the impact of global health at a local level, and obtaining buy-in from institutional administrators can establish Global Health Education Management Partnerships that birth the future of healthcare system delivery designed to meet the needs of a global society.

\section{References}

1. American College of Healthcare Executives (2016). ACHE Healthcare Executive Competencies Assessment Tool 2016. Retrieved on February 22, 2016 from https://www. ache.org/pdf/nonsecure/careers/competencies_booklet.pdf

2. Aveling, E-L., Martin, G. (2013). Realizing the transformative potential of healthcare partnerships: Insights from divergent literatures and contrasting cases in high-and low-income country contexts. Journal of Social Science \& Medicine: 92, 74-82.

3. Frenk, J., Moon, S. (2013). Governance Challenges in Global Health. The New England Journal of Medicine: 368, 936-42. DOI: 10.1056/NEJMra1109339.

4. International Hospital Federation (2015). Leadership competencies for healthcare services managers. Retrieved February 22, 2016 from https:/www.ihf- fih.org/resources/pdf/ Leadership_Competencies_for_Healthcare_ Services_Managers.pdf

5. Rajaram, Shireen S., Bockrath, S. (2014). Cultural Competence: New Conceptual Insights into its Limits and Potential for Addressing Health Disparities. Journal of Health Disparities Research and Practice: Vol. 7: Is. 5, Article 6.

6. Truong, M., Paradies, Y., Priest, N (2014). Interventions to improve cultural competency in healthcare: a systematic review of reviews. BMC Health Services Research: (14) 99.

7. West, D. (1995). Building relationships in developing and growing economies. BRIDGE Model. University of Scranton, PA. 


\section{Contributor's guidelines}

Allow me to introduce a new expert journal - Clinical Social Work and Health Care. We would like to offer you an opportunity to contribute to its content as we would like to aspire to create a collection of real experiences of social workers, doctors, missionaries, teachers, etc. CWS Journal is published by the International Scientific Group of Applied Preventive Medicine I-GAP in Vienna, Austria.

The journal is to be published semi-annually and only in English language as it will be distributed in various foreign countries.

We prefer to use the term 'clinical social work' rather than social work even though it is less common. In the profession of clinical social work, there clearly is some tension coming from unclear definitions of competence of social workers and their role in the lives of the clients; the position of social work in the structures of scientific disciplines especially in cases where people declare themselves to be professionals even though they have no professional educational background. These are only few of the topics we would like to discuss in the CWS Journal.

Your contribution should fit into the following structure:

1. Editorial

2. Interview, Case Reports

3. Review

4. Original article

5. Letters

\section{Instructions for contributors:}

All articles must be in accordance with the current language standards in English, current ISO and the law on copyrights and rights related to copyrights.

Your contributions are to be sent via e-mail (addressed to: michalolah (agmail.com) as an attachment or on a CD via regular postal service. In both cases written and saved in MS Word (no older version than year 2000).

Style Sheet Requirements:

Maximum length: 3500 words

Letter type: Times New Roman

Letter size: 12

Lining: 1

\section{All articles must include:}

Name of the article and author's address in English

Article abstract of 150 words in English

Brief professional CV of the author (100 words)

Publishing languages: English

Text of the article consisting of at most 3500 words

Each article must be an original never published before. When using references, parts of other articles or publications it is inevitable to quote them and provide information about the source.

We reserve the right to formally edit and reduce the text if needed. Academic articles undergo an anonymous critique. Each author will receive a prior statement of publishing his/ her article. Reference styles writing: "name and year".

When writing a review it is necessary to attach a copy of the cover of the book.

\section{Published Statement of Human and Animal Rights}

When reporting experiments on human subjects, authors should indicate whether the procedures followed were in accordance with the ethical standards of the responsible committee on human experimentation (institutional and national) and with the Helsinki Declaration of 1975 , as revised in 2000 (5).

\section{Published Statement of Informed Consent}

Patients / klients have a right to privacy that should not be infringed without informed consent. Identifying information, including patients' names, initials, or hospital numbers, should not be published in written descriptions, photographs, and pedigrees unless the information is essential for scientific purposes and the patient (or parent or guardian) gives written informed consent for publication. Informed consent for this purpose requires that a patient who is identifiable be shown the manuscript to be published. Authors should identify Individuals who provide writing assistance and disclose the funding source for this assistance.

Identifying details should be omitted if they are not essential. Complete anonymity is difficult to achieve, however, and informed consent should be obtained if there is any doubt. For example, masking the eye region in photographs of patients is inadequate protection of anonymity. If identifying characteristics are altered to protect anonymity, such as in genetic pedigrees, authors should provide assurance that alterations do not distort scientific meaning and editors should so note.

\section{Published Conflict-of-Interest Statement}

Public trust in the peer review process and the credibility of published articles depend in part on how well conflict of interest is handled during writing, peer review, and editorial decision making. Conflict of interest exists when an author (or the author's institution), reviewer, or editor has financial or personal relationships that inappropriately influence (bias) his or her actions (such relationships are also known as dual commitments, competing interests, or competing loyalties). These relationships vary from those with negligible potential to those with great potential to influence judgment, and not all relationships represent true conflict of interest. The potential for conflict of interest can exist whether or not an individual believes that the relationship affects his or her scientific judgment. Financial relationships (such as employment, consultancies, stock ownership, honoraria, paid expert testimony) are the most easily identifiable conflicts of interest and the most likely to undermine the credibility of the journal, the authors, and of science itself. However, conflicts can occur for other reasons, such as personal relationships, academic competition, and intellectual passion.

The journal works on the non-profit basis. The Original Articles are published free of charge / the scope up up to 3,500 words, over the scope should be paid 50 EUR / USD for every 500 words/. All the published Articles are charged 100 EUR / USD with standard range which cannot be exceed. 
No. 4, Vol. 7, 2016

Editor-in-chief: Peter G. Fedor-Freybergh, Michael Olah

\title{
CLINICAL SOCIAL WORK AND HEALTH INTERVENTION
}

\author{
Indexed by: \\ ERIH \\ Ulrich's \\ CrossRef \\ Universitat de Barcelona - MIAR \\ International Committee of Medical Journal Editors (ICMJE) \\ ScienceOpen \\ Cabell's
}

Journal DOI 10.22359/cswhi

Issue DOI 10.22359/cswhi 74

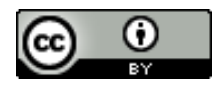

